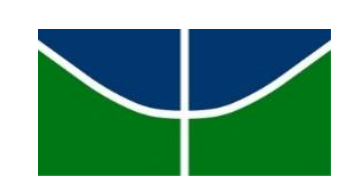

UNIVERSIDADE DE BRASÍLIA

FACULDADE UNB DE PLANALTINA

PROGRAMA DE PÓS-GRADUAÇÃO EM MEIO AMBIENTE E DESENVOLVIMENTO RURAL

NATHAN DE CASTRO SOARES SIMPLÍCIO

ECOTOXICIDADE DE FERTILIZANTES: UMA ANÁLISE COMPARATIVA ENTRE PRODUTOS A BASE DE NITROGÊNIO, FÓSFORO E POTÁSSIO E SEUS INGREDIENTES ATIVOS ISOLADAMENTE

DISSERTAÇÃO DE MESTRADO

BRASÍLIA 
NATHAN DE CASTRO SOARES SIMPLÍCIO

\title{
ECOTOXICIDADE DE FERTILIZANTES: UMA ANÁLISE COMPARATIVA ENTRE PRODUTOS A BASE DE NITROGÊNIO, FÓSFORO E POTÁSSIO E SEUS INGREDIENTES ATIVOS ISOLADAMENTE
}

\begin{abstract}
Dissertação apresentada como requisito parcial para obtenção do Título de Mestre em Meio Ambiente e Desenvolvimento Rural pelo Programa de Pós-Graduação em Meio Ambiente e Desenvolvimento Rural - PPG MADER da Universidade de Brasília.
\end{abstract}

ORIENTADOR: PROF. DR. EDUARDO CYRINO OLIVEIRA-FILHO

BRASÍLIA 


\section{UNIVERSIDADE DE BRASÍLIA \\ FACULDADE UnB PLANALTINA \\ MESTRADO EM MEIO AMBIENTE E DESENVOLVIMENTO RURAL}

Termo de Aprovação

"Ecotoxicidade de Fertilizantes: Uma análise comparativa entre produtos a base de nitrogênio, fósforo e potássio e seus ingredientes ativos isoladamente"

Nathan de Castro Soares Simplício

Banca Examinadora

Prof. Dr. Eduardo Cyrino Oliveira-Filho

Presidente (Embrapa)

Prof. Dr. Ludgero Cardoso Galli Vieira

Membro Interno vinculado ao programa (UnB/FUP)

Prof. Dr ${ }^{\mathrm{a}}$. Elaine Nolasco Ribeiro

Membro Interno não vinculado ao programa (UnB/FUP) 
Dedico este trabalho a minha irmã

Fernanda. "Amizade é uma mente em dois corpos" (Meng-tzu). 


\section{AGRADECIMENTOS}

Aos meus pais Dante de Castro Simplício e Liliane Maria Soares pelo incentivo, acolhimento e por me mostrarem que dedicação àquilo que se ama é mais importante que dedicar-se àquilo que seja mais rentável. Tudo que sou hoje devo a vocês dois.

Aos meus amigos Julia, Marcelle e Pedro que não me deixaram enlouquecer durante este fase e acreditaram em mim quando eu mesmo tinha perdido as esperanças. Desculpem-me por ter desaparecido durante esse tempo.

Aos colegas de Monitoramento Ambiental Leonardo e Nayara. O mestrado torna-se mais suportável quando temos alguém para compartilharmos nossos sucessos e fracassos, além de termos alguém com quem fofocar sobre disciplinas e orientador.

À Embrapa Cerrados e ao LABOCIEN por terem disponibilizado a infraestrutura onde este trabalho foi realizado.

Aos estagiários e técnicos do Laboratório de Ecotoxicologia e Química da Água da Embrapa Cerrados Bruno, Daphne, Dênis, Fernanda Rocha e Zélia pela ajuda primordial sem a qual este trabalho não teria se concretizado, tanto na realização dos ensaios, quanto na análise dos resultados. Vocês me ajudaram a rir mais quando tudo induzia ao contrário.

Aos membros da banca examinadora, Professores Dr. Carlos Passos, Dra. Elaine Nolasco e Dr. Ludgero Vieira por terem aceitado compor a banca, lido o trabalho e pelas considerações sobre o mesmo.

Ao meu professor e orientador Dr. Eduardo Cyrino Oliveira-Filho por estar comigo desde 2010. Obrigado pela confiança e pela paciência em toda essa jornada. Meu crescimento científico e profissional é devido graças a você. 


\section{RESUMO}

SIMPLÍCIO, N. Ecotoxicidade de fertilizantes: Uma análise comparativa entre produtos a base de nitrogênio, fósforo e potássio e seus ingredientes ativos isoladamente. 2015. 81f. Dissertação (Mestrado) - Faculdade UnB de Planaltina, Universidade de Brasília, Brasília, 2015.

O desenvolvimento da agricultura nos últimos tempos tem intensificado a produção e melhorado as tecnologias no campo. Dentro da cadeia de produção agrícola, os nutrientes nitrogênio, potássio e fósforo possuem grande importância, sendo utilizados principalmente como fertilizantes para culturas ou obtidos como resíduo de excreta animal. Logo, o manejo incorreto desses nutrientes pode trazer consequências adversas para os seres humanos e ecossistemas, tendo em vista que o mau uso dos fertilizantes trazem sérios riscos aos recursos hídricos, pois na presença de água, muitos compostos são interconvertidos em íons. Isso representa um risco, pois se as concentrações de fósforo, nitrogênio e potássio apresentarem-se em concentrações elevadas no corpo hídrico, podem causar a eutrofização do meio. Esses fertilizantes muitas vezes chegam aos recursos hídricos em virtude de sua acumulação no solo e posterior escoamento para córregos e rios pelo escoamento superficial. O conhecimento sobre a toxicidade dos fertilizantes é importante para poder estabelecer práticas de prevenção de problemas ambientais e melhor estruturar uma legislação para controle e uso destes compostos químicos. Mesmo existindo muitos dados toxicológicos a respeito dos fertilizantes, obrigatórios para o seu registro, ainda há pouca informação sobre o efeito dessas substâncias para a saúde humana e seus impactos para o meio ambiente. Para melhor dimensionar a problemática dos fertilizantes, os testes ecotoxicológicos vêm como uma alternativa ambiental, pois a execução de bioensaios consiste em um método rápido e de baixo custo, sem a necessidade de análises químicas, muitas vezes inviabilizadas pelo alto custo. Com isso esse estudo teve como objetivo avaliar a ecotoxicidade de fertilizantes a base de nitrogênio, fósforo e potássio, e seus ingredientes ativos isoladamente, visando apresentar os potenciais efeitos adversos decorrentes da presença desses elementos nos ambientes aquáticos. Para tanto, foi realizado um levantamento sobre os fertilizantes mais utilizados comercialmente e, seguindo esse critério, realizou-se a escolha dos compostos testados. A partir disso, realizaram-se diluições dos fertilizantes e seus reagentes equivalentes para a realização de ensaios agudos buscando estabelecer a concentração letal de metade da população. Dez indivíduos das espécies Biomphalaria glabrata e Danio rerio foram expostos a cada concentração dos compostos testados. Como resultados, obteve-se a toxicidade do cloreto de potássio, do nitrato de potássio e da ureia para o B. glabrata e o D. rerio, sendo este mais suscetível ao cloreto de potássio presente no fertilizante e aquele aos demais compostos. Quanto ao superfosfato simples, não foi encontrado valores de toxicidade significativos a este. Esse estudo conclui que os bioensaios demonstraram servir de complemento às análises químicas na definição de parâmetros ambientais sobre os efeitos adversos do elemento presente nos compostos testados para o ambiente e os organismos, sendo que a espécie $B$. glabrata foi a que demonstrou ser mais sensível aos compostos com nitrogênio e o $D$. rerio ao potássio presente no fertilizante comercial não somente em virtude deste composto, mas também por causa das impurezas contidas neste e baseado na sensibilidade que a espécie possui ao processo de salinização.

Palavras-chave: bioensaios, agricultura, concentração letal, química ambiental. 


\begin{abstract}
SIMPLÍCIO, N. Fertilizers ecotoxicity: A comparative analysis of nitrogen, phosphorus and potassium-based products and its active ingredients separately. 2015. 81f. Master's thesis Faculdade UnB de Planaltina, Universidade de Brasília, Brasília.
\end{abstract}

In recent times agricultural development has intensified production and improved technologies in the field. Within the agricultural production chain, the nutrients nitrogen, potassium and phosphorus are of great importance and is mainly used as fertilizer for crops or obtained as animal waste. Therefore, the incorrect management of these nutrients can have adverse consequences for human beings and ecosystems because of the bad use of fertilizers brings serious risks to water resources, because in water presence, many compounds are interconverted into ions. This is a risk because if the concentrations of phosphorus, nitrogen and potassium presents in high concentrations in the water body, can cause eutrophication of the environment. These fertilizers often come to water resources due to its accumulation in the soil and subsequent drainage into streams and rivers through runoff. The knowledge about the toxicity of fertilizers is important to establish prevention of environmental problems and best practices to structure legislation to control and use of these chemical compounds. Although there are many toxicological data on fertilizer, required for your registration, there is still a lack of information on the effect of these substances on human health and its impact on the environment. To better measure the problem of fertilizers, ecotoxicological tests come as an alternative, since the implementation of bioassays is a quick and inexpensive method without the need for chemical analysis often negated by the high cost. This study aimed to evaluate the ecotoxicity of nitrogen, phosphorus and potassium-based fertilizers and its active ingredients separately, aiming to present the potential adverse effects arising from the presence of these elements in aquatic environments. For this, a survey was conducted on fertilizers more used commercially and, following this criterion, was made the choice of the compounds tested. Dilutions were made and equivalents fertilizer reagents for conducting tests to establish acute lethal concentration to half of the population. Ten organisms of different trophic levels involving Danio rerio and Biomphalaria glabrata species were exposed to the compounds. As a result, we obtained the toxicity of potassium chloride, potassium nitrate and urea for B. glabrata and D. rerio, being this more susceptible to the potassium chloride present in the fertilizer and that to the other compounds. For the superphosphate, was not found significant toxicity values to this. This study concludes that the bioassays showed to serve as a complement of chemical analysis in the definition of environmental parameters on the adverse effects of the elements presented on tested compounds to the environment and to the organisms, being the species B. glabrata more sensitive to nitrogen compounds and $D$. rerio to potassium present in commercial fertilizer not only because this compound but also because of the impurities contained in and based on the sensitivity that the species has to the salination.

Keywords: bioassays, agriculture, lethal concentration, environmental chemistry. 


\section{SUMÁRIO}

LISTA DE SIGLAS E ABREVIATURAS ….............................................................

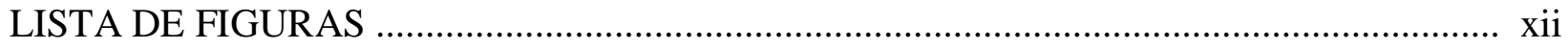

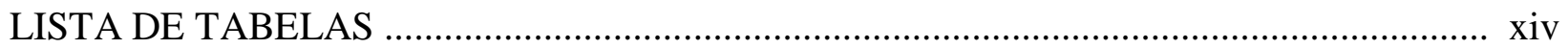

1. INTRODUÇÃ

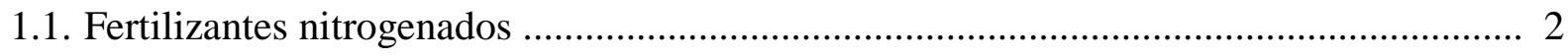

1.2. Fertilizantes fosfatados .............................................................................. 4

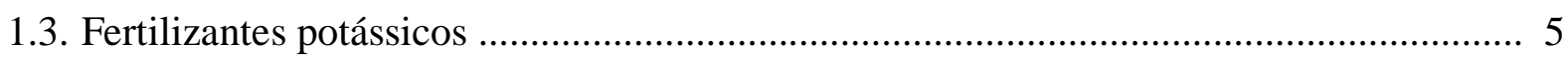

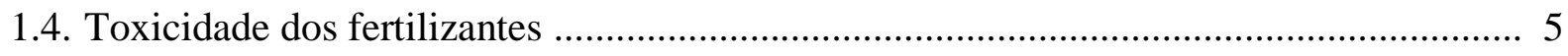

2. OBJETIVOS GERAL E ESPECÍFICOS …........................................................... 8

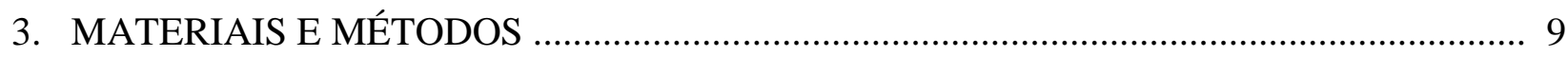

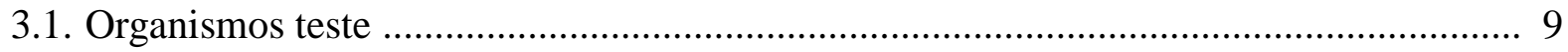

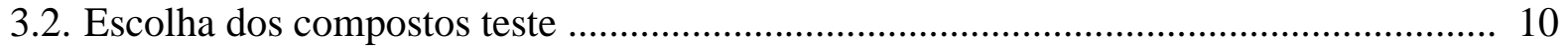

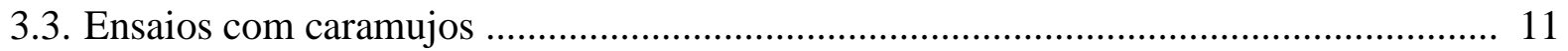

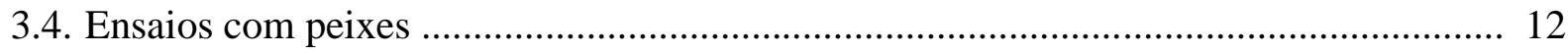

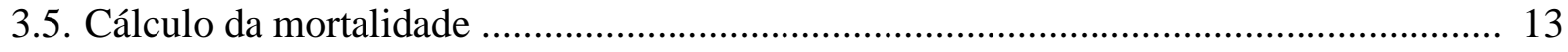

3.6. Análises químicas ...................................................................................... 15

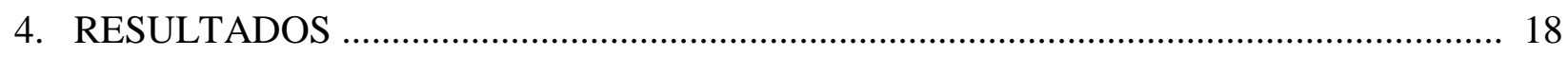

4.1. Ensaios com cloreto de potássio $(\mathrm{KCl})$......................................................... 18

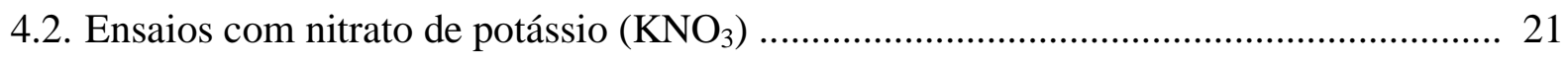


4.3. Ensaios com ureia $\left(\mathrm{CO}\left(\mathrm{NH}_{2}\right)_{2}\right)$

4.4. Ensaios com fosfato

4.5. Comparação entre os compostos

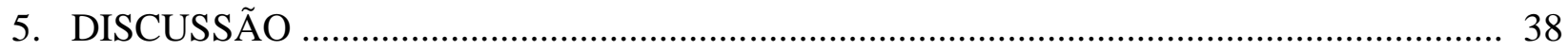

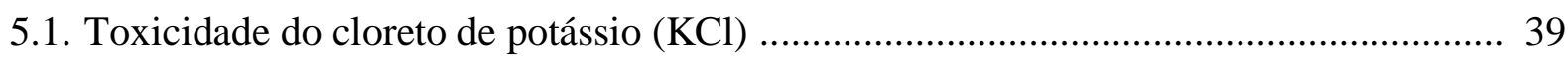

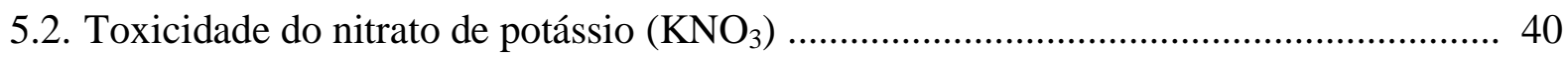

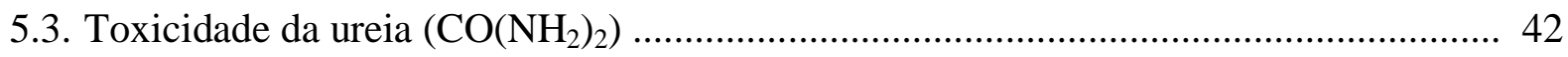

5.4. Toxicidade do fosfato .................................................................................. 45

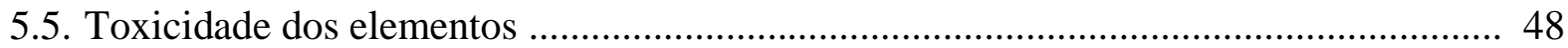

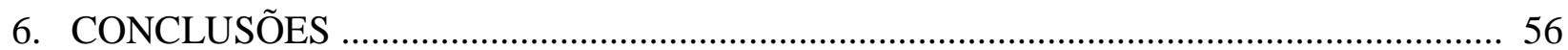

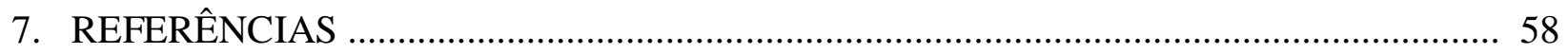




\section{LISTA DE SIGLAS E ABREVIATURAS}

AAPFCO Association of American plant food control Officials

ABNT Associação Brasileira de Normas Técnicas

ANDA Associação Nacional para Difusão de Adubos

APHA Associação Americana de Saúde Pública

$\mathrm{Br}^{-}$Brometo

CETESB Companhia de Tecnologia de Saneamento Ambiental

CEUA Comissão de Ética no Uso de Animais

CFIA Agência Canadense de inspeção de alimentos

$\mathrm{Ca}^{2+}$ Cálcio

$\mathrm{CE}_{50}$ Concentração Efetiva para $50 \%$ da População

$\mathrm{Cl}^{-}$Cloreto

$\mathrm{CL}_{50}$ Concentração Letal para $50 \%$ da População

$\mathrm{CL}_{(\mathrm{I}) 50}$ Concentração Letal Inicial para $50 \%$ da População

$\mathrm{CL}_{\text {zero }}$ Concentração Letal Máxima para 0\% da População

df Grau de liberdade

F Fluoreto

IFA Associação Internacional da Indústria de Fertilizantes

$\mathrm{K}^{+}$Potássio

$\mathrm{Kg} / \mathrm{ha}$ Quilogramas por hectare

$\mathrm{Na}^{+}$Sódio

$\mathrm{Mg} / \mathrm{L}$ Miligrama por litro 
$\mathrm{Mg}^{2+}$ Magnésio

N Nitrogênio

$\mathrm{NO}_{3}^{-}$Nitrato

$\mathrm{NO}_{2}^{-}$Nitrito

$\mathrm{NH}_{4}{ }^{+}$Amônio

P Fósforo

$\mathrm{PO}_{4}{ }^{3-}$ Fosfato

$\mathrm{SO}_{4}{ }^{2-}$ Sulfato

$\mathrm{T}$ Teste $\mathrm{t}$

USEPA Agência Americana de Proteção Ambiental

W Teste Wilcoxon/Mann-Whitney

$\mu \mathrm{S} / \mathrm{cm}$ Microsiemens por centímetro 


\section{LISTA DE FIGURAS}

Figura 1: Caramujo Biomphalaria glabrata

Figura 2: Peixe Danio rerio

Figura 3: Cromatógrafo Iônico 761 Compact IC

Figura 4: Cromatograma da calibração de cátions mostrando a curva da condutividade (em $\mu \mathrm{S} / \mathrm{cm}$ ) de cada elemento em função do tempo (em minutos). Unidades mostradas em mg/L ... 16

Figura 5: Cromatograma da calibração de ânions mostrando a curva da condutividade (em $\mu \mathrm{S} / \mathrm{cm}$ ) de cada elemento em função do tempo (em minutos). Unidades mostradas em mg/L ... 16

Figura 6: Comparação entre as Concentrações Letais (CLs ${ }_{50}$ ) encontradas nos testes com $\mathrm{KCl}$ para o caramujo B. glabrata e o peixe D. rerio em 96 horas de exposição e os respectivos intervalos de confiança (unidades em $\mathrm{mg} / \mathrm{L}$ )

Figura 7: Comparação entre as Concentrações Letais (CLs ${ }_{50}$ ) encontradas nos testes com $\mathrm{KNO}_{3}$ para o caramujo B. glabrata e o peixe $D$. rerio em 96 horas de exposição e os respectivos intervalos de confiança (unidades em $\mathrm{mg} / \mathrm{L}$ )

Figura 8: Comparação entre as Concentrações Letais (CLs 50) encontradas nos testes com ureia para o caramujo B. glabrata e o peixe D. rerio em 96 horas de exposição e os respectivos intervalos de confiança (unidades em $\mathrm{mg} / \mathrm{L}$ ) 28

Figura 9: Comparação entre as Concentrações Letais (CLs 50 ) encontradas no amônio para o caramujo $B$. glabrata e o peixe $D$. rerio em 48 horas de exposição e os respectivos intervalos de confiança (unidades em $\mathrm{mg} / \mathrm{L}$ )

Figura 10: Comparação entre as Concentrações Letais (CLs 50) encontradas nos testes com fosfato para o caramujo B. glabrata e o peixe D. rerio em 96 horas de exposição e os respectivos intervalos de confiança (unidades em $\mathrm{mg} / \mathrm{L}$ ) 33

Figura 11: Concentrações Letais (CLs ${ }_{50}$ ) encontradas para o caramujo B. glabrata e o peixe $D$. rerio em 48 horas (esquerda) e 96 horas (direita) de exposição (unidades em mg/L) 34

Figura 12: Comparação entre concentrações Letais (CLs ${ }_{50}$ ) do $\mathrm{KCl}$ em diferentes espécies em 48 horas de exposição com intervalos de confiança, quando informados (unidades em mg/L). Dados obtidos no presente estudo(*) com a de outros estudos 
Figura 13: Comparação entre concentrações Letais (CLs 50) do $\mathrm{KNO}_{3}$ em diferentes espécies em 24 e 96 horas de exposição com intervalos de confiança, quando informados (unidades em mg/L). Dados obtidos no presente estudo $(*)$ com a de outros estudos

Figura 14: Comparação entre concentrações Letais (CLs ${ }_{50}$ ) da ureia em diferentes espécies em 48 horas de exposição com intervalos de confiança, quando informados (unidades em mg/L). Dados obtidos no presente estudo(*) com a de outros estudos

Figura 15: Comparação entre concentrações Letais (CLs 50) do fosfato em diferentes espécies em 24 horas de exposição com intervalos de confiança, quando informados (unidades em mg/L). Dados obtidos no presente estudo(*) com a de outros estudos 45

Figura 16: Comparação entre concentrações Letais (CLs 50) do superfosfato simples em diferentes espécies em 96 horas de exposição com intervalos de confiança, quando informados (unidades em mg/L). Dados obtidos no presente estudo(*) com a de outros estudos 48

Figura 17: Comparação entre concentrações Letais (CLs 50) do potássio em diferentes espécies em 48 e 96 horas de exposição com intervalos de confiança, quando informados (unidades em $\mathrm{mg} / \mathrm{L})$. Dados obtidos no presente estudo(*) com a de outros estudos

Figura 18: Comparação entre concentrações Letais (CLs 50) do nitrogênio em diferentes espécies em 48 e 96 horas de exposição com intervalos de confiança, quando informados (unidades em $\mathrm{mg} / \mathrm{L})$. Dados obtidos no presente estudo(*) com a de outros estudos

Figura 19: Comparação entre concentrações Letais (CLs ${ }_{50}$ ) do amônio em diferentes espécies em 48 e 96 horas de exposição com intervalos de confiança, quando informados (unidades em mg/L). Dados obtidos no presente estudo(*) com a de outros estudos 52

Figura 20: Comparação entre concentrações Letais (CLs 50 ) do fosfato de diversas substâncias em diferentes espécies em 48 e 96 horas de exposição com intervalos de confiança, quando informados (unidades em $\mathrm{mg} / \mathrm{L}$ ). Dados obtidos no presente estudo(*) com a de outros estudos 


\section{LISTA DE TABELAS}

Tabela 1: Fertilizantes selecionados para o estudo e suas respectivas purezas

Tabela 2: Diluição das substâncias utilizadas nos ensaios com a espécie Biomphalaria glabrata (unidades em $\mathrm{mg} / \mathrm{L}$ )

Tabela 3: Diluição das substâncias utilizadas nos ensaios com a espécie Danio rerio (unidades $\mathrm{em} \mathrm{mg} / \mathrm{L})$

Tabela 4: Normalidade e estatística dos íons encontrados nas análises químicas do $\mathrm{KCl}$ reagente e do comercial 18

Tabela 5: Análise das diluições de cloreto de potássio (unidades em mg/L) 19

Tabela 6: Dados de concentração letal $\left(\mathrm{CL}_{50}\right)$ encontrados no teste com o $\mathrm{KCl}$ para cada substância no teste com B. glabrata. Valores entre parênteses mostram o intervalo de confiança. 20

Tabela 7: Dados de concentração letal $\left(\mathrm{CL}_{50}\right)$ encontrados no teste com o $\mathrm{KCl}$ para cada substância no teste com D. rerio. Valores entre parênteses mostram o intervalo de confiança .. 20

Tabela 8: Normalidade e estatística dos íons encontrados nas análises químicas do $\mathrm{KNO}_{3}$ reagente e do comercial

Tabela 9: Análise das diluições de nitrato de potássio (unidades em mg/L) 22

Tabela 10: Dados de concentração letal $\left(\mathrm{CL}_{50}\right)$ encontrados no teste com o $\mathrm{KNO}_{3}$ para cada substância no teste com B. glabrata. Valores entre parênteses mostram o intervalo de confiança. 23

Tabela 11: Dados de concentração letal $\left(\mathrm{CL}_{50}\right)$ encontrados no teste com o $\mathrm{KNO}_{3}$ para cada substância no teste com D. rerio. Valores entre parênteses mostram o intervalo de confiança .. 24 
Tabela 12: Normalidade e estatística dos íons encontrados nas análises químicas da ureia reagente e do comercial 25

Tabela 13: Análise das diluições de ureia (unidades em mg/L) ..... 26

Tabela 14: Dados de concentração letal $\left(\mathrm{CL}_{50}\right)$ encontrados no teste com a ureia para cada substância no teste com B. glabrata. Valores entre parênteses mostram o intervalo de confiança. 27

Tabela 15: Dados de concentração letal $\left(\mathrm{CL}_{50}\right)$ encontrados no teste com a ureia para cada substância no teste com $D$. rerio. Valores entre parênteses mostram o intervalo de confiança .. 27

Tabela 16: Normalidade e estatística dos íons encontrados nas análises químicas do fosfato reagente (fosfato de potássio monobásico) e do comercial (superfosfato simples)

Tabela 17: Análise das diluições de fosfato (unidades em mg/L)

Tabela 18: Dados de concentração letal $\left(\mathrm{CL}_{50}\right)$ encontrados no teste com o fosfato para cada substância no teste com B. glabrata. Valores entre parênteses mostram o intervalo de confiança.

Tabela 19: Dados de concentração letal $\left(\mathrm{CL}_{50}\right)$ encontrados no teste com o fosfato para cada substância no teste com D. rerio. Valores entre parênteses mostram o intervalo de confiança .. 32

Tabela 20: Comparação entre as concentrações letais (CLs ${ }_{50}$ ) obtidos com diferentes testes com o potássio presente para o reagente e para o fertilizante comercial para o caramujo B. glabrata e o peixe D. rerio (unidades em $\mathrm{mg} / \mathrm{L}$ ) 35

Tabela 21: Comparação entre as concentrações letais (CLs ${ }_{50}$ ) obtidos com diferentes testes com o nitrogênio presente para o reagente e para o fertilizante comercial para o caramujo B. glabrata e o peixe D. rerio (unidades em $\mathrm{mg} / \mathrm{L}$ ) ......................................................................... 36

Tabela 22: Comparação entre as concentrações letais (CLs ${ }_{50}$ ) obtidos com diferentes testes com o fosfato presente para o reagente e para o fertilizante comercial para o caramujo B. glabrata e o peixe D. rerio (unidades em $\mathrm{mg} / \mathrm{L}$ ) 


\section{INTRODUÇÃO}

Com o início da Revolução Verde no Brasil na década de 1960, houve um incentivo nas pesquisas que buscassem uma lógica produtiva baseada nas áreas de química, mecânica e genética (MARCATTO, 2006; SAUER, BALESTRO, 2009). Essas pesquisas tinham como intenção impulsionar o desenvolvimento produtivo nacional, ou seja, a dita Revolução Verde trouxe benefícios a partir do momento em que permitiu a transferência de tecnologias e também a implementação de novos processos produtivos. Contudo, Cereda (2011) destaca que as tecnologias desenvolvidas com essa revolução deixaram de ter uma função social a partir do momento que não conseguiam atender àquela sociedade a qual foram destinadas. Dentre essas tecnologias e benfeitorias para o campo estão os fertilizantes.

Dentro da cadeia agrícola de produção, o nitrogênio $(\mathrm{N})$, o potássio $(\mathrm{K})$ e o fósforo $(\mathrm{P})$ possuem grande importância para a prática da atividade agrícola, sendo o Brasil o quarto maior consumidor de fertilizantes do mundo em 2010 (IFA, 2013). Dentro do processo de produção é difícil para o agricultor obter uma boa safra sem utilizar no mínimo fertilizantes a base de fosfato, nitrogênio e potássio. Segundo a Associação Internacional da Indústria de Fertilizantes (IFA), a cada safra são utilizados no Brasil, em média, 2.855.000 toneladas de nitrogênio, 3.384.000 toneladas de fosfato e 3.894.000 toneladas de potássio (IFA, 2013).

Em especial para o bioma Cerrado, os fertilizantes possuem grande importância, pois para Lopes e Cox (1977), a baixa disponibilidade de fósforo e sua alta capacidade de fixação em solo, são provavelmente as maiores limitações para o crescimento de culturas nesse bioma. Mesmo com todos os nutrientes e minerais disponíveis na Terra, nem todos eles são de fácil obtenção, como por exemplo, o nitrogênio, uma vez que este não é comumente encontrado na constituição de solo e rochas terrestres (SAAB; PAULA, 2008).

O mau uso desses compostos e seus derivados pode trazer consequências severas para o meio ambiente e para as pessoas inseridas nesse contexto. Conley e colaboradores (2009) mostraram essas consequências como a perda de habitat em algumas regiões do globo e riscos a saúde pública detectados nas áreas estudadas. Mesmo que, em princípio, não apresentem elevada toxicidade, concentrações pontuais desses elementos na forma iônica no corpo hídrico podem desencadear efeitos tóxicos para a biota que faz uso desse meio (SIMMONS, 2012). 
$\mathrm{Na}$ presença de água, muitos compostos são bioquimicamente interconvertidos em íons (APHA, 1998). Isso representa um risco tanto para a biota quanto para o ser humano, pois se as concentrações de fósforo, nitrogênio e potássio apresentarem-se elevadas no corpo hídrico, poderão causar a eutrofização do meio (SHIGAKI et al., 2006).

Esses fertilizantes muitas vezes chegam ao corpo hídrico em virtude de sua acumulação no solo e posterior escoamento para córregos e rios. Para Tucci (2009), esse processo, conhecido como escoamento superficial, possui grande importância no conhecimento de ciclos hidrológicos em córregos e bacias. Farias e Araújo (2011) complementam essa discussão quando expõem que o processo de descarga nos rios é de grande importância para o planejamento dos recursos hídricos e na tomada de decisões.

De maneira geral, o escoamento superficial representa o fluxo de matéria presente em água de descarga sobre a superfície do solo e pelos seus múltiplos canais. Vários fatores podem influenciar nesse processo, dentre eles o relevo, a cobertura vegetal da área e a distribuição, duração e intensidade da precipitação (TUCCI, 2009).

O processo de escoamento superficial ocorre naturalmente, contudo alguns fatores podem torná-lo mais intenso como o regime de chuvas, o estado de conservação da vegetação ripária, o relevo da região e intervenções antrópicas no ambiente (TUCCI, 2009), podendo este processo se tornar o principal responsável pela contaminação de águas subterrâneas e superficiais (OLIVEIRA et al., 2000). Em ambientes preservados, em especial, a cobertura vegetal interfere no escoamento e grande parte da matéria presente nessa água infiltra para o solo, chegando menos matéria ao corpo hídrico (TUCCI, 2009).

\subsection{Fertilizantes Nitrogenados}

O nitrogênio $(\mathrm{N})$, em especial, constitui uma classe importante de fertilizantes, pois este se apresenta abundante na biosfera, apesar de somente depois que se converte em amônia e em nitrato é que pode ser utilizado na agricultura (DRISCOLL et al., 2003, SOUSA; LOBATO, 2004a). Por isso os principais fertilizantes nitrogenados utilizados na agricultura são a Ureia $\mathrm{CO}\left(\mathrm{NH}_{2}\right)_{2}$, o Sulfato de Amônio - $\left(\mathrm{NH}_{4}\right)_{2} \mathrm{SO}_{4}$, o Nitrato de Sódio - $\mathrm{NaNO}_{3}$, o Nitrato de Potássio - $\mathrm{KNO}_{3}$ e o Nitrato de Amônia - $\mathrm{NH}_{4} \mathrm{NO}_{3}$ (SOUSA; LOBATO, 2004a).

Esses compostos, mesmo possuindo características individuais, possuem um grande potencial na correção nutricional do solo, sendo observadas grandes respostas na produtividade 
de milho e soja quando expostos a fertilizantes (SOUSA; LOBATO, 2004a, NUNES et al., 2011). Como exemplo pode-se citar culturas de milho, que são amplamente cultivadas no Cerrado, onde foram obtidas respostas em doses por volta de $100 \mathrm{Kg} / \mathrm{ha}$ de $\mathrm{N}$ em solo com pouca disponibilidade de matéria orgânica (SOUSA; LOBATO, 2004a).

Salienta-se que o correto manejo dos fertilizantes a base de $\mathrm{N}$, ajudam na obtenção de leguminosas de qualidade, principalmente se houver rotação de culturas (SISTI et al., 2004; DIEKOW et al., 2005). Contudo, rotações onde a soja esteja presente como única leguminosa pode afetar o acúmulo de N no solo (NUNES et al., 2011).

O maior risco dentro da classe dos fertilizantes nitrogenados baseia-se no seu processo de conversão em nitrato $\left(\mathrm{NO}_{3}{ }^{-}\right)$. Adubos compostos por amônio $\left(\mathrm{NH}_{4}{ }^{+}\right)$ou outros compostos que tenham esse como produto intermediário tendem a ser menos carreados do que $\mathrm{o}_{\mathrm{NO}_{3}}{ }^{-}$, devido ao cátion ser retido pelas cargas negativas presentes no solo (RESENDE, 2002; SOUSA; LOBATO, 2004a). Em solos de Cerrado onde o solo é caracteristicamente arenoso, Gomes et al. (2004) mostram que o escoamento do $\mathrm{NO}_{3}{ }^{-}$é facilitado e mais rápido se comparado com o solo argiloso.

Fertilizantes nitrogenados são importantes poluidores dos ecossistemas aquáticos, sendo que os organismos são os principais alvos para esse tipo de mudança no ecossistema. Eles exibem diferentes graus de alterações no padrão de comportamento quando o seu habitat está impactado (SANGEETHA et al., 2011).

O N, quando em meio aquoso, é convertido em amônia, nitrito e nitrato em um processo de três etapas (APHA, 1998). É conhecido que destes três íons, a amônia é a mais tóxica para os organismos aquáticos (CAMARGO; ALONSO; SALAMANCA, 2005), contudo estes compostos costumam existir em concentrações baixas nos ecossistemas aquáticos por serem a principal fonte de nitrogênio para os produtores primários (ESTEVES, 1998). Os desequilíbrios ecológicos e os riscos ao consumo humano passam a ser considerados, quando as concentrações de nitrato e nitrito se tornam elevadas devido à deposição destes nutrientes no corpo hídrico por meio de atividades como a agricultura e a pecuária (CAMARGO; ALONSO; SALAMANCA, 2005).

Além de estar envolvido no processo de eutrofização da água, a forma iônica do nitrogênio também participa no processo de acidificação de córregos e rios. Isso traz riscos ambientais, pois além de gerar impacto sobre os ecossistemas aquáticos, as reduções no pH da água também aumentam a solubilidade de metais (CAMARGO; ALONSO, 2006). 


\subsection{Fertilizantes Fosfatados}

O fósforo $(\mathrm{P})$ também possui grande atenção dentro das culturas, uma vez que, os solos do Cerrado possuem pequena concentração desse elemento (LOPES; COX, 1977), por isso frequentemente são utilizadas doses maiores desse fertilizante, por volta de $300 \mathrm{~kg} / \mathrm{ha}$ de $\mathrm{P}_{2} \mathrm{O}_{5}$. Contudo, com esse elemento em especial deve ser observado o $\mathrm{pH}$ do solo, uma vez que solos de Cerrado são ácidos e sua solubilização no mesmo torna-se reduzida com aplicações de calcário para a correção desta acidez no solo (BEDIN et al., 2003, SOUSA; LOBATO; REIN, 2004, VIEIRA; RAMOS, 1999), tornando-se mais suscetível ao escoamento superficial. Além disso, Bertol et al. (2010) alertam que solos já adubados podem contribuir para perda do fósforo por escoamento superficial, além de outros fatores como o regime de chuvas e o tempo da adubação deste fertilizante. Os principais tipos de fertilizantes fosfatados utilizados dentro da agricultura são o Fosfato Diamônico - $\left(\mathrm{NH}_{4}\right) \mathrm{HPO}_{4}$, o Hiperfosfato e o Superfosfato Simples - $\mathrm{Ca}\left(\mathrm{H}_{2} \mathrm{PO}_{4}\right)$, o Fosfato Bicálcico - $\mathrm{Ca}\left(\mathrm{HPO}_{4}\right)$ e a Escória de Thomas (SOUSA; LOBATO; REIN, 2004).

O P pode ocorrer em águas naturais e residuais quase somente na forma de fosfatos. Eles são classificados em ortofosfatos, fosfatos orgânicos e fosfatos condensados (pirometafosfatos e outros polifosfatos). A terceira forma não é muito relevante nos estudos de controle de qualidade de água, porque os fosfatos condensados sofrem hidrólise, convertendo-se rapidamente em ortofosfatos nas águas naturais (APHA, 1998). Os ortofosfatos são representados pelos radicais $\mathrm{PO}_{4}{ }^{3-}, \mathrm{HPO}_{4}{ }^{2-}, \mathrm{H}_{2} \mathrm{PO}_{4}{ }^{-}$que se combinam com cátions formando sais inorgânicos nas águas. $\mathrm{A}$ descarga de fosfatos provenientes de esgoto bruto ou tratado, drenagem agrícola, ou de determinados resíduos industriais podem estimular o crescimento de micro e macro organismos aquáticos fotossintéticos em grandes quantidades, desencadeando o processo de eutrofização (CETESB, 2001).

O mau uso dos fosfatos, por sua vez, além de contribuir com o escoamento superficial, promove também o decréscimo de sua eficiência para culturas futuras, pois o uso excessivo desse fertilizante influencia em fatores como tipo do solo, método de aplicação do fertilizante, preparo do solo e sequência de cultivos utilizada (SOUSA; LOBATO; REIN, 2004). O experimento de Sousa, Volkweiss e Castro (1987) comprovam essa afirmação a partir do momento em que esses pesquisadores tiveram decréscimo do efeito imediato de fertilizantes fosfatados de $60 \%, 45 \%$, 35\%, 15\% e 5\%, após um, dois, três, quatro e cinco anos de aplicações consecutivas, respectivamente. 


\subsection{Fertilizantes Potássicos}

O potássio $(\mathrm{K})$ é mais um dos elementos mais demandados pelas culturas, contudo a sua fixação no solo é mais dificultada uma vez que seus sais possuem baixa capacidade de troca catiônica (VILELA; SOUSA; SILVA, 2004, ROSOLEM; VICENTINI; STEINER, 2012). Logo, para adubações com $\mathrm{K}$, recomenda-se a sua extração através de métodos específicos com acetato de amônio. Após esse processo, já foram observadas respostas das culturas à adubação potássica, principalmente na produção de soja e milho, onde foi observado o aumento da produção com adição de $100 \mathrm{~kg} / \mathrm{ha}$ de $\mathrm{K}_{2} \mathrm{O}$ para a soja e $300 \mathrm{~kg} / \mathrm{ha}$ de $\mathrm{K}_{2} \mathrm{O}$ para o milho (SOUSA; LOBATO, 2004b).

O K é pouco produzido no Brasil, tendo somente uma mina em operação em território nacional e em condições de produzir somente até 2016 (BRASIL, 2014). Por isso, comumente este nutriente é importando para o país na forma de cloreto de potássio $(\mathrm{KCl})$, o que representa um grande ônus para o país se não forem encontradas fontes alternativas de produção de K para a agricultura. Normalmente este composto é extraído de fontes sedimentares de depósitos marinhos sob a forma de $\mathrm{KCl}$ ou de sulfato de potássio $\left(\mathrm{K}_{2} \mathrm{SO}_{4}\right)$ (RESENDE et al., 2006).

O K também está envolvido no processo de salinização da água, sendo que em alguns lugares esse processo de salinização pode alterar a composição da fauna local (UTZ; BÖHRER, 2001). Devido a esse efeito na mudança salina, o elemento potássio possui uma grande toxicidade mesmo quando presente em concentrações pequenas (ROMANO, ZENG, 2007). Os principais tipos de fertilizantes potássicos utilizados são o Cloreto de Potássio $(\mathrm{KCl})$, o Sulfato de Potássio $\left(\mathrm{K}_{2} \mathrm{SO}_{4}\right)$ e o Nitrato de Potássio $\left(\mathrm{KNO}_{3}\right)$, sendo utilizados na agricultura sempre em pequenas quantidades devido a sua eficiência e a sua baixa solubilidade em solo (VILELA; SOUSA; SILVA, 2004).

\subsection{Toxicidade dos Fertilizantes}

O conhecimento sobre a toxicidade dos fertilizantes é importante para poder estabelecer práticas de prevenção de problemas ambientais e melhor estruturar uma legislação para controle e uso destes compostos químicos. Mesmo existindo muitos dados toxicológicos a respeito dos fertilizantes, obrigatórios para o seu registro, ainda há pouca informação sobre o efeito dessas 
substâncias para a saúde humana e seus impactos para o meio ambiente (GOMES, BARIZON, 2014).

$\mathrm{Na}$ literatura, a maioria dos trabalhos que tratam a respeito de fertilizantes nitrogenados dá maior enfoque ao risco que estes trazem para o processo de eutrofização da água, trazendo poucos dados ligados ao risco para os organismos que vivem no corpo hídrico ou para a população que faz uso deste recurso (BARBOSA et al., 2009; GONÇALVES et al., 2005; MARTÍNEZ-BASTIDA; ARAUZO; VALLADOLID, 2006; SHIGAKI et al., 2006).

Resende (2002) complementa essa discussão alertando que a presença excessiva de nitrato no corpo hídrico pode causar prejuízos para a prática pecuária, pois se consumidos por animais, o $\mathrm{NO}_{3}{ }^{-}$é convertido em nitrito por bactérias presente no trato digestivo de ruminantes, ocasionando a morte do animal por envenenamento. Em humanos, principalmente em bebês menores de seis meses, $\mathrm{o} \mathrm{NO}_{3}{ }^{-}$também é convertido em nitrito no corpo destes e, quando alcança a circulação, reage com a hemoglobina presente no sangue formando a metahemoglobina, inviabilizando o transporte de oxigênio.

Uma alternativa ambiental para melhor dimensionar a problemática dos fertilizantes são os testes ecotoxicológicos, pois a execução de bioensaios consiste em um método rápido e de baixo custo, importantes para avaliar os efeitos nocivos das atividades humanas, sem a necessidade de análises químicas, muitas vezes inviabilizadas pelo alto custo (OLIVEIRAFILHO; PARRON, 2007).

Abbasi e Abbasi (2012) apontam que inicialmente os bioensaios eram a principal ferramenta no monitoramento de córregos e bacias, contudo com o aumento do uso das análises químicas por serem mais rápidas em mostrar resultados do que a realização do biomonitoramento, o uso de bioensaios começou a ser menos demandados, contudo esses autores ainda chamam atenção que amostras consideradas quimicamente próprias para o consumo humano podem conter níveis perigosos de metais pesados, pesticidas ou radioatividade que somente são detectados através dos bioensaios e de análises mais específicas.

Além disso, esses autores ainda ressaltam a importância da realização dos testes ecotoxicológicos em conjunto com as análises químicas, uma vez que a subutilização dos bioensaios têm sido o responsável pela deterioração da integridade ecológica de ecossistemas aquáticos, uma vez que os organismos aquáticos refletem não somente a qualidade da água, mas também a "saúde" do ecossistema presente no corpo hídrico (ABBASI; ABBASI, 2012). 
Os bioensaios podem, na visão de Zagatto (2006), mostrar os efeitos adversos de certos poluentes, no que diz respeito à quantificação de organismos vivos ou mortos após teste agudo, ou taxa de reprodução, número de anomalias ou incidência de tumores e alterações fisiológicas após teste crônico. O autor ainda chama a atenção para a necessidade de mais estudos sobre fertilizantes, pois a cada 70 mil substâncias químicas conhecidas e de uso cotidiano (como fertilizantes e pesticidas), apenas 2 mil possuem os seus efeitos tóxicos conhecidos. Esse fato aumenta a dificuldade de execução de práticas mais eficientes na mitigação de problemas relacionados a acidentes ambientais (ZAGATTO, 2006).

Esses ensaios ainda revelam efeitos tóxicos de substâncias através dos efeitos agudos ou crônicos, produzidos por substâncias químicas em matéria viva (KNIE; LOPES, 2004). Esses ensaios com matéria viva ou bioensaios possuem pontos positivos e negativos em sua concepção. O lado positivo é que permitem simular condições ambientais controladas em laboratório e com isso facilitar a análise dos resultados obtidos, além dos resultados dos bioensaios serem mais expressivos do que os parâmetros físico-químicos. Por outro lado, o fato destes testes serem executados em ambientes artificiais não permite ao pesquisador generalizar os seus resultados à nível de ecossistema, ficando este restrito ao organismo teste específico. De todo modo, os ensaios ecotoxicológicos fornecem informações e indicações sobre possíveis riscos para o meio ambiente e com isso prever impactos futuros e orientar decisões de maneira a minimizar ou evitar desastres ambientais (ABBASI, ABBASI, 2012; KNIE, LOPES, 2004; OLIVEIRA-FILHO et al., 2006; ZAGATTO, 2006).

Com isso, o presente estudo teve como objetivo avaliar a ecotoxicidade de fertilizantes a base de nitrogênio, fósforo e potássio, e seus ingredientes ativos isoladamente, visando apresentar os potenciais efeitos adversos decorrentes da presença desses elementos nos ambientes aquáticos.

No presente estudo, o objetivo de analisar quimicamente os cátions e ânions contidos no produto formulado foi com a intenção também de avaliar se a toxicidade observada nos testes estava realmente sendo em função do elemento ou das impurezas no produto. 


\section{OBJETIVO GERAL}

Avaliar a ecotoxicidade de fertilizantes a base de nitrogênio, fósforo e potássio, e seus ingredientes ativos isoladamente, visando investigar os potenciais efeitos adversos decorrentes da presença desses elementos nos ambientes aquáticos.

\section{OBJETIVOS ESPECÍFICOS}

1. Comparar a susceptibilidade dos organismos aquáticos aos diferentes compostos químicos estudados;

2. Relacionar os resultados dos bioensaios com as análises químicas dos compostos estudados;

3. Comparar a toxicidades dos produtos fertilizantes comerciais com a toxicidade de seus reagentes químicos com pureza analítica;

4. Indicar o potencial elemento no composto responsável pela toxicidade. 


\section{MATERIAIS E MÉTODOS}

\subsection{Organismos teste}

Para os ensaios foram utilizados os organismos da espécie Biomphalaria glabrata e Danio rerio, sendo o primeiro um molusco e o segundo um peixe, ambos organismos de água doce, com o intuito de englobar organismos com biologias e hábitos distintos, uma vez que o caramujo é um organismo bentônico e o peixe, pelágico.

A opção de utilizar organismos de diferentes níveis tróficos para as mesmas soluções teste foi dada em virtude de nos testes ecotoxicológicos ser recomendado a utilização de organismos de níveis tróficos distintos para poder estimar a toxicidade de uma dada substância para o ambiente (OLIVEIRA-FILHO, 2013), contudo segundo dados do estudo de Krull e Barros (2012), onde os autores fizeram uma pesquisa sobre o uso de ensaios ecotoxicológicos em artigos publicados nas principais bases de dados (Web of Knowledge, Scielo e Science Direct) entre os anos de 1981 e 2009, percebeu-se que 25,5\% usavam mais de uma espécie em ensaios separados, além de existirem ainda muito poucos dados sobre toxicidade das substância para gastrópodes, tendo somente $3,2 \%$ dos artigos pesquisados pelos autores usado esse grupo em algum tipo de bioensaio.

Os caramujos do gênero Biomphalaria são organismos aquáticos e pulmonados, com grande distribuição pelo território brasileiro (BRASIL, 2007a; OLIVEIRA-FILHO et al., 2014). Além disso, os organismos dessa espécie são nativos dos ecossistemas de água doce naturais, sendo este um dos motivos pelo qual vários autores propõem a sua utilização como organismo teste em ensaios ecotoxicológicos (RAVERA, 1977; BELLAVERE; GORBI, 1981; MÜNZINGER, 1987, OLIVEIRA-FILHO; LOPES; PAUMGARTTEN, 2004, OLIVEIRAFILHO et al., 2005, TALLARICO et al., 2014).

Os caramujos da espécie $B$. glabrata utilizados no estudo são cultivados no Laboratório de Ecotoxicologia da Embrapa Cerrados, onde a colônia é mantida em água mole sintética e fotoperíodo de 8 horas com fornecimento de luz e 16 horas sem. Os procedimentos de ensaio seguiram os modelos já padronizados no laboratório (OLIVEIRA-FILHO et al., 2005) e antes dos testes, foram realizados ensaios de sensibilidade utilizando sulfato de cobre $\left(\mathrm{CuSO}_{4}\right)$ como substância de referência. O ensaio consiste na exposição dos organismos adultos ao material testado, visando a determinação da mortalidade. 
O peixe D. rerio (conhecido popularmente por paulistinha) é uma espécie tropical de água doce utilizado em bioensaios desde 1930 (KNIE; LOPES, 2004). Esta espécie é muito empregada em ensaios ecotoxicológicos, pois além de serem organismos de fácil manutenção, sua biologia é bem compreendida por ser um ótimo modelo em estudos de desenvolvimento genético em vertebrados (RUBINSTEIN, 2003, COFIEL; MATTIOLI, 2009).

Para o peixe $D$. rerio, realizou-se a sua aquisição periódica junto com um fornecedor comercial, e a manutenção por uma semana em isolamento para aclimatação à água de diluição, ao alimento e à temperatura. Sua sobrevivência avaliada durante o presente estudo seguiu a norma NBR 15088 (ABNT, 2004), onde também utilizou-se as diretrizes da norma para ensaios de sensibilidade antes dos testes em si, utilizando cloreto de sódio $(\mathrm{NaCl})$ como substância de referência.

A preparação da água de diluição (água mole sintética) para todos os testes seguiu os protocolos padronizados pelas diretrizes da norma NBR 15088 (ABNT, 2004), onde eram dissolvidos $48 \mathrm{mg}$ de bicarbonato de sódio $\left(\mathrm{NaHCO}_{3}\right), 30 \mathrm{mg}$ de sulfato de cálcio $\left(\mathrm{CaSO}_{4}\right), 30$ $\mathrm{mg}$ de sulfato de magnésio $\left(\mathrm{MgSO}_{4}\right)$ e $2 \mathrm{mg}$ de cloreto de potássio $(\mathrm{KCl})$ em 1 litro de água destilada preparada a partir de água encanada. $\mathrm{O}$ pH da água de diluição foi mantido em 7,2 $\pm 0,1$ e dureza entre $40-48 \mathrm{mg} / \mathrm{L}$ de $\mathrm{CaCO}_{3}$.

\subsection{Escolha dos compostos teste}

Para definição dos compostos a serem testados, foi realizado um levantamento sobre os fertilizantes mais utilizados na agricultura em solos de Cerrado e, seguindo esse critério, escolheram-se os compostos testados no presente estudo. Desse modo foram definidos o cloreto de potássio $(\mathrm{KCl})$, o fosfato de potássio monobásico $\left(\mathrm{KH}_{2} \mathrm{PO}_{4}\right)$, o nitrato de potássio $\left(\mathrm{KNO}_{3}\right)$, o superfosfato simples $\left(\mathrm{Ca}\left(\mathrm{H}_{2} \mathrm{PO}_{4}\right)_{2}+\mathrm{CaSO}_{4}\right)$ e a ureia $\left(\mathrm{CO}\left(\mathrm{NH}_{2}\right)_{2}\right)$.

A partir dessa escolha, foram realizadas diluições dos respectivos fertilizantes (Tabela 1) e de seus reagentes químicos equivalentes, sendo utilizados o cloreto de potássio, da marca J.T. Baker® (pureza de 99,8\%), o nitrato de potássio, da Impex® (pureza de 99\%), a ureia, da Merck® (pureza de 100\%) e o fosfato de potássio monobásico, da Merck® (pureza de 99,5\%). Após as diluições, foram realizados ensaios agudos com todos os organismos teste escolhidos, buscando estabelecer a concentração letal de metade da população. 
Tabela 1: Fertilizantes selecionados para o estudo e suas respectivas purezas.

\begin{tabular}{ccccc}
\hline Nome & Marca & \% de N & \% de $\mathbf{K}_{\mathbf{2}} \mathbf{O}$ & \% de $\mathbf{P O}_{\mathbf{4}}$ \\
\hline Cloreto de potássio & Araguaia ${ }^{\circledR}$ & 0 & 60 & 0 \\
Nitrato de potássio & Yara & 12 & 45 & 0 \\
Ureia & Yara & 46 & 0 & 0 \\
Superfosfato simples & Heringer ${ }^{\circledR}$ & 0 & 0 & 21 \\
\hline
\end{tabular}

\subsection{Ensaios com caramujos}

Para os ensaios com o B. glabrata (Figura 1) as diluições realizadas estão ilustradas na Tabela 2. Estas concentrações foram determinadas a partir de testes preliminares, além disso nos testes foram realizados no mínimo três diluições para poder-se realizar o cálculo da CL $_{50}$, os ensaios que demandaram mais testes foram para melhor dimensionar o intervalo de confiança.

Tabela 2: Diluição das substâncias utilizadas nos ensaios com a espécie Biomphalaria glabrata (unidades em mg/L).

\begin{tabular}{|c|c|c|}
\hline Substância & Reagente (mg/L) & Comercial (mg/L) \\
\hline Cloreto de Potássio (KCl) & $200,500,1000$ e 1800 & $\begin{array}{c}200,500,1000,1500,1750 \mathrm{e} \\
2000\end{array}$ \\
\hline Nitrato de Potássio $\left(\mathrm{KNO}_{3}\right)$ & $500,750,1000$ e 3000 & $100,250,500,750$ e 1000 \\
\hline Ureia $\left(\mathrm{CO}\left(\mathrm{NH}_{2}\right)_{2}\right)$ & $1000,2000,5000$ e 10000 & 10000,15000 e 20000 \\
\hline $\begin{array}{c}\text { Fosfato de Potássio } \\
\text { Monobásico }\left(\mathrm{KH}_{2} \mathrm{PO}_{4}\right)\end{array}$ & $75,150,500$ e 1000 & - \\
\hline $\begin{array}{c}\text { Superfosfato Simples } \\
\left(\mathrm{Ca}\left(\mathrm{H}_{2} \mathrm{PO}_{4}\right)_{2}+\mathrm{CaSO}_{4}\right)\end{array}$ & - & $\begin{array}{c}250,500,1000,1500,2000 \\
2500 \text { e } 3000\end{array}$ \\
\hline
\end{tabular}

Nos testes com os caramujos foi utilizada a metodologia de ensaio estático, onde as soluções eram preparadas somente no início do teste, sem renovação durante a exposição. Para a ureia, em especial, foi utilizada a metodologia semi-estática, onde as soluções eram renovadas diariamente para evitar perdas por degradação e volatilização, conforme recomendado pelo Guideline EPA 821-R-02-012 (USEPA, 2002). Durante o ensaio, pH e oxigênio dissolvido foram verificados diariamente com o intuito identificar possíveis mudanças bruscas nesses parâmetros durante o período de exposição.

Antes de cada ensaio, 1 litro das soluções foi colocado em béqueres de 2 litros e agitadas por 24 horas em agitador orbital. Após isso, foram inseridos 10 organismos em cada concentração, com a presença de um grupo controle, totalizando 410 organismos no ensaio. 
Para este teste, foi avaliada a mortalidade dos indivíduos após 48 e 96 horas de exposição, sendo considerado morto aquele indivíduo que apresentava retração para a concha, ausência de mobilidade quando retirado da água ou nítidos sinais de mortalidade, como hemorragia.

Figura 1: Caramujo Biomphalaria glabrata.

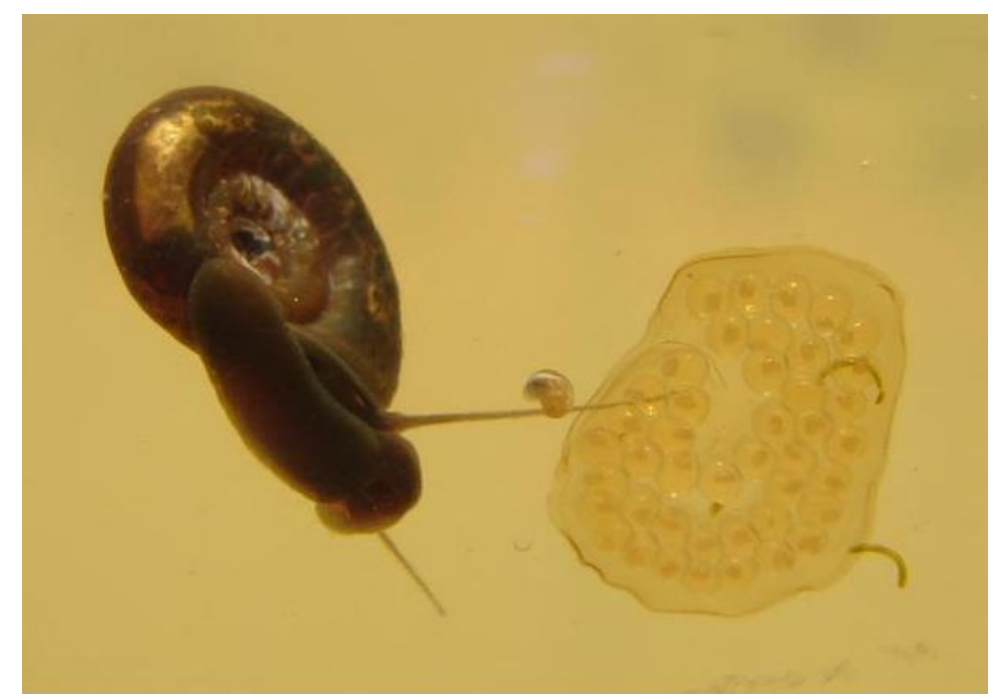

\subsection{Ensaios com peixes}

Os ensaios com o D. rerio (Figura 2), por sua vez, as diluições realizadas estão ilustradas na Tabela 3. Estas concentrações também foram determinadas a partir de testes preliminares, com o mínimo de três diluições para o cálculo da $\mathrm{CL}_{50}$, os ensaios que demandaram mais testes foram para melhor dimensionar o intervalo de confiança.

Tabela 3: Diluição das substâncias utilizadas nos ensaios com a espécie Danio rerio (unidades em mg/L).

\begin{tabular}{|c|c|c|}
\hline Substância & Reagente (mg/L) & Comercial (mg/L) \\
\hline Cloreto de Potássio (KCl) & $700,900,1200$ e 1500 & 700,1100 e 1500 \\
\hline Nitrato de Potássio $\left(\mathrm{KNO}_{3}\right)$ & $\begin{array}{c}250,750,1000,1500,1750 \\
2000 \text { e } 3000\end{array}$ & $\begin{array}{c}250,500,1500,2000,2500 \mathrm{e} \\
3000\end{array}$ \\
\hline Ureia $\left(\mathrm{CO}\left(\mathrm{NH}_{2}\right)_{2}\right)$ & $\begin{array}{c}5000,10000,15000,20000 \\
25000,30000 \text { e } 40000\end{array}$ & $10000,20000,30000$ e 40000 \\
\hline $\begin{array}{c}\text { Fosfato de Potássio } \\
\text { Monobásico }\left(\mathrm{KH}_{2} \mathrm{PO}_{4}\right)\end{array}$ & $750,1000,1500,2000$ e 3000 & - \\
\hline $\begin{array}{c}\text { Superfosfato Simples } \\
\left(\mathrm{Ca}\left(\mathrm{H}_{2} \mathrm{PO}_{4}\right)_{2}+\mathrm{CaSO}_{4}\right)\end{array}$ & - & $700,1000,2000,2500$ e 3000 \\
\hline
\end{tabular}


Três litros de cada solução foram agitados em béqueres de 4 litros e, após isso, foram acondicionados 10 organismos em cada concentração, também com a presença de um grupo controle, totalizando 450 organismos no teste. Para os testes com peixes, todas as soluções eram renovadas diariamente de maneira a garantir o fornecimento de oxigênio para os organismos e evitar possíveis alterações nas concentrações de ureia, conforme recomendado pelo protocolo EPA 821-R-02-012 (USEPA, 2002) e pela Norma NBR 15088 (ABNT, 2004). Também de maneira a garantir a observância a esses protocolos, $\mathrm{pH}$ e oxigênio dissolvido foram verificados diariamente com o intuito identificar possíveis mudanças bruscas nesses parâmetros durante o período de exposição.

A mortalidade foi avaliada após 48 e 96 horas de exposição, sendo considerado morto o indivíduo que apresentasse ausência de natação e movimentação no opérculo.

Por envolver o uso de animais vertebrados vivos e em observância à Lei no 11.794 , de 8 de outubro de 2008 (BRASIL, 2008), este estudo foi submetido e aprovado pela Comissão de Ética no Uso de Animais (CEUA) do Centro Universitário de Brasília (UniCEUB), sob o parecer número 003/15, em 19 de março de 2015.

Figura 2: Peixe Danio rerio.

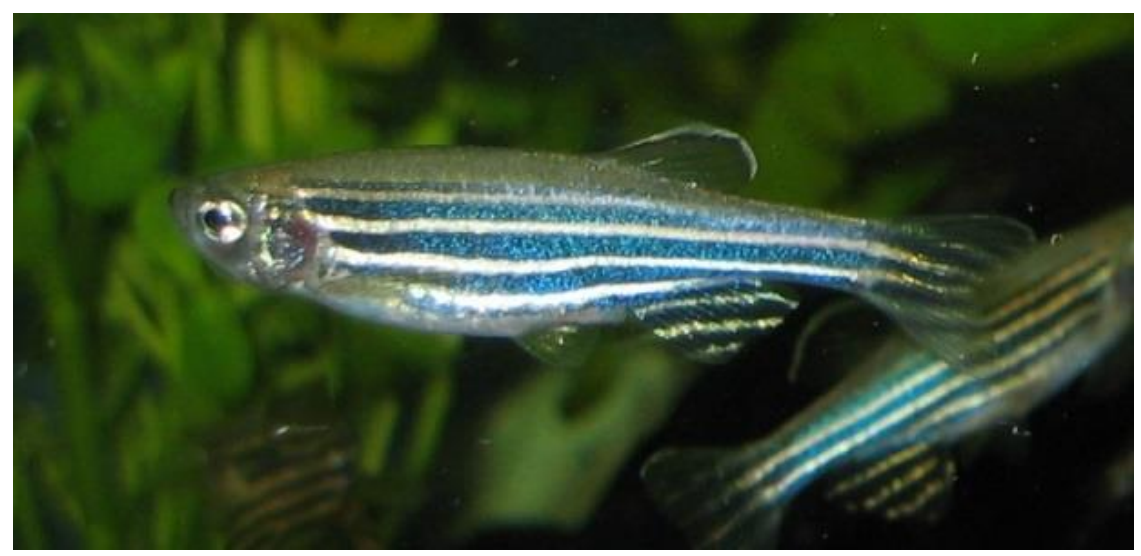

\subsection{Cálculo da mortalidade}

Para todos os organismos, a concentração letal para metade da população testada $\left(\mathrm{CL}_{50}\right)$ e seus respectivos intervalos com 95\% de confiança, foram determinados pelo programa Trimmed Spearman Karber (HAMILTON; RUSSO; THURSTON, 1977), versão 1.5. 
A CL50, segundo a norma NBR 15088 é a "concentração real da amostra que causa efeito agudo a 50\% dos organismos no tempo de exposição, nas condições de ensaio" (ABNT, 2004), onde este valor é obtido a partir de dados quantitativos, como número de indivíduos mortos ou com ausência de movimentação (BURATINI; BERTOLETTI, 2006). A opção de definir a concentração letal para metade $(50 \%)$ da população vem no sentido de observar a resposta mais uniforme para os organismos da população testada em comparação a outros percentuais, como $10 \%$, onde poderia representar somente os mais sensíveis ou 90\% da população, onde também estão incluídos os mais resistentes (BERTOLETTI, 2013).

Este valor pode ser inicial $\left(\mathrm{CL}_{(\mathrm{I})}\right)$, quando a toxicidade é calculada em relação ao valor que foi estipulado inicialmente para a diluição, mediano (CL), quando o cálculo é realizado em cima do valor real da substância que se está testando, considerando o tempo de exposição e as condições de ensaio e, por fim, zero $\left(\mathrm{CL}_{\text {zero }}\right)$, onde busca-se encontrar a maior concentração onde não desperta efeito agudo nos organismos teste (ABNT, 2004).

Como a observação da $\mathrm{CL}_{50}$ representa uma observação pontual da amostra sobre a espécie, para ter-se maior confiabilidade dos dados, calcula-se também o intervalo de confiança (BURATINI; BERTOLETTI, 2006). A definição do intervalo de confiança indica a faixa de valores onde a $\mathrm{CL}_{50}$ pode ser encontrada com uma probabilidade de $95 \%$. A extensão do intervalo de confiança varia em função das mudanças das condições de ensaio (BERTOLETTI, 2013).

O método Trimmed Spearman Karber é a alternativa não paramétrica para o cálculo de Spearman Karber, onde os dados de concentração/efeito são ajustados e eliminada uma porcentagem dos valores de cada extremidade da distribuição da tolerância antes da condução do teste estatístico. Essa constante de corte (estabelecida pelo analista) permite a exclusão de dados que não seguem padrões de efeito esperado. O método é recomendado quando a concentração mais alta testada nos bioensaios não produz efeito sobre $100 \%$ dos organismos expostos e quando a menor concentração não apresenta ausência de mortalidade (USEPA, 2002; BURATINI; BERTOLETTI, 2006).

Ressalta-se que os valores numéricos obtidos nos testes estatísticos possuem uma relação inversa com a toxicidade, logo menores valores numéricos indicam maior toxicidade. 


\subsection{Análises Químicas}

Para certificar as concentrações dos elementos diluídos nas condições de ensaio, definir as concentrações a serem utilizadas no cálculo da concentração letal $\left(\mathrm{CL}_{50}\right)$ e quantificar cada íon presente nas soluções testadas, foi realizada a leitura de cada amostra por cromatografia iônica, incluindo a água de diluição que foi destinada ao grupo controle. Foi analisada a presença dos íons brometo $\left(\mathrm{Br}^{-}\right)$, cloreto $\left(\mathrm{Cl}^{-}\right)$, fluoreto $\left(\mathrm{F}^{-}\right)$, nitrato $\left(\mathrm{NO}_{3}^{-}\right)$, nitrito $\left(\mathrm{NO}_{2}^{-}\right)$, fosfato $\left(\mathrm{PO}_{4}^{3^{-}}\right)$, sulfato $\left(\mathrm{SO}_{4}{ }^{2-}\right)$, Lítio $\left(\mathrm{Li}^{+}\right)$, Sódio $\left(\mathrm{Na}^{+}\right)$, Potássio $\left(\mathrm{K}^{+}\right)$, Amônio $\left(\mathrm{NH}_{4}{ }^{+}\right)$, Cálcio $\left(\mathrm{Ca}^{+}\right)$e Magnésio $\left(\mathrm{Mg}^{+}\right)$.

O equipamento utilizado para este fim foi o Cromatógrafo Iônico 761 Compact IC, da Metrohm (Figura 3). A cromatografia iônica é uma técnica cromatográfica que aplica princípios da troca iônica, de modo que a condutividade elétrica é utilizada para a detecção e determinação quantitativa dos íons em solução (FRANKENBERGER-JR; MEHRA; GJERD, 1990).

Figura 3: Cromatógrafo Iônico 761 Compact IC.

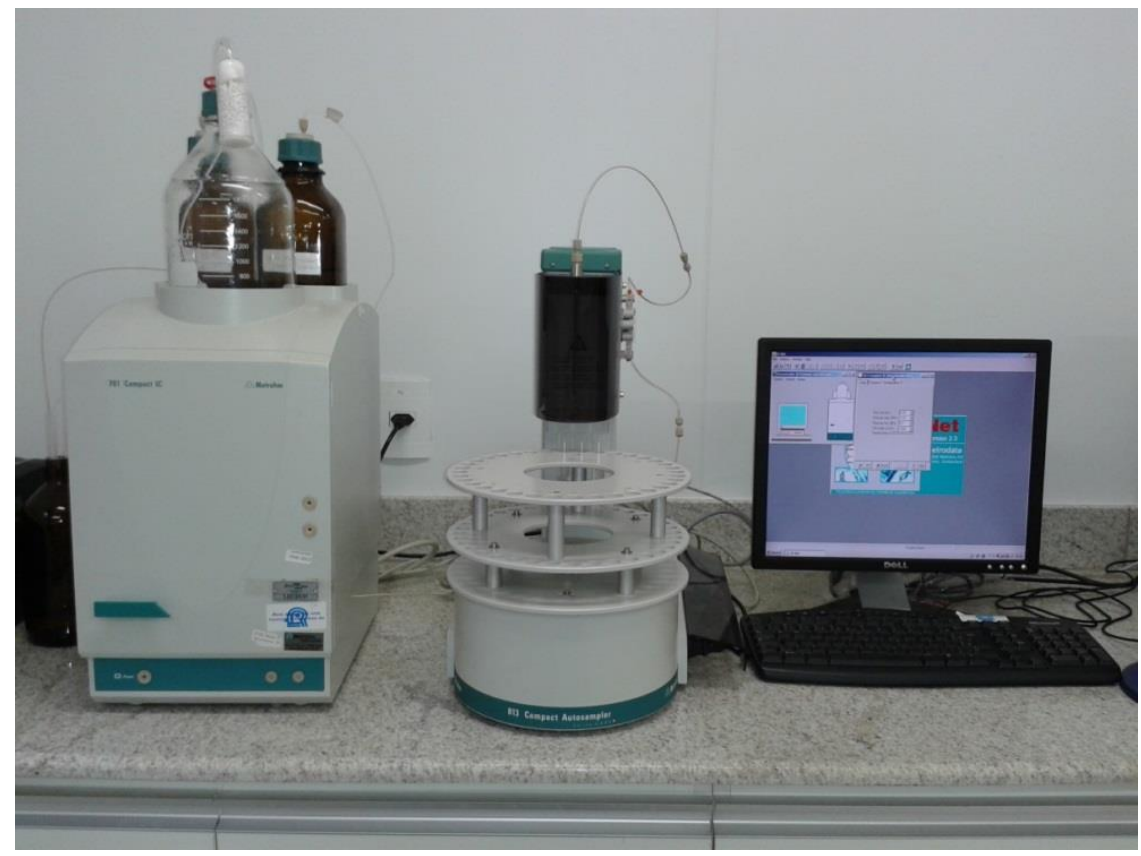

Para a análise de cátions foi utilizada uma coluna de troca iônica Metrosep C2 e como eluente uma solução tampão de 4,0 mM de Ácido Tartárico e 0,75 mM de Ácido Dipicolínico (ácido 2,6-piridinodicarboxílico). Na análise de ânions foi utilizada uma coluna Metrosep Asup5 e solução tampão de 3,2 mM de bicarbonato de sódio e 1,0 mM de hidrogenocarbonato de sódio 
como eluente e ainda uma solução supressora de $100 \mathrm{mM}$ de ácido sulfúrico utilizada no ramal da supressão iônica, paralelamente à água bidestilada, com um gradiente pré-fixado em 50\% (água/ácido).

Figura 4: Cromatograma da calibração de cátions mostrando a curva da condutividade (em $\mu \mathrm{S} / \mathrm{cm}$ ) de cada elemento em função do tempo (em minutos). Unidades mostradas em mg/L.

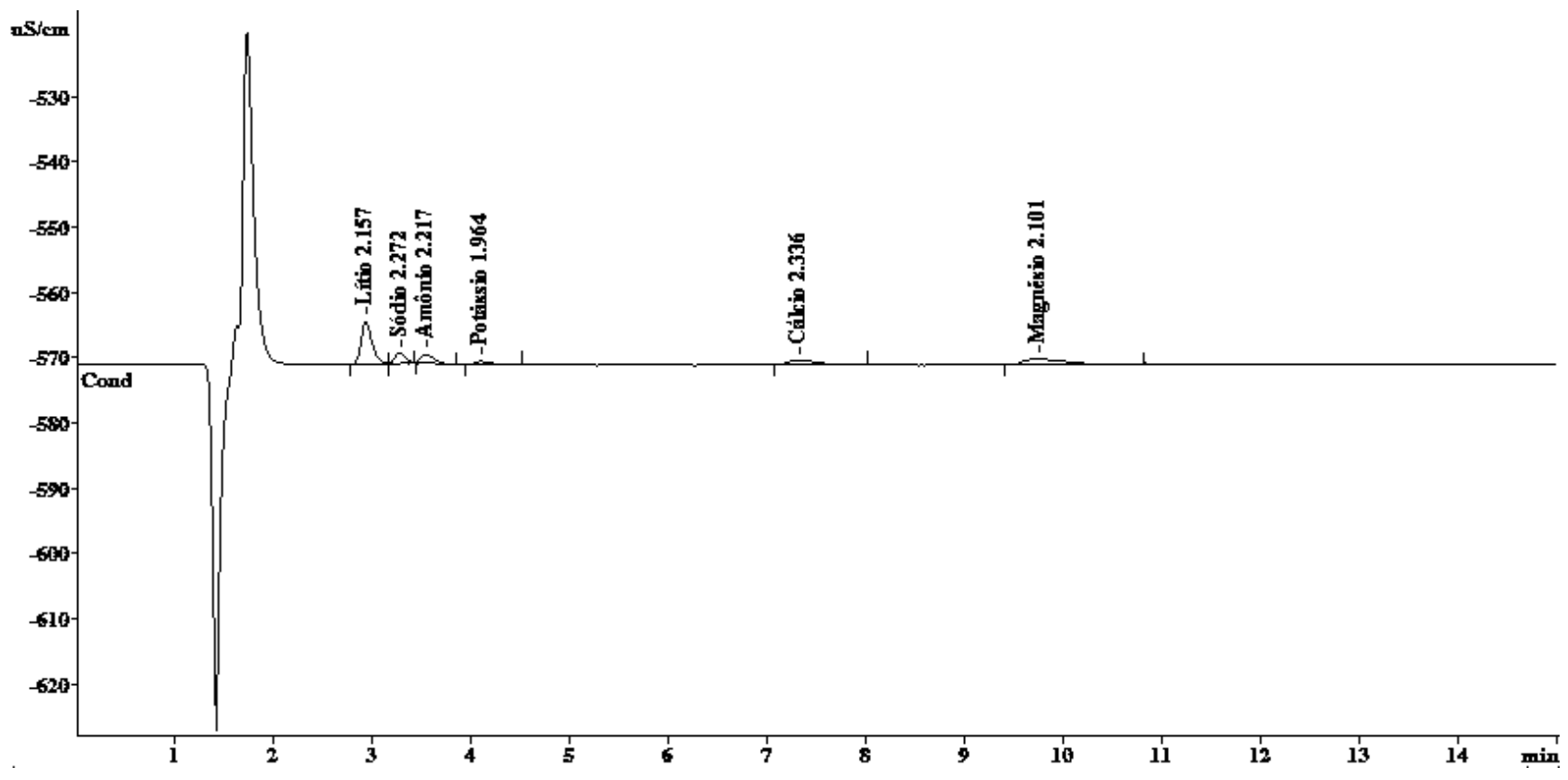

Figura 5: Cromatograma da calibração de ânions mostrando a curva da condutividade (em $\mu \mathrm{S} / \mathrm{cm}$ ) de cada elemento em função do tempo (em minutos). Unidades mostradas em mg/L.

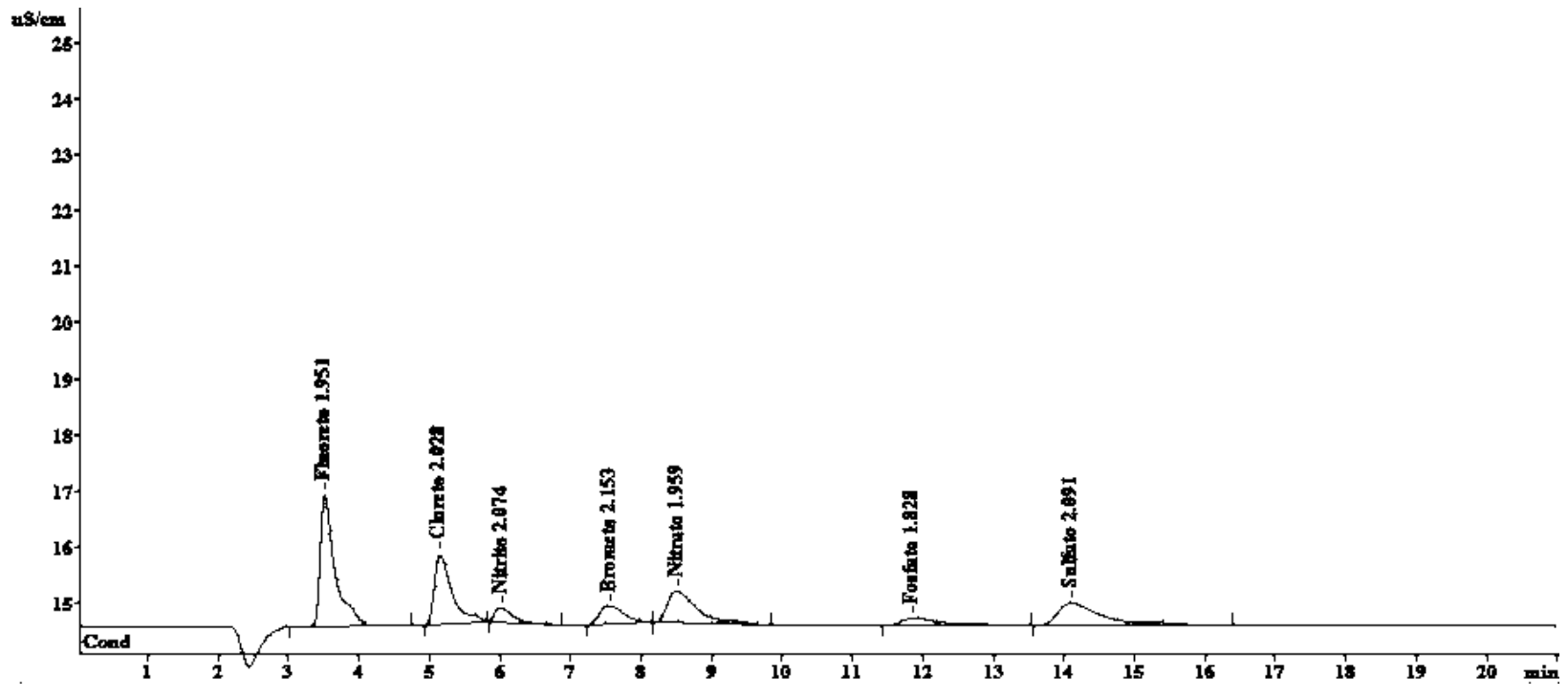


De maneira a garantir o controle da qualidade das análises, padrões de calibração foram preparados no dia de cada análise, usando reagentes da marca Merck® (Figuras 4 e 5). Brancos, duplicatas e amostras enriquecidas artificialmente também foram utilizadas para este fim. Coeficientes de calibração foram mantidos em pelo menos três noves antes de prosseguir com as amostras $(\mathrm{r}=0,999)$.

Para certificar se houve alguma diferença significativa nas concentrações dos nutrientes analisados antes e depois de cada ensaio, as maiores concentrações de teste foram selecionadas para serem analisadas antes e depois do tempo exposição e foi submetida a estatística dos resultados obtidos da cromatografia iônica para essas amostras.

Foi realizado o teste de normalidade de Shapiro-Wilk com nível de significância de 5\% (função "shapiro.test") para definir o teste estatístico a ser empregado. Para os dados com distribuição normal, foi realizado o teste T pareado (função “t.test"), para as que não obtiveram distribuição normal, realizou-se o teste de Wilcoxon-Mann-Whitney (função "wilcox.test").

Esses tratamentos estatísticos foram realizados com o software R versão 2.15.3 (R CORE TEAM, 2013) e tiveram a intenção de analisar apenas se houve mudança significativa nas concentrações dos nutrientes analisados ao longo do período de exposição. 


\section{RESULTADOS}

Todos os testes as análises da cromatografia iônica demonstraram, como já esperado, presença de Cloreto $\left(\mathrm{Cl}^{-}\right)$e Potássio $\left(\mathrm{K}^{+}\right)$nas amostras destinadas ao grupo controle e na água de diluição nas concentrações de $0,649 \mathrm{mg} / \mathrm{L}$ para $\mathrm{Cl}^{-}$e $2,079 \mathrm{mg} / \mathrm{L}$ para $\mathrm{K}^{+}$, uma vez que é prevista a utilização de $\mathrm{KCl}$ na confecção da água de diluição.

\subsection{Ensaios com cloreto de potássio (KCl)}

O teste de normalidade de Shapiro-Wilk não mostrou distribuição normal para a variável magnésio no reagente, nem para o cloreto no comercial, contudo nem o teste $\mathrm{T}$ nem o teste de Wilcoxon-Mann-Whitney (para as variáveis que não apresentaram distribuição normal) mostraram diferença significativa entre a diluição inicial para a final (Tabela 4).

Tabela 4: Normalidade e estatística dos íons encontrados nas análises químicas do KCl reagente e do comercial.

\begin{tabular}{ccccccccc}
\hline & Sódio & Amônio & Potássio & Cálcio & Magnésio & Cloreto & Nitrato & Fosfato \\
\hline \multicolumn{7}{c}{} & \multicolumn{7}{c}{ Reagente } \\
\hline $\begin{array}{c}\text { Shapiro- } \\
\text { Wilk }\end{array}$ & 0,120 & - & 0,079 & 0,783 & $0,0002 *$ & 0,456 & - & - \\
T/W & 1,207 & - & 0,378 & 0,051 & 3 & 0,249 & - & - \\
$\quad \boldsymbol{p}$ & 0,285 & - & 0,720 & 0,961 & 0,7 & 0,812 & - & - \\
df & 4,703 & - & 5,278 & 5,037 & - & 5,959 & - & - \\
\hline \multicolumn{7}{c}{ Comercial } \\
\hline $\begin{array}{l}\text { Shapiro- } \\
\text { Wilk }\end{array}$ & 0,672 & - & 0,291 & 0,330 & 0,840 & $0,013 *$ & - & - \\
T/W & 0,051 & - & 0,116 & 1,393 & 0,023 & 017 & - & - \\
$\quad \boldsymbol{P}$ & 0,960 & - & 0,910 & 0,210 & 0,982 & 0,937 & - & - \\
Df & 9,968 & - & 9,768 & 6,373 & 9,932 & - & - & - \\
\hline
\end{tabular}

$\mathrm{T}=$ Teste $\mathrm{t} / \mathrm{W}=$ Teste de Wilcoxon-Mann-Whitney (usado para as variáveis que não tiveram distribuição normal) / df $=$ Grau de liberdade $/ *=$ Variável sem distribuição não normal.

Como o teste estatístico não apresentou nenhuma diferença significativa entre as análises químicas realizadas antes e depois dos ensaios, são mostrados somente na Tabela 5 os resultados das análises antes dos ensaios, com o intuito de melhor apresentação dos resultados.

Quanto à toxicidade, nos ensaios envolvendo a espécie B. glabrata com o cloreto de potássio reagente (pureza de 99\%), foi observada morte em todas as concentrações, menos na de $200 \mathrm{mg} / \mathrm{L}$ após 96 horas de exposição, sendo que na maior concentração todos os indivíduos 
morreram dentro de um espaço de 24 horas, nas de 500 e de $1000 \mathrm{mg} / \mathrm{L}$ as mortes aconteceram em até 72 horas de exposição, não sendo reportada nenhuma morte depois.

Tabela 5: Análise das diluições de cloreto de potássio (unidades em mg/L).

\begin{tabular}{|c|c|c|c|c|c|c|c|c|}
\hline $\begin{array}{c}\text { Concentração } \\
(\mathrm{mg} / \mathrm{L})\end{array}$ & Sódio & Amônio & Potássio & Cálcio & Magnésio & Cloreto & Nitrato & Fosfato \\
\hline \multicolumn{9}{|c|}{ Reagente } \\
\hline 200 & 13,190 & 0,000 & 113,404 & 7,771 & 5,953 & 132,215 & 0,000 & 0,000 \\
\hline 500 & 15,975 & 0,000 & 280,618 & 26,556 & 12,301 & 247,497 & 0,000 & 0,000 \\
\hline 700 & 18,551 & 0,000 & 436,371 & 44,772 & 16,729 & 341,327 & 0,000 & 0,000 \\
\hline 900 & 12,659 & 0,000 & 524,042 & 68,866 & 20,923 & 390,964 & 0,000 & 0,000 \\
\hline 1000 & 14,257 & 0,000 & 541,509 & 85,433 & 22,916 & 511,656 & 0,000 & 0,000 \\
\hline 1200 & 15,046 & 0,000 & 699,090 & 56,504 & 20,309 & 549,267 & 0,000 & 0,000 \\
\hline 1500 & 17,083 & 0,000 & 920,948 & 91,600 & 10,852 & 806,979 & 0,000 & 0,000 \\
\hline 1800 & 15,113 & 0,000 & 1038,781 & 84,163 & 21,668 & 1043,386 & 0,000 & 0,000 \\
\hline $\begin{array}{c}\text { Concentração } \\
(\mathrm{mg} / \mathrm{L})\end{array}$ & Sódio & Amônio & Potássio & Cálcio & Magnésio & Cloreto & Nitrato & Fosfato \\
\hline \multicolumn{9}{|c|}{ Comercial } \\
\hline 200 & 18,867 & 0,000 & 101,197 & 7,771 & 5,953 & 128,476 & 0,000 & 0,000 \\
\hline 500 & 25,878 & 0,000 & 262,491 & 35,471 & 14,41 & 255,333 & 0,000 & 0,000 \\
\hline 700 & 38,271 & 0,000 & 435,041 & 46,734 & 17,426 & 336,497 & 0,000 & 0,000 \\
\hline 1000 & 36,063 & 0,000 & 523,457 & 95,311 & 27,846 & 463,743 & 0,000 & 0,000 \\
\hline 1100 & 38,606 & 0,000 & 597,048 & 66,284 & 21,572 & 509,181 & 0,000 & 0,000 \\
\hline 1500 & 50,530 & 0,000 & 898,853 & 67,129 & 19,479 & 693,791 & 0,000 & 0,000 \\
\hline 2000 & 59,654 & 0,000 & 1020,555 & 61,715 & 16,587 & 854,058 & 0,000 & 0,000 \\
\hline $\begin{array}{l}\text { Água de } \\
\text { Diluiçãão }\end{array}$ & 11,697 & 0,000 & 2,079 & 6,249 & 4,722 & 0,649 & 0,000 & 0,000 \\
\hline
\end{tabular}

Para o teste com a variedade comercial do cloreto de potássio (pureza de $60 \%$ ), observouse mortalidade a partir da concentração de $1000 \mathrm{mg} / \mathrm{L}$ com 72 horas de exposição, sendo que na maior concentração todos os indivíduos morreram dentro de 24 horas. Neste ensaio nenhuma morte foi observada nas concentrações de 200 e de 500 mg/L e no grupo controle após o período de 96 horas.

Para o cálculo da $\mathrm{CL}_{50}$, foram somados os valores de cloreto e potássio presentes nas análises e considerados estes as concentrações reais de teste. Com isso, a estatística mostrou, com intervalo de $95 \%$ de confiança mostrado entre parênteses, valor de concentração letal (CL50) igual a $841,20 \mathrm{mg} / \mathrm{L}(542,72$ - 1303,86 mg/L) para o teste de 48 horas e 522,74 mg/L (369,61 - 826,60 $\mathrm{mg} / \mathrm{L}$ ) no teste de 96 horas para o $\mathrm{KCl}$ reagente. O comercial, por sua vez, apresentou $\mathrm{CL}_{50}$ igual 
a 1627,97 mg/L (1455,49 - 1820,90 mg/L) para o teste de 48 horas e 1451,87 mg/L (1149,63 $1833,58 \mathrm{mg} / \mathrm{L}$ ) no de 96 horas.

A partir dos dados da cromatografia iônica, também foi possível estabelecer a CL $_{50}$ de cada elemento individualmente presente no $\mathrm{KCl}$ para o caramujo, sendo estes valores mostrados na Tabela 6. Nesta, é possível ver maior toxicidade do reagente do que a variedade comercial para a espécie $B$. glabrata, mas não foi possível encontrar diferença na toxicidade do $\mathrm{K}^{+}$para o $\mathrm{Cl}^{-}$em ambas as variedades do composto.

Tabela 6: Dados de concentração letal $\left(\mathrm{CL}_{50}\right)$ encontrados no teste com o $\mathrm{KCl}$ para cada substância no teste com $B$. glabrata. Valores entre parênteses mostram o intervalo de confiança.

\begin{tabular}{ccc}
\hline & $\begin{array}{c}\mathbf{C L}_{\mathbf{5 0}} \mathbf{4 8 h} \\
(\mathbf{m g} / \mathbf{L})\end{array}$ & $\begin{array}{c}\mathbf{C L}_{\mathbf{5 0}} \mathbf{9 6 h} \\
(\mathbf{m g} / \mathbf{L})\end{array}$ \\
\hline & Reagente & \\
\hline Cloreto de potássio $(\mathbf{K C l})$ & $841,20(542,72-1303,86)$ & $522,74(369,61-826,60)$ \\
Potássio $(\mathbf{K})$ & $422,27(270,14-660,07)$ & $277,98(183,58-420,92)$ \\
Cloro (Cl) & $418,02(271,18-644,37)$ & $273,81(184,90-405,47)$ \\
\hline & Comercial \\
\hline Cloreto de potássio $(\mathbf{K C l})$ & $1627,97(1455,49-1820,90)$ & $1451,87(1149,63-1833,58)$ \\
Potássio $(\mathbf{K})$ & $891,98(801,01-993,29)$ & $785,20(610,17-1010,43)$ \\
Cloro $(\mathbf{C l})$ & $733,22(652,35-824,11)$ & $664,08(537,09-821,10)$ \\
\hline
\end{tabular}

Para o D. rerio, o ensaio com cloreto de potássio mostrou mortalidade em todas as concentrações, salvo na de $700 \mathrm{mg} / \mathrm{L}$ para o $\mathrm{KCl}$ reagente, contudo no comercial houve mortalidade na mesma concentração em 96 horas de exposição.

A $\mathrm{CL}_{50}$ encontrada para o $\mathrm{KCl}$ reagente foi igual a 1468,64 mg/L (887,58 - 2430,29 $\mathrm{mg} / \mathrm{L})$ no teste de 48 horas e 929,43 mg/L (759,51 - 1137,37 mg/L) no de 96 horas. Para a variedade comercial, o teste de 48 horas mostrou $\mathrm{CL}_{50}$ igual a 1067,96 mg/L (911,16 - 1251,74 mg/L) e 923,83 mg/L (793,95 - 1075,43 mg/L) no de 96 horas (Tabela 7). Para este teste, diferente do realizado para o $B$. glabrata, a estatística não mostrou diferença na toxicidade da variedade comercial em relação ao reagente.

Quando comparado os dados de toxicidade encontrados para o caramujo e para o peixe, nota-se maior sensibilidade do peixe ao $\mathrm{KCl}$ comercial do que o caramujo (Figura 6), sendo observada a mesma sensibilidade aos compostos isolados presentes no fertilizante comercial. Para o $\mathrm{KCl}$ reagente não é notada diferença na sobrevivência do caramujo para o peixe devido ao limite do intervalo de confiança. 
Tabela 7: Dados de concentração letal $\left(\mathrm{CL}_{50}\right)$ encontrados no teste com o $\mathrm{KCl}$ para cada substância no teste com $D$. rerio. Valores entre parênteses mostram o intervalo de confiança.

\begin{tabular}{ccc}
\hline & $\begin{array}{c}\mathbf{C L}_{\mathbf{5 0}} \mathbf{4 8 h} \\
(\mathbf{m g} / \mathbf{L})\end{array}$ & $\begin{array}{c}\mathbf{C L}_{\mathbf{5 0}} \mathbf{9 6 h} \\
(\mathbf{m g} / \mathbf{L})\end{array}$ \\
\hline & Reagente \\
\hline Cloreto de potássio (KCl) & $1468,64(887,58-2430,29)$ & $929,43(759,51-1137,37)$ \\
Potássio (K) & $802,39(523,53-1229,78)$ & $527,91(432,64-644,16)$ \\
Cloro (Cl) & $665,77(366,85-1208,26)$ & $401,46(326,75-493,25)$ \\
\hline \multicolumn{3}{c}{ Comercial } \\
\hline Cloreto de potássio (KCl) & $1067,96(911,16-1251,74)$ & $923,85(793,95-1075,43)$ \\
Potássio (K) & $589,25(502,64-690,79)$ & $509,65(445,97-582,42)$ \\
Cloro (Cl) & $478,38(408,25-560,56)$ & $413,93(347,60-492,92)$ \\
\hline
\end{tabular}

Figura 6: Comparação entre as Concentrações Letais ( $\mathrm{CLs}{ }_{50}$ ) encontradas nos testes com $\mathrm{KCl}$ para o caramujo $B$. glabrata e o peixe $D$. rerio em 96 horas de exposição e os respectivos intervalos de confiança (unidades em mg/L).

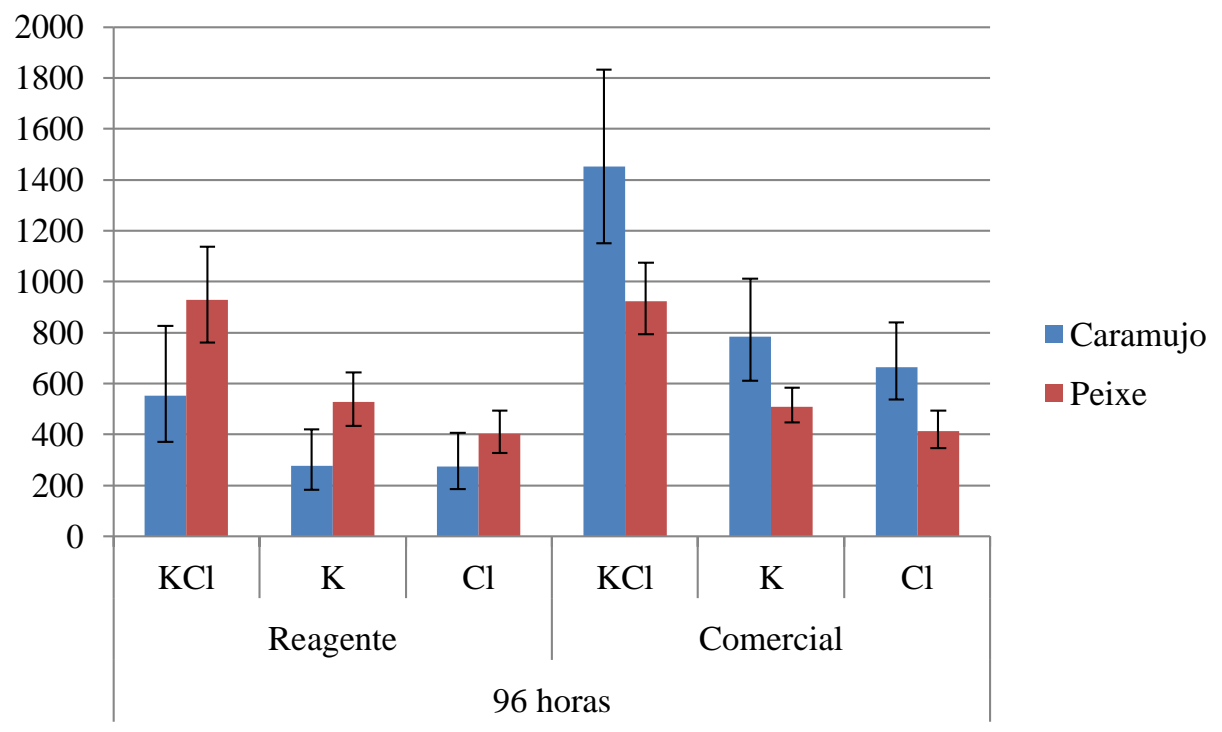

\subsection{Ensaios com nitrato de potássio $\left(\mathrm{KNO}_{3}\right)$}

O teste de normalidade de Shapiro-Wilk não mostrou distribuição normal para o potássio nem para o nitrato presentes no reagente e para o cálcio no comercial, mas o teste estatístico não mostrou diferença significativa entre a diluição inicial para a final (Tabela 8).

Como não houve nenhuma diferença significativa entre as análises químicas realizadas antes e depois dos ensaios, novamente foram mostrados somente na Tabela 9 os resultados das análises antes dos ensaios. 
Tabela 8: Normalidade e estatística dos íons encontrados nas análises químicas do $\mathrm{KNO}_{3}$ reagente e do comercial.

\begin{tabular}{|c|c|c|c|c|c|c|c|c|}
\hline & Sódio & Amônio & Potássio & Cálcio & Magnésio & Cloreto & Nitrato & Fosfato \\
\hline & \multicolumn{8}{|c|}{ Reagente } \\
\hline $\begin{array}{l}\text { Shapiro- } \\
\text { Wilk }\end{array}$ & 0,413 & - & $6,06 \times 10^{-5 *}$ & 0,320 & 0,528 & 0,838 & $0,004 *$ & - \\
\hline $\mathbf{T} / \mathbf{W}$ & 0,463 & - & 18 & 0,169 & 0,308 & 0,340 & 19 & - \\
\hline$p$ & 0,659 & - & 1 & 0,869 & 0,764 & 0,759 & 0,937 & - \\
\hline \multirow[t]{2}{*}{ df } & 6,385 & - & - & 9,793 & 9,925 & 2,746 & - & - \\
\hline & \multicolumn{8}{|c|}{ Comercial } \\
\hline $\begin{array}{l}\text { Shapiro- } \\
\text { Wilk }\end{array}$ & 0,623 & - & 0,533 & $0,021^{*}$ & 0,162 & 0,128 & 0,371 & - \\
\hline $\mathbf{T} / \mathbf{W}$ & 0,525 & - & 0,191 & 28 & 0,511 & 0,983 & 0,073 & - \\
\hline$p$ & 0,611 & - & 0,852 & 0,710 & 0,619 & 0,425 & 0,943 & - \\
\hline df & 9,907 & - & 11,993 & - & 11,11 & 2,1 & 11,968 & - \\
\hline
\end{tabular}

Tabela 9: Análise das diluições de nitrato de potássio (unidades em mg/L).

\begin{tabular}{ccccccccc}
\hline $\begin{array}{c}\text { Concentração } \\
\text { (mg/L) }\end{array}$ & Sódio & Amônio & Potássio & Cálcio & Magnésio & Cloreto & Nitrato & Fosfato \\
\hline & & \multicolumn{7}{c}{ Reagente } \\
$\mathbf{2 5 0}$ & 17,485 & 0,000 & 105,629 & 15,032 & 8,815 & 2,553 & 100,671 & 0,000 \\
$\mathbf{5 0 0}$ & 18,115 & 0,000 & 207,566 & 61,281 & 21,825 & 3,085 & 212,532 & 0,000 \\
$\mathbf{7 5 0}$ & 23,998 & 0,000 & 292,475 & 47,639 & 11,067 & 10,920 & 314,847 & 0,000 \\
$\mathbf{1 0 0 0}$ & 19,708 & 0,000 & 408,597 & 64,201 & 16,232 & 0,000 & 432,030 & 0,000 \\
$\mathbf{1 5 0 0}$ & 32,721 & 0,000 & 662,639 & 89,055 & 20,696 & 0,000 & 765,017 & 0,000 \\
$\mathbf{1 7 5 0}$ & 17,291 & 0,000 & 769,530 & 79,758 & 27,925 & 0,000 & 867,430 & 0,000 \\
$\mathbf{2 0 0 0}$ & 27,093 & 0,000 & 914,135 & 67,079 & 20,785 & 0,000 & 903,218 & 0,000 \\
$\mathbf{3 0 0 0}$ & 50,884 & 0,000 & 1343,164 & 61,833 & 24,094 & 0,000 & 1314,378 & 0,000 \\
Concentração & Sódio & Amônio & Potássio & Cálcio & Magnésio & Cloreto & Nitrato & Fosfato \\
(mg/L) & & & & & & & & \\
& & & & & & & & \\
$\mathbf{1 0 0}$ & 21,289 & 0,000 & 38,875 & 25,186 & 14,854 & 1,442 & 41,208 & 0,000 \\
$\mathbf{2 5 0}$ & 23,473 & 0,000 & 99,700 & 13,812 & 6,840 & 1,758 & 105,049 & 0,000 \\
$\mathbf{5 0 0}$ & 22,338 & 0,000 & 182,397 & 35,395 & 12,568 & 3,150 & 302,817 & 0,000 \\
$\mathbf{7 5 0}$ & 23,116 & 0,000 & 283,192 & 58,043 & 20,125 & 10,566 & 290,222 & 0,000 \\
$\mathbf{1 0 0 0}$ & 22,316 & 0,000 & 387,933 & 89,597 & 22,082 & 0,000 & 383,668 & 0,000 \\
$\mathbf{1 5 0 0}$ & 24,983 & 0,000 & 618,153 & 79,714 & 26,824 & 0,000 & 637,831 & 0,000 \\
$\mathbf{2 0 0 0}$ & 26,429 & 0,000 & 862,156 & 70,811 & 30,217 & 0,000 & 857,736 & 0,000 \\
$\mathbf{2 5 0 0}$ & 20,764 & 0,000 & 935,442 & 132,5740 & 36,830 & 0,000 & 859,753 & 0,000 \\
$\mathbf{3 0 0 0}$ & 23,555 & 0,000 & 1055,488 & 139,581 & 43,605 & 0,000 & 1135,409 & 0,000 \\
Água de & 11,697 & 0,000 & 2,079 & 6,249 & 4,722 & 0,649 & 0,000 & 0,000 \\
Diluição & & & & & & & &
\end{tabular}


O ensaio com nitrato de potássio para o B. glabrata mostrou mortalidade a partir da concentração de $750 \mathrm{mg} / \mathrm{L}$ nas primeiras 24 horas de ensaio para o reagente e $250 \mathrm{mg} / \mathrm{L}$ para a variedade comercial dentro das primeiras 72 horas de teste.

Mais uma vez as análises cromatográficas serviram tanto na definição da concentração letal, quanto na toxicidade dos compostos separadamente. Logo, a estatística mostrou toxicidade igual a 701,21 mg/L (615,08 - 799,41 mg/L) tanto nos testes de 48, quanto no de 96 horas para o reagente. A variedade comercial, por sua vez, apresentou valores de toxicidade igual a 300,91 $\mathrm{mg} / \mathrm{L}(246,43$ - 367,42 mg/L) para o teste de 48 horas e 220,61 mg/L (148,71 - 327,25 mg/L) no teste de 96 horas (Tabela 10).

Os dados da Tabela 10 mostraram maior toxicidade na variedade comercial do $\mathrm{KNO}_{3}$, do $\mathrm{K}^{+}$e do $\mathrm{NO}_{3}{ }^{-}$isoladamente para o B. glabrata, contudo quando comparada a toxicidade dos compostos entre si, não foi possível encontrar diferença significativa na $\mathrm{CL}_{50}$ do $\mathrm{K}^{+}$com a do $\mathrm{NO}_{3}{ }^{-}$em ambos compostos.

Tabela 10: Dados de concentração letal $\left(\mathrm{CL}_{50}\right)$ encontrados no teste com o $\mathrm{KNO}_{3}$ para cada substância no teste com B. glabrata. Valores entre parênteses mostram o intervalo de confiança.

\begin{tabular}{ccc}
\hline & $\begin{array}{c}\mathbf{C L}_{\mathbf{5 0}} \mathbf{4 8 h} \\
(\mathbf{m g} / \mathbf{L})\end{array}$ & $\begin{array}{c}\mathbf{C L}_{\mathbf{5 0}} \mathbf{9 6 h} \\
(\mathbf{m g} / \mathbf{L})\end{array}$ \\
\hline & Reagente \\
\hline Nitrato de potássio $\left(\mathbf{K N O}_{\mathbf{3}}\right)$ & $701,21(615,08-799,41)$ & $701,21(615,08-799,41)$ \\
Potássio $(\mathbf{K})$ & $347,07(303,49-396,89)$ & $347,07(303,49-396,89)$ \\
Nitrato $\left(\mathbf{N O}_{\mathbf{3}}\right)$ & $354,09(311,55-402,44)$ & $354,09(311,55-402,44)$ \\
\hline & Comercial \\
\hline Nitrato de potássio $\left(\mathbf{K N O}_{\mathbf{3}}\right)$ & $300,91(246,43-367,42)$ & $220,61(148,71-327,25)$ \\
Potássio $(\mathbf{K})$ & $139,90(111,63-175,33)$ & $102,73(68,40-154,29)$ \\
Nitrato $\left(\mathbf{N O}_{\mathbf{3}}\right)$ & $153,38(125,98-186,87)$ & $117,40(79,88-172,56)$ \\
\hline
\end{tabular}

O peixe D. rerio apresentou mortalidade somente a partir da concentração de $1750 \mathrm{mg} / \mathrm{L}$ com 48 horas de ensaio para o reagente e $2500 \mathrm{mg} / \mathrm{L}$ para a variedade comercial, sendo estas dentro das primeiras 24 horas de teste. Com isso a $\mathrm{CL}_{50}$ encontrada foi igual a 1613,48 mg/L $(1553,79$ - 1675,47 mg/L) tanto nos testes de 48, quanto no de 96 horas para o reagente e 1983,20 mg/L (1823,44 - 2156,96 mg/L) também sem diferença nos testes de 48 e 96 horas para a variedade comercial (Tabela 11). 
Os dados da Tabela 11 mostraram maior toxicidade tanto para o $\mathrm{KNO}_{3}$, quanto para o $\mathrm{K}^{+}$ do reagente para o comercial, contudo quando analisado o nitrato isoladamente, percebeu-se não existe diferença significativa na toxicidade para o peixe do reagente para o fertilizante.

A análise da toxicidade dos compostos entre si novamente não mostrou diferença significativa entre $\mathrm{K}^{+}$e o $\mathrm{NO}_{3}{ }^{-}$em ambos os compostos.

Tabela 11: Dados de concentração letal $\left(\mathrm{CL}_{50}\right)$ encontrados no teste com o $\mathrm{KNO}_{3}$ para cada substância no teste com D. rerio. Valores entre parênteses mostram o intervalo de confiança.

\begin{tabular}{ccc}
\hline & $\begin{array}{c}\mathbf{C L}_{\mathbf{5 0}} \mathbf{4 8 h} \\
(\mathbf{m g} / \mathbf{L})\end{array}$ & $\begin{array}{c}\mathbf{C L}_{\mathbf{5 0}} \mathbf{9 6 h} \\
(\mathbf{m g} / \mathbf{L})\end{array}$ \\
\hline & Reagente & \\
\hline Nitrato de potássio $\left(\mathbf{K N O}_{\mathbf{3}}\right)$ & $1613,48(1553,79-1675,47)$ & $1613,48(1553,79-1675,47)$ \\
Potássio (K) & $786,45(732,92-843,89)$ & $786,45(732,92-843,89)$ \\
Nitrato $\left(\mathbf{N O}_{\mathbf{3}}\right)$ & $856,23(825,64-887,95)$ & $856,23(825,64-887,95)$ \\
\hline & Comercial \\
\hline Nitrato de potássio $\left(\mathbf{K N O}_{\mathbf{3}}\right)$ & $1983,20(1823,44-2156,96)$ & $1983,20(1823,44-2156,96)$ \\
Potássio $(\mathbf{K})$ & $993,65(944,33-1045,55)$ & $993,65(944,33-1045,55)$ \\
Nitrato $\left(\mathbf{N O}_{\mathbf{3}}\right)$ & $988,01(878,70-1110,93)$ & $988,01(878,70-1110,93)$ \\
\hline
\end{tabular}

Os dados de toxicidade obtidos para o $\mathrm{KNO}_{3}$ mostraram maior sensibilidade do $B$. glabrata à substância se comparado ao D. rerio (Figura 7), tanto para o reagente, quanto para a variedade comercial, contudo o caramujo ainda apresentou maior sensibilidade ao fertilizante, enquanto ao peixe ao reagente.

Figura 7: Comparação entre as Concentrações Letais (CLs ${ }_{50}$ ) encontradas nos testes com $\mathrm{KNO}_{3}$ para o caramujo $B$. glabrata e o peixe $D$. rerio em 96 horas de exposição e os respectivos intervalos de confiança (unidades em mg/L).

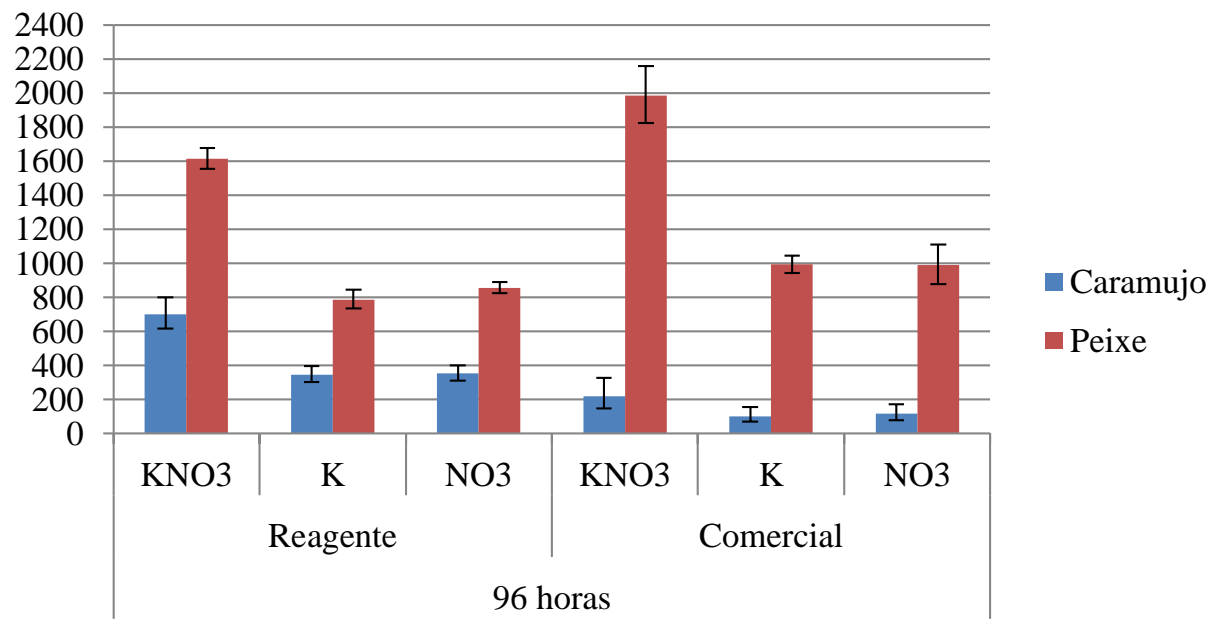




\subsection{Ensaios com ureia $\left(\mathrm{CO}\left(\mathrm{NH}_{2}\right)_{2}\right)$}

O teste de normalidade de Shapiro-Wilk mostrou distribuição normal para todas as variáveis, mas o teste $\mathrm{T}$ não apresentou diferença significativa entre as análises químicas realizadas antes e depois dos ensaios (Tabela 12). Foram mostrados somente na Tabela 13 os resultados das análises antes dos ensaios, com o intuito de melhor apresentação dos resultados.

Tabela 12: Normalidade e estatística dos íons encontrados nas análises químicas da ureia reagente e do comercial.

\begin{tabular}{|c|c|c|c|c|c|c|c|c|}
\hline & Sódio & Amônio & Potássio & Cálcio & Magnésio & Cloreto & Nitrato & Fosfato \\
\hline & \multicolumn{8}{|c|}{ Reagente } \\
\hline $\begin{array}{l}\text { Shapiro- } \\
\text { Wilk }\end{array}$ & 0,773 & 0,882 & 0,765 & 0,597 & 0,0824 & 0,597 & - & - \\
\hline $\mathbf{T}$ & 0,134 & 0,214 & 0,611 & 0,270 & 0,163 & 0,807 & - & - \\
\hline$p$ & 0,898 & 0,838 & 0,580 & 0,797 & 0,876 & 0,469 & - & - \\
\hline \multirow[t]{2}{*}{ df } & 5,558 & 5,426 & 3,36 & 0,270 & 5,839 & 3,635 & - & - \\
\hline & \multicolumn{8}{|c|}{ Comercial } \\
\hline $\begin{array}{l}\text { Shapiro- } \\
\text { Wilk }\end{array}$ & 0,820 & 0,346 & 0,214 & 0,923 & 0,146 & 0,436 & - & - \\
\hline $\mathbf{T}$ & 0,252 & 0,644 & 3,328 & 0,131 & 0,238 & 1,317 & - & - \\
\hline$p$ & 0,814 & 0,550 & 0,052 & 0,900 & 0,820 & 0,236 & - & - \\
\hline df & 3,939 & 4,665 & 2,697 & 5,817 & 5,498 & 5,981 & - & - \\
\hline
\end{tabular}

$\mathrm{T}=$ Teste $\mathrm{t} / \mathrm{df}=$ Grau de liberdade.

As concentrações de ureia utilizadas nos experimentos apresentaram alta variação nas análises cromatográficas, uma vez que a substância possui grande dinâmica de degradação quando diluída, por isso algumas concentrações, quando analisadas, já apresentavam a substância num estágio que não foi possível ser detectado.

O ensaio com ureia mostrou mortalidade para o B. glabrata em concentrações a partir de 1000 mg/L em 72 horas de exposição para o reagente e a partir de 15000 mg/L para o comercial também nas 72 horas de ensaio. Logo, a CL50 calculada foi igual a 4363,09 mg/L (3066,60 6207,70 mg/L) no ensaio de 48 horas e 2184,19 mg/L (1213,15 - 3932,45 mg/L) com 96 horas de exposição para o reagente. No fertilizante, a toxicidade calculada foi igual a 23643,54 mg/L $(19552,24$ - 28590,94) e 13126,49 mg/L (11595,75 - 14859,31 mg/L) no ensaio de 96 horas (Tabela 14). 
Tabela 13: Análise das diluições de ureia (unidades em mg/L).

\begin{tabular}{|c|c|c|c|c|c|c|c|c|}
\hline $\begin{array}{c}\text { Concentração } \\
(\mathrm{mg} / \mathrm{L})\end{array}$ & Sódio & Amônio & Potássio & Cálcio & Magnésio & Cloreto & Nitrato & Fosfato \\
\hline \multicolumn{9}{|c|}{ Reagente } \\
\hline 1000 & 20,124 & 0,000 & 1,255 & 9,454 & 6,500 & 1,867 & 0,000 & 0,000 \\
\hline 2000 & 17,152 & 0,565 & 1,161 & 10,100 & 7,328 & 1,775 & 0,000 & 0,000 \\
\hline 5000 & 18,094 & 0,715 & 2,280 & 8,304 & 7,368 & 2,713 & 0,000 & 0,000 \\
\hline 10000 & 17,407 & 1,890 & 0,000 & 42,198 & 17,519 & 1,780 & 0,000 & 0,000 \\
\hline 15000 & 19,061 & 5,935 & 0,000 & 78,862 & 19,388 & 0,000 & 0,000 & 0,000 \\
\hline 20000 & 15,389 & 7,347 & 0,000 & 31,511 & 15,328 & 1,880 & 0,000 & 0,000 \\
\hline 25000 & 16,654 & 8,975 & 0,000 & 37,115 & 13,792 & 2,039 & 0,000 & 0,000 \\
\hline 30000 & 16,578 & 9,494 & 0,000 & 101,165 & 49,497 & 0,000 & 0,000 & 0,000 \\
\hline 40000 & 16,832 & 12,357 & 0,000 & 41,208 & 13,827 & 1,669 & 0,000 & 0,000 \\
\hline $\begin{array}{l}\text { Concentração } \\
(\mathrm{mg} / \mathrm{L})\end{array}$ & Sódio & Amônio & Potássio & Cálcio & Magnésio & Cloreto & Nitrato & Fosfato \\
\hline \multicolumn{9}{|c|}{ Comercial } \\
\hline 10000 & 14,857 & 2,300 & 5,263 & 8,320 & 6,711 & 5,742 & 0,000 & 0,000 \\
\hline 15000 & 16,409 & 4,178 & 0,000 & 36,878 & 16,689 & 0,000 & 0,000 & 0,000 \\
\hline 20000 & 16,972 & 5,683 & 8,547 & 30,191 & 14,725 & 0,000 & 0,000 & 0,000 \\
\hline 25000 & 18,430 & 6,609 & 0,000 & 86,432 & 38,072 & 0,000 & 0,000 & 0,000 \\
\hline 30000 & 16,191 & 9,731 & 5,665 & 29,894 & 14,898 & 9,469 & 0,000 & 0,000 \\
\hline 40000 & 19,980 & 20,867 & 0,000 & 88,792 & 40,728 & 0,000 & 0,000 & 0,000 \\
\hline $\begin{array}{l}\text { Água de } \\
\text { Diluição }\end{array}$ & 11,697 & 0,000 & 2,079 & 6,249 & 4,722 & 0,649 & 0,000 & 0,000 \\
\hline
\end{tabular}

Quando analisada toxicidade do amônio, vê-se valores baixos de $\mathrm{CL}_{50}$, chegando a próximo de zero para o reagente. Isso mostra grande sensibilidade da espécie ao nitrogênio em sua forma de $\mathrm{NH}_{4}^{+}$.

Os dados da Tabela 14 ainda mostram que existe diferença significativa na toxicidade da ureia reagente para o fertilizante comercial para a espécie B. glabrata, mas não é possível afirmar estatisticamente se esta toxicidade é em virtude do $\mathrm{NH}_{4}{ }^{+}$presente em ambos compostos, uma vez que no teste de 96 horas não houve diferença significativa do reagente para o comercial devido ao intervalo de confiança.

Quanto ao D. rerio, foram encontradas mortalidades a partir de $25000 \mathrm{mg} / \mathrm{L}$ para o reagente nas primeiras 48 horas de teste e $20000 \mathrm{mg} / \mathrm{L}$ para o comercial também nas primeiras 48 horas de ensaio. Contudo, ao contrário do caramujo, não foi possível encontrar diferença significativa na $\mathrm{CL}_{50}$ do reagente para o comercial, sendo os valores de toxicidade iguais a $27563,45 \mathrm{mg} / \mathrm{L}(24666,62$ - 30800,47 mg/L) no ensaio de 48 horas e 24249,53 mg/L (22188,28 - 
26502,26 mg/L) em 96 horas de exposição para o reagente e valores iguais a 23521,58 mg/L $(18644,40$ - 29674,57 mg/L) tanto no ensaio de 48, quanto no de 96 horas para o fertilizante (Tabela 15).

Tabela 14: Dados de concentração letal $\left(\mathrm{CL}_{50}\right)$ encontrados no teste com a ureia para cada substância no teste com $B$. glabrata. Valores entre parênteses mostram o intervalo de confiança.

\begin{tabular}{ccc}
\hline & $\begin{array}{c}\mathbf{C L}_{\mathbf{5 0}} \mathbf{4 8 h} \\
(\mathbf{m g} / \mathbf{L})\end{array}$ & $\begin{array}{c}\mathbf{C L}_{\mathbf{5 0}} \mathbf{9 6 h} \\
(\mathbf{m g} / \mathbf{L})\end{array}$ \\
\hline & Reagente \\
\hline Ureia $\left(\mathbf{C O}\left(\mathbf{N H}_{2}\right)_{\mathbf{2}}\right)$ & $4363,09(3066,60-6207,70)$ & $2184,19(1213,15-3932,45)$ \\
Amônio $\left(\mathbf{N H}_{\mathbf{4}}\right)$ & $0,81(0,62-1,05)$ & $0,10(0,001-17,73)$ \\
\hline \multicolumn{3}{c}{ Comercial } \\
\hline Ureia $\left(\mathbf{C O}\left(\mathbf{N H}_{2}\right)_{\mathbf{2}}\right)$ & $23643,54(19552,24-$ & $13126,49(11595,75-$ \\
Amônio $\left(\mathbf{N H}_{4}\right)$ & $28590,94)$ & $14859,31)$ \\
& $8,51(5,38-13,45)$ & $3,39(2,89-3,99)$ \\
\hline
\end{tabular}

Tabela 15: Dados de concentração letal $\left(\mathrm{CL}_{50}\right)$ encontrados no teste com a ureia para cada substância no teste com $D$. rerio. Valores entre parênteses mostram o intervalo de confiança.

\begin{tabular}{ccc}
\hline & $\begin{array}{c}\mathbf{C L} \\
(\mathbf{m g} / \mathbf{L})\end{array}$ & $\begin{array}{c}\mathbf{C L}_{\mathbf{5 0}} \mathbf{9 6 h} \\
(\mathbf{m g} / \mathbf{L})\end{array}$ \\
\hline & Reagente & \\
\hline Ureia $\left(\mathbf{C O}\left(\mathbf{N H}_{2}\right)_{2}\right)$ & $27563,45(24666,62-30800,47)$ & $24249,53(22188,28-26502,26)$ \\
Amônio $\left(\mathbf{N H}_{4}\right)$ & $9,05(8,36-9,81)$ & $8,55(8,08-9,04)$ \\
\hline & Comercial & \\
\hline Ureia $\left(\mathbf{C O}\left(\mathbf{N H}_{2}\right)_{2}\right)$ & $23521,58(18644,40-29674,57)$ & $23521,58(18644,40-29674,57)$ \\
Amônio $\left(\mathbf{N H}_{4}\right)$ & $6,28(4,65-8,48)$ & $6,28(4,65-8,48)$ \\
\hline
\end{tabular}

Quando analisado o composto isoladamente em ambos os compostos, vê-se nítida diferença na toxicidade do $\mathrm{NH}_{4}{ }^{+}$para a ureia, sendo aquele muito mais tóxico que este. Contudo, ainda baseado nos resultados obtidos na análise do $\mathrm{NH}_{4}{ }^{+}$, não foi possível observar diferença na $\mathrm{CL}_{50}$ do reagente para o comercial.

Os dados da toxicidade obtidos para a ureia mostraram sensibilidade para ambos os organismos somente em quantidades elevadas da substância, sendo que para o caramujo já foram observadas mortalidade em concentrações a partir de $1000 \mathrm{mg} / \mathrm{L}$ e o peixe em concentrações a partir de $25000 \mathrm{mg} / \mathrm{L}$ para o reagente, mostrando maior tolerância do D. rerio a ureia (Figura 8).

Quando comparado os resultados obtidos nos ensaios com a ureia comercial, não foi possível detectar qual espécie mais sensível ao fertilizante devido aos limites do intervalo de confiança com 48 horas de exposição, contudo quando visto somente os resultados obtidos em 96 
horas de exposição, o caramujo torna-se mais sensível que o peixe a essa substância, mostrando que para este caso o tempo de exposição pode alterar a mortalidade vista.

Figura 8: Comparação entre as Concentrações Letais (CLs ${ }_{50}$ ) encontradas nos testes com ureia para o caramujo $B$. glabrata e o peixe D. rerio em 96 horas de exposição e os respectivos intervalos de confiança (unidades em mg/L).

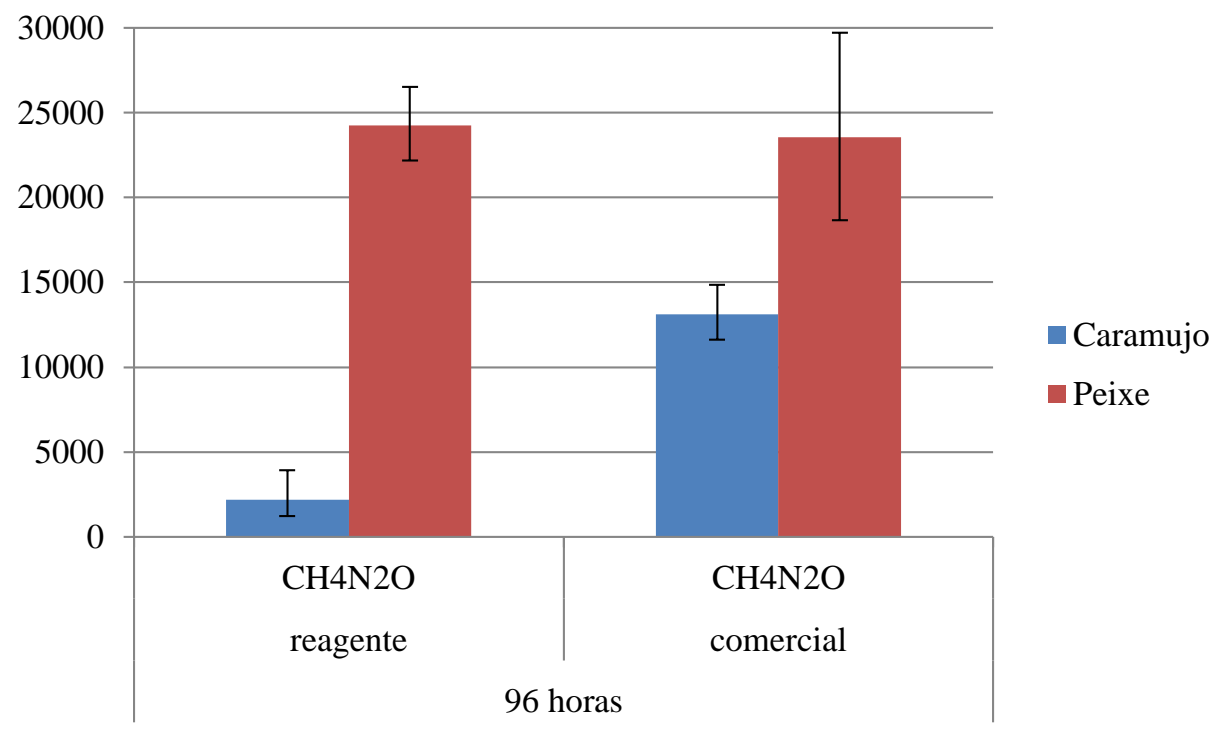

Quando analisada a toxicidade do amônio contido na ureia individualmente, nota-se que esta já desperta mortalidade em concentrações muito pequenas, sendo observada $\mathrm{CL}_{50}$ abaixo de $20 \mathrm{mg} / \mathrm{L}$ para todos os organismos. Como a escala representada na Figura 8 não representaria nitidamente os resultados de toxicidade do $\mathrm{NH}_{4}{ }^{+}$, estes valores foram representados em outro gráfico. Neste, é possível ver maior toxicidade do $\mathrm{NH}_{4}{ }^{+}$contido no reagente para o B. glabrata em 48 horas de exposição (Figura 9), mas sem diferença entre ambas as espécies quando avaliados somente os resultados de 96 horas devido ao grande intervalo de confiança.

Para a variedade comercial ocorre o contrário, onde somente é possível ver diferença a partir de 96 horas, não havendo diferença significativa nas primeiras 48 horas de exposição, contudo tanto o reagente quanto o comercial ainda mostram maior sensibilidade da espécie $B$. glabrata para o $\mathrm{NH}_{4}{ }^{+}$contido na ureia. 
Figura 9: Comparação entre as Concentrações Letais $\left(\mathrm{CLs}_{50}\right)$ encontradas no amônio para o caramujo B. glabrata e o peixe $D$. rerio em 48 horas de exposição e os respectivos intervalos de confiança (unidades em mg/L).

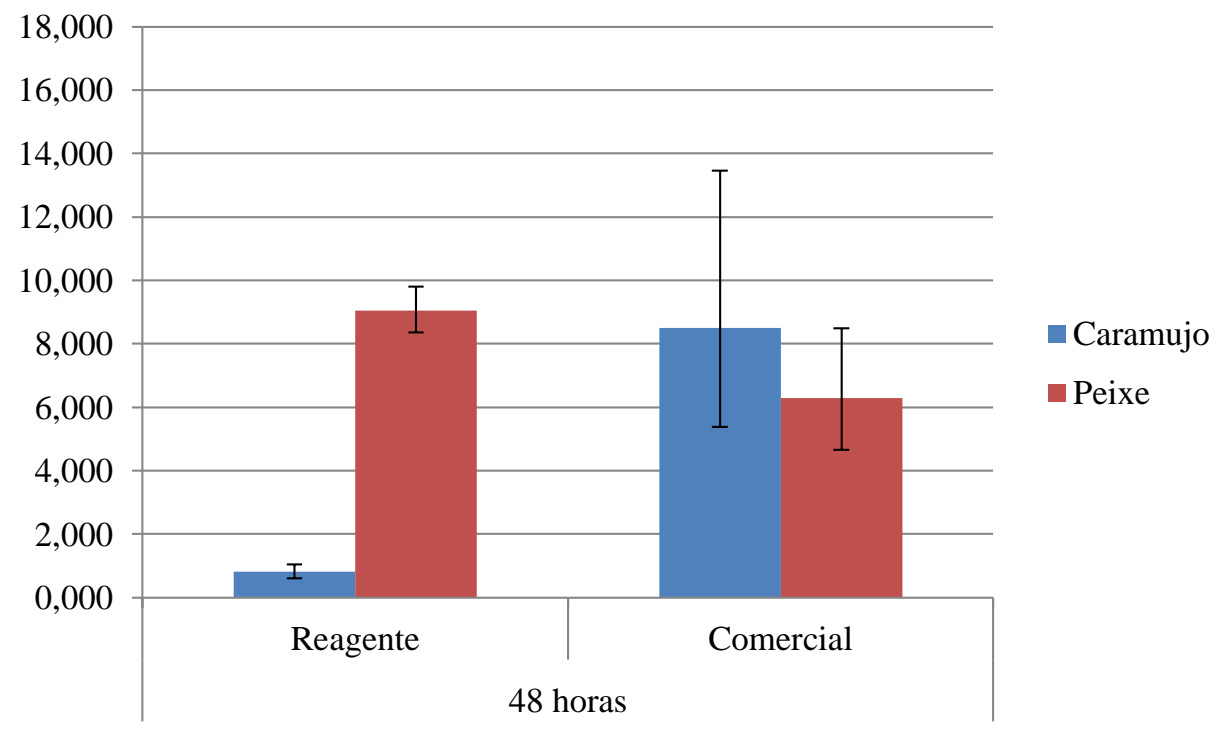

\subsection{Ensaios com fosfato}

O teste de normalidade de Shapiro-Wilk mostrou distribuição normal para todas as variáveis (Tabela 16). Como a estatística não apresentou nenhuma diferença significativa entre as análises químicas realizadas antes e depois dos ensaios para o reagente, nem para o fertilizante, foram mostrados somente na Tabela 17 os resultados das análises antes dos ensaios.

Tabela 16: Normalidade e estatística dos íons encontrados nas análises químicas do fosfato reagente (fosfato de potássio monobásico) e do comercial (superfosfato simples).

\begin{tabular}{|c|c|c|c|c|c|c|c|c|}
\hline & Sódio & Amônio & Potássio & Cálcio & Magnésio & Cloreto & Nitrato & Fosfato \\
\hline & \multicolumn{8}{|c|}{ Reagente } \\
\hline $\begin{array}{c}\text { Shapiro- } \\
\text { Wilk }\end{array}$ & 0,312 & - & 0,302 & 0,477 & 0,250 & - & - & 0,258 \\
\hline $\mathbf{T}$ & 0,998 & - & 0,018 & 0,444 & 0,288 & - & - & 0,053 \\
\hline$p$ & 0,389 & - & 0,986 & 0,682 & 0,789 & - & - & 0,961 \\
\hline \multirow[t]{2}{*}{ df } & 3,138 & - & 3,964 & 3,673 & 3,767 & - & - & 3,967 \\
\hline & \multicolumn{8}{|c|}{ Comercial } \\
\hline $\begin{array}{l}\text { Shapiro- } \\
\text { Wilk }\end{array}$ & 0,753 & - & - & 0,205 & 0,904 & - & - & 0,996 \\
\hline $\mathbf{T}$ & 0,259 & - & - & 0,022 & 0,804 & - & - & 0,025 \\
\hline$p$ & 0,800 & - & - & 0,983 & 0,437 & - & - & 0,981 \\
\hline df & 11,987 & - & - & 11,934 & 11,936 & - & - & 11,989 \\
\hline
\end{tabular}

$\mathrm{T}=$ Teste $\mathrm{t} / \mathrm{df}=$ Grau de liberdade. 
Tabela 17: Análise das diluições de fosfato (unidades em mg/L).

\begin{tabular}{|c|c|c|c|c|c|c|c|c|}
\hline $\begin{array}{c}\text { Concentração } \\
(\mathrm{mg} / \mathrm{L})\end{array}$ & Sódio & Amônio & Potássio & Cálcio & Magnésio & Cloreto & Nitrato & Fosfato \\
\hline \multicolumn{9}{|c|}{ Reagente } \\
\hline 75 & 21,893 & 0,000 & 22,590 & 10,025 & 7,267 & 0,240 & 0,000 & 66,702 \\
\hline 150 & 21,377 & 0,000 & 46,182 & 30,871 & 13,335 & 0,000 & 0,000 & 144,467 \\
\hline 500 & 17,680 & 0,000 & 149,486 & 98,917 & 32,357 & 0,000 & 0,000 & 214,519 \\
\hline 700 & 21,325 & 0,000 & 289,454 & 67,758 & 26,266 & 0,000 & 0,000 & 426,385 \\
\hline 1000 & 15,773 & 0,000 & 352,616 & 113,964 & 40,254 & 0,000 & 0,000 & 843,735 \\
\hline 2000 & 16,493 & 0,000 & 677,292 & 89,786 & 28,928 & 0,000 & 0,000 & 1760,480 \\
\hline 2500 & 14,919 & 0,000 & 818,352 & 77,437 & 31,164 & 0,000 & 0,000 & 2201,184 \\
\hline 3000 & 21,081 & 0,000 & 1001,143 & 142,758 & 55,677 & 0,000 & 0,000 & 2732,077 \\
\hline $\begin{array}{c}\text { Concentração } \\
(\mathrm{mg} / \mathrm{L})\end{array}$ & Sódio & Amônio & Potássio & Cálcio & Magnésio & Cloreto & Nitrato & Fosfato \\
\hline \multicolumn{9}{|c|}{ Comercial } \\
\hline 250 & 22,406 & 0,000 & 0,000 & 59,222 & 18,562 & 1,495 & 0,000 & 28,753 \\
\hline 500 & 22,785 & 0,000 & 0,000 & 158,851 & 22,662 & 1,850 & 0,000 & 97,423 \\
\hline 1000 & 17,989 & 0,000 & 0,000 & 288,706 & 22,444 & 4,656 & 0,000 & 165,804 \\
\hline 1500 & 15,501 & 0,000 & 0,000 & 318,377 & 32,181 & 0,000 & 0,000 & 247,590 \\
\hline 2000 & 20,554 & 0,000 & 0,000 & 350,640 & 39,587 & 0,000 & 0,000 & 380,832 \\
\hline 2500 & 19,527 & 0,000 & 0,000 & 378,675 & 49,062 & 0,000 & 0,000 & 460,538 \\
\hline 3000 & 19,585 & 0,000 & 0,000 & 533,687 & 55,067 & 0,000 & 0,000 & 576,473 \\
\hline $\begin{array}{l}\text { Água de } \\
\text { Diluição }\end{array}$ & 11,697 & 0,000 & 2,079 & 6,249 & 4,722 & 0,649 & 0,000 & 0,000 \\
\hline
\end{tabular}

As análises das concentrações de fosfato mostraram grande concentração de cálcio na variedade comercial utilizada no estudo (superfosfato simples), fato esse que dificultou a solubilização do mesmo para o estudo, mesmo o fabricante do fertilizante tendo informado que o material era solúvel em água.

O ensaio com a espécie $B$. glabrata mostrou mortalidade em concentrações a partir de 75 mg/L em 96 horas e $150 \mathrm{mg} / \mathrm{L}$ nas primeiras 48 horas de exposição para o reagente. No fertilizante comercial, por sua vez, a única concentração em que houve mortalidade foi na de $3000 \mathrm{mg} / \mathrm{L}$ com 72 horas de ensaio, sendo impossível testar concentrações maiores que estas devido à alta concentração de cálcio no composto.

Por isso, a $\mathrm{CL}_{50}$ calculada com os dados de cromatografia no reagente foi igual a 351,36 mg/L (138,17 - 893,47 mg/L) no teste de 48 horas e 178,81 mg/L (80,84 - 391,96 mg/L) com 96 horas de exposição para o reagente. No fertilizante, devido a impossibilidade de realizar testes em concentrações maiores, a única toxicidade possível de ser calculada foi a de 96 horas cujo 
resultado foi 2738,61 mg/L (sem intervalo de confiança). Para o teste de 48 horas, devido a ausência de mortalidade, é possível estipular que sua toxicidade deverá encontrar-se em concentrações acima de $3000 \mathrm{mg} / \mathrm{L}$ de superfosfato simples (Tabela 18).

Quando somente analisada toxicidade do fosfato, percebe-se que não houve diferença significativa na toxicidade do fosfato em 48 horas de exposição do reagente para o fertilizante devido aos limites do intervalo de confiança, contudo quando analisado somente os resultados obtidos em função das 96 horas de exposição, o fosfato presente no reagente mostra-se mais tóxico que o fertilizante. Quanto a variedade comercial, teve-se toxicidade igual a 515, $26 \mathrm{mg} / \mathrm{L}$ (sem intervalo de confiança) no teste de 96 horas. No de 48 horas, devido a ausência de mortalidade, é possível estipular que a toxicidade encontre-se em concentrações acima de $576,473 \mathrm{mg} / \mathrm{L}$ de fosfato, com base nos dados das análises cromatográficas.

Quando comparada somente a toxicidade dos compostos entre si, não foi possível ver diferença entre a $\mathrm{CL}_{50}$ do $\mathrm{K}^{+}$e do $\mathrm{PO}_{4}{ }^{3-}$ presentes no fosfato de potássio monobásico. Para o superfosfato simples, foi possível ver que a toxicidade deste composto aumenta em função do tempo.

Tabela 18: Dados de concentração letal $\left(\mathrm{CL}_{50}\right)$ encontrados no teste com o fosfato para cada substância no teste com B. glabrata. Valores entre parênteses mostram o intervalo de confiança.

\begin{tabular}{ccc}
\hline & $\begin{array}{c}\mathbf{C L}_{\mathbf{5 0}} \mathbf{4 8 h} \\
(\mathbf{m g} / \mathbf{L})\end{array}$ & $\begin{array}{c}\mathbf{C L}_{\mathbf{5 0}} \mathbf{9 6 h} \\
(\mathbf{m g} / \mathbf{L})\end{array}$ \\
\hline Reagente & \\
\hline Fosfato de potássio & $351,36(138,17-893,47)$ & $178,81(80,84-391,96)$ \\
monobásico $\left(\mathbf{K H}_{\mathbf{2}} \mathbf{P O}_{\mathbf{4}}\right)$ & $90,32(33,11-246,34)$ & $44,26(19,83-98,75)$ \\
Potássio $\left(\mathbf{K}^{{ }^{3}}\right)$ & $260,75(105,14-646,65)$ & $133,73(61,00-293,16)$ \\
\hline Fosfato $\left(\mathbf{P O}_{\mathbf{4}}{ }^{-}\right)$ & Comercial & \\
\hline Superfosfato simples & $>3000,00$ & 2738,61 \\
Fosfato $\left(\mathbf{P O}_{\mathbf{4}}{ }^{{ }^{-}}\right)$ & $>576,473$ & 515,26 \\
\hline
\end{tabular}

Para o D. rerio, as primeiras mortalidades no fosfato de potássio monobásico ocorreram na concentração de $2500 \mathrm{mg} / \mathrm{L}$ nas primeiras 24 horas de ensaio e no superfosfato simples, não foi observada nenhuma mortalidade até a concentração em que foi possível diluir o fertilizante.

Com isso, a única toxicidade possível de ser calculada foi a do reagente, onde os valores foram iguais a 2982,93 mg/L (2501,38 - 3557,17 mg/L) no teste de 48 horas e 2831,23 mg/L (2623,41 - 3055,52 mg/L) com 96 horas de exposição. Com o fertilizante, devido a ausência de 
mortalidade, é possível estipular que sua toxicidade deverá encontrar-se em concentrações acima de $3000 \mathrm{mg} / \mathrm{L}$ de superfosfato simples e $576,473 \mathrm{mg} / \mathrm{L}$ de fosfato, com base nos dados das análises cromatográficas (Tabela 19).

Quando comparada somente a toxicidade dos compostos entre si presentes no fosfato de potássio, o K ${ }^{+}$foi quem se mostrou mais tóxico para a espécie em relação ao $\mathrm{PO}_{4}{ }^{3-}$ e ao $\mathrm{KH}_{2} \mathrm{PO}_{4}$.

Tabela 19: Dados de concentração letal $\left(\mathrm{CL}_{50}\right)$ encontrados no teste com o fosfato para cada substância no teste com D. rerio. Valores entre parênteses mostram o intervalo de confiança.

\begin{tabular}{ccc}
\hline & $\begin{array}{c}\mathbf{C L}_{\mathbf{5 0}} \mathbf{4 8 h} \\
(\mathbf{m g} / \mathbf{L})\end{array}$ & $\begin{array}{c}\mathbf{C L}_{\mathbf{5 0}} \mathbf{9 6 h} \\
(\mathbf{m g} / \mathbf{L})\end{array}$ \\
\hline Reagente & \\
\hline $\begin{array}{c}\text { Fosfato de potássio } \\
\text { monobásico }\left(\mathbf{K H}_{\mathbf{2}} \mathbf{P O} \mathbf{}_{\mathbf{4}}\right)\end{array}$ & $2982,93(2501,38-3557,17)$ & $2831,23(2623,41-3055,52)$ \\
Potássio $\left(\mathbf{K}^{3}\right)$ & $811,47(690,15-954,12)$ & $774,16(721,89-830,21)$ \\
Fosfato $\left(\mathbf{P O}_{\mathbf{4}}{ }^{{ }^{-}}\right)$ & $2171,37(1811,21-2603,15)$ & $2056,98(1901,46-2225,22)$ \\
\hline & Comercial & \\
\hline Superfosfato simples & $>3000,00$ & $>3000,00$ \\
Fosfato $\left(\mathbf{P O}_{\mathbf{4}}{ }^{{ }^{-}}\right)$ & $>576,473$ & $>576,473$ \\
\hline
\end{tabular}

Diante desses resultados foi possível perceber que o caramujo foi a espécie mais sensível para o superfosfato simples com 96 horas de exposição, contudo o teste de 48 horas não foi possível definir qual a espécie mais sensível ao fertilizante. A espécie também demonstrou ligeira sensibilidade ao fosfato diluído no composto se comparado com o peixe, mas sem a possibilidade de saber se essa diferença é significativa devido a ausência de intervalo de confiança.

A espécie mais suscetível tanto ao $\mathrm{KH}_{2} \mathrm{PO}_{4}$, quanto ao seu fosfato e potássio diluído também foi o B. glabrata (Figura 10). Salienta-se que, diferente das demais figuras apresentadas até o momento, esta apresenta a concentração letal mediana $\left(\mathrm{CL}_{50}\right)$ do fosfato de potássio monobásico e a concentração letal inicial $\left(\mathrm{CL}_{(\mathrm{I}) 50}\right)$ do superfosfato simples, uma vez que por se tratar de uma mistura complexa não foi possível prever a reação de dissociação de cada componente e quantificar quanto de cada elemento encontrava-se no composto através da cromatografia. 
Figura 10: Comparação entre as Concentrações Letais (CLs ${ }_{50}$ ) encontradas nos testes com fosfato para o caramujo $B$. glabrata e o peixe $D$. rerio em 96 horas de exposição e os respectivos intervalos de confiança (unidades em $\mathrm{mg} / \mathrm{L}$ ).

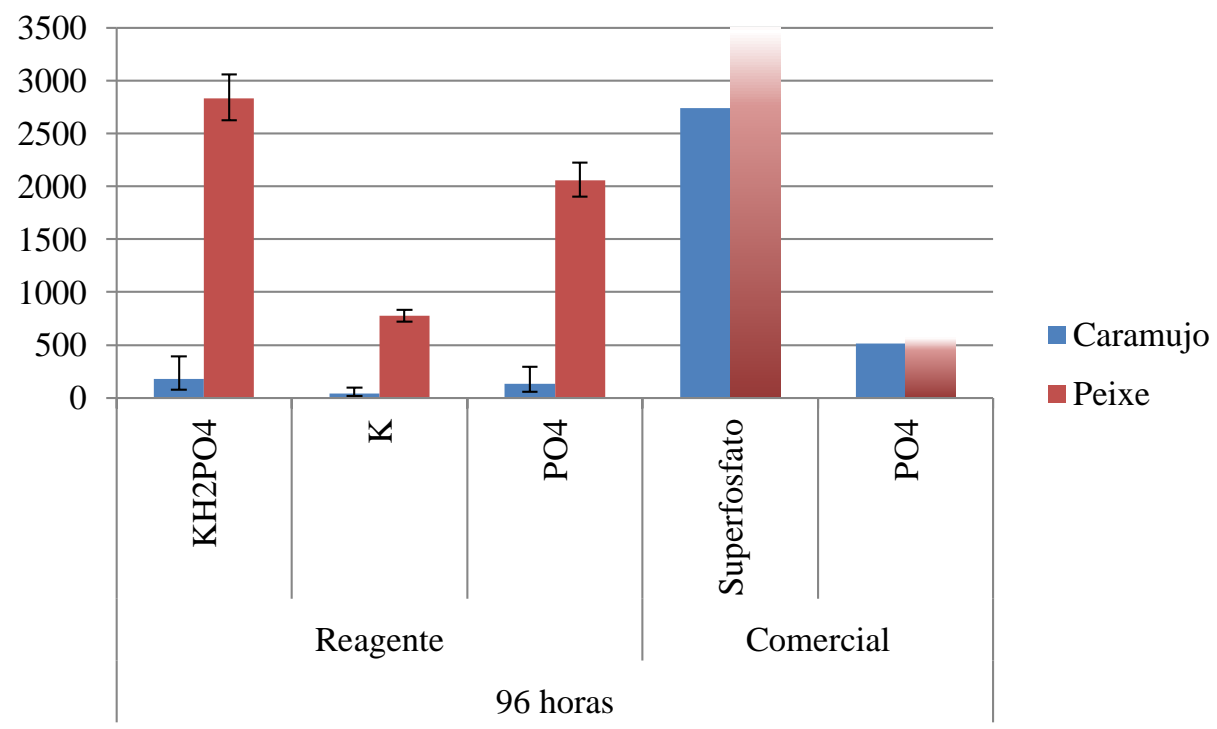

\subsection{Comparação entre os compostos}

Após o término de todos os ensaios foi possível também determinar qual foi a substância mais tóxica e o organismo mais sensível para os fertilizantes testados tanto em 48, quanto em 96 horas de exposição (Figura 11). 
Figura 11: Concentrações Letais $\left(\mathrm{CLs}_{50}\right.$ ) encontradas para o caramujo B. glabrata e o peixe $D$. rerio em 48 horas (esquerda) e 96 horas (direita) de exposição (unidades em $\mathrm{mg} / \mathrm{L}$ ).
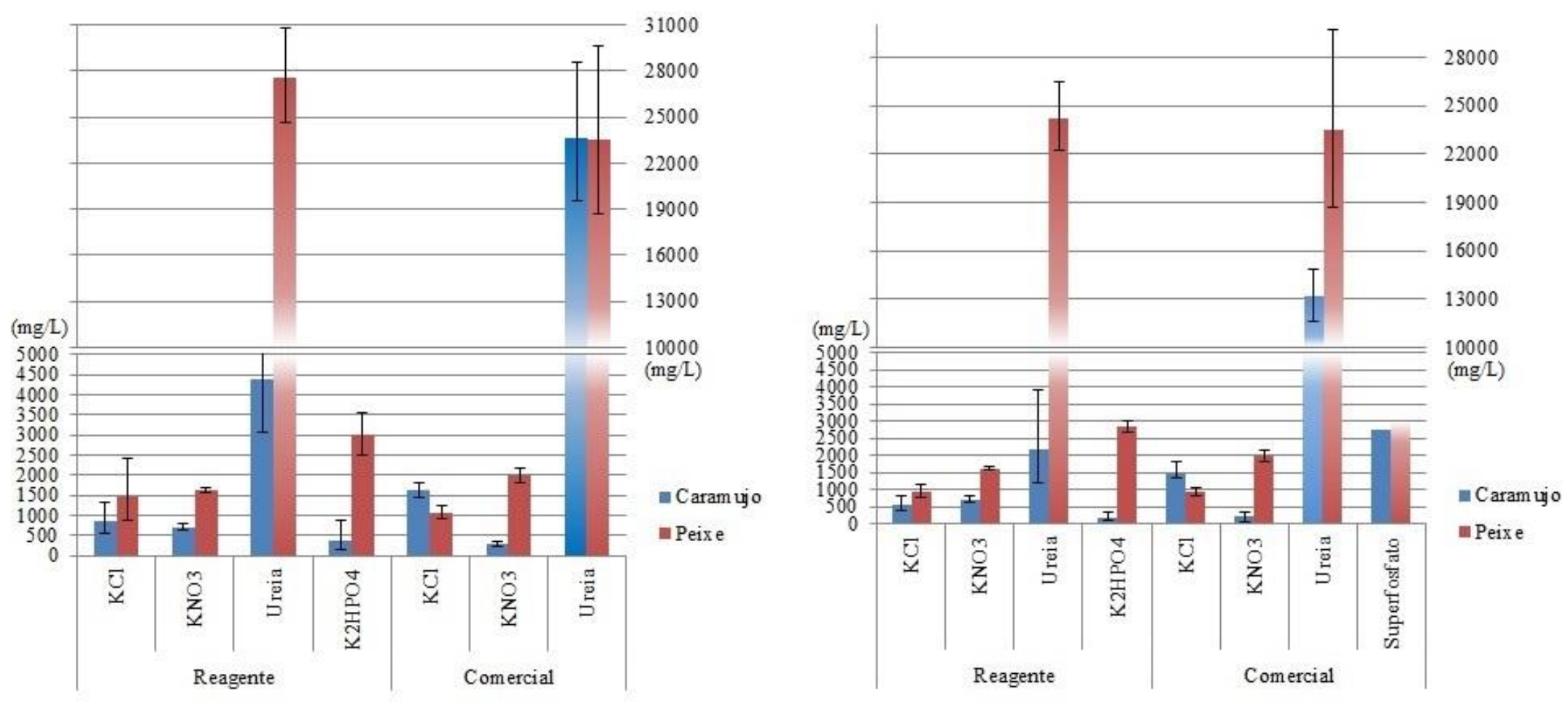
Os gráficos acima mostraram que o composto mais tóxico, em 48 horas de exposição foi o fosfato de potássio monobásico $\left(\mathrm{KH}_{2} \mathrm{PO}_{4}\right)$ e o $\mathrm{KNO}_{3}$ em 96 horas para o caramujo e o cloreto de potássio $(\mathrm{KCl})$ para o peixe, contudo quando somente analisado os compostos utilizados como fertilizantes, observou-se maior toxicidade ao $\mathrm{KNO}_{3}$ para a espécie $B$. glabrata.

Também foi possível inferir a partir dos resultados obtidos que, para praticamente todos os ensaios realizados, (salvo o teste com $\mathrm{KCl}$ ) o caramujo se demostrou mais sensível aos compostos testados do que o D. rerio.

A interação individual entre os compostos mostraram que toxicidade do potássio foi afetada pela presença de outros elementos nas diluições testadas, uma vez que a toxicidade do potássio isoladamente variou em função da substância testada e do organismo exposto, tendo o $\mathrm{K}^{+}$presente no $\mathrm{KH}_{2} \mathrm{PO}_{4}$ se mostrado mais tóxico do que no $\mathrm{K}^{+}$presente no $\mathrm{KCl}$ e no $\mathrm{KNO}_{3}$ (que não houveram diferença significativa entre si) para o B. glabrata. Contudo, para o D. rerio, o $\mathrm{K}^{+}$ presente no $\mathrm{KCl}$ foi mais tóxico do que o presente no $\mathrm{KNO}_{3}$ e no $\mathrm{KH}_{2} \mathrm{PO}_{4}$ (que não houveram diferença significativa entre si) (Tabela 20).

Quando analisado os resultados individuais do $\mathrm{K}^{+}$nos fertilizantes, observa-se um cenário oposto ao encontrado no reagente, tendo sido observada maior toxicidade do $\mathrm{K}^{+}$presente no $\mathrm{KNO}_{3}$ para o B. glabrata e do $\mathrm{K}^{+}$presente no $\mathrm{KCl}$ para o D. rerio.

Tabela 20: Comparação entre as concentrações letais (CLs ${ }_{50}$ ) obtidos com diferentes testes com o potássio presente para o reagente e para o fertilizante comercial para o caramujo B. glabrata e o peixe D. rerio (unidades em mg/L).

\begin{tabular}{|c|c|c|c|c|}
\hline & \multicolumn{4}{|c|}{ Reagente } \\
\hline & \multicolumn{2}{|c|}{48 horas } & \multicolumn{2}{|c|}{96 horas } \\
\hline & B. glabrata & D. rerio & B. glabrata & D. rerio \\
\hline $\mathbf{K C l}-\mathbf{K}$ & $\begin{array}{c}422,27(270,14- \\
660,07)\end{array}$ & $\begin{array}{c}802,39(523,53- \\
1229,78)\end{array}$ & $\begin{array}{c}277,98(183,58- \\
420,92)\end{array}$ & $\begin{array}{c}527,91(432,64- \\
644,16)\end{array}$ \\
\hline $\mathrm{KNO}_{3}-\mathrm{K}$ & $\begin{array}{c}347,07(303,49- \\
396,89)\end{array}$ & $\begin{array}{c}786,45(732,92- \\
843,89)\end{array}$ & $\begin{array}{c}347,07(303,49- \\
396,89)\end{array}$ & $\begin{array}{c}786,45(732,92- \\
843,89)\end{array}$ \\
\hline \multirow[t]{4}{*}{$\mathrm{KH}_{2} \mathrm{PO4}-\mathrm{K}$} & $\begin{array}{c}90,32(33,11- \\
246,34)\end{array}$ & $\begin{array}{c}811,47(690,15- \\
954,12)\end{array}$ & $\begin{array}{c}44,26(19,83- \\
98,75)\end{array}$ & $\begin{array}{c}774,16(721,89- \\
830,21)\end{array}$ \\
\hline & \multicolumn{4}{|c|}{ Comercial } \\
\hline & \multicolumn{2}{|c|}{48 horas } & \multicolumn{2}{|c|}{96 horas } \\
\hline & B. glabrata & D. rerio & B. glabrata & D. rerio \\
\hline $\mathbf{K C l}-\mathbf{K}$ & $\begin{array}{c}891,98(801,01- \\
993,29)\end{array}$ & $\begin{array}{c}589,25(502,64- \\
690,79)\end{array}$ & $\begin{array}{c}785,20(610,17- \\
1010,43)\end{array}$ & $\begin{array}{c}509,65(445,97- \\
582,42)\end{array}$ \\
\hline KNO3 - K & $\begin{array}{c}139,90(111,63- \\
175,33)\end{array}$ & $\begin{array}{c}993,65(944,33- \\
1045,55)\end{array}$ & $\begin{array}{c}102,73(68,40- \\
154,29)\end{array}$ & $\begin{array}{c}993,65(944,33- \\
1045,55)\end{array}$ \\
\hline
\end{tabular}


A toxicidade do nitrogênio, por sua vez pôde ser maximizada em virtude da sua dissociação em água, uma vez que o composto na forma de $\mathrm{NH}_{4}{ }^{+}$mostrou-se muito mais tóxico do que na sua forma de $\mathrm{NO}_{3}{ }^{-}$(Tabela 21). Além disso, a maior toxicidade do $\mathrm{N}$ para a espécie $B$. glabrata pode ser associada a uma maior intolerância desta ao composto em função do tempo, uma vez que os valores que mais destoam dos demais podem ser vistos a partir de 96 horas de exposição.

Tabela 21: Comparação entre as concentrações letais ( $\mathrm{CLs}{ }_{50}$ ) obtidos com diferentes testes com o nitrogênio presente para o reagente e para o fertilizante comercial para o caramujo B. glabrata e o peixe D. rerio (unidades em $\mathrm{mg} / \mathrm{L})$.

\begin{tabular}{|c|c|c|c|c|}
\hline & \multicolumn{4}{|c|}{ Reagente } \\
\hline & \multicolumn{2}{|c|}{48 horas } & \multicolumn{2}{|c|}{96 horas } \\
\hline & B. glabrata & D. rerio & B. glabrata & D. rerio \\
\hline KNO3 - N & $\begin{array}{c}354,09(311,55- \\
402,44)\end{array}$ & $\begin{array}{c}856,23(825,64- \\
887,95)\end{array}$ & $\begin{array}{c}354,09(311,55- \\
402,44)\end{array}$ & $\begin{array}{c}856,23(825,64- \\
887,95)\end{array}$ \\
\hline \multirow[t]{4}{*}{$\mathrm{CO}(\mathrm{NH} 2) 2-\mathrm{N}$} & $0,81(0,62-1,05)$ & $9,05(8,36-9,81)$ & $\begin{array}{c}0,10(0,001- \\
17,73)\end{array}$ & $8,55(8,08-9,04)$ \\
\hline & \multicolumn{4}{|c|}{ Comercial } \\
\hline & \multicolumn{2}{|c|}{48 horas } & \multicolumn{2}{|c|}{96 horas } \\
\hline & B. glabrata & D. rerio & B. glabrata & D. rerio \\
\hline KNO3 - N & $\begin{array}{c}153,38(125,98- \\
186,87)\end{array}$ & $\begin{array}{c}988,01(878,70- \\
1110,93)\end{array}$ & $\begin{array}{c}117,40(79,88- \\
172,56)\end{array}$ & $\begin{array}{c}988,01(878,70- \\
1110,93)\end{array}$ \\
\hline $\mathrm{CO}(\mathrm{NH} 2) 2-\mathrm{N}$ & $\begin{array}{c}8,51(5,38- \\
13,45)\end{array}$ & $6,28(4,65-8,48)$ & $3,39(2,89-3,99)$ & $6,28(4,65-8,48)$ \\
\hline
\end{tabular}

A toxicidade do fosfato também pode ter sido influenciada devido às impurezas contidas no superfosfato, uma vez que as análises cromatográficas mostraram a presença de outros elementos (como cálcio, magnésio e sulfato) em grandes quantidades na solução. Mesmo assim, o fosfato presente no reagente ainda demonstrou maior toxicidade do que o presente no fertilizante para o B. glabrata em 96 horas de exposição (Tabela 22).

Para o peixe $D$. rerio não é possível afirmar qual fonte de potássio teve maior toxicidade da espécie, uma vez que para o superfosfato existe somente a estimativa de que esta estará em concentrações acima de 576,473 mg/L. 
Tabela 22: Comparação entre as concentrações letais (CLs $\left.{ }_{50}\right)$ obtidos com diferentes testes com o fosfato presente para o reagente e para o fertilizante comercial para o caramujo B. glabrata e o peixe $D$. rerio (unidades em mg/L).

\begin{tabular}{ccccc}
\hline & \multicolumn{2}{c}{ 48 horas } & \multicolumn{2}{c}{$\mathbf{9 6}$ horas } \\
& B. glabrata & D. rerio & B. glabrata & D. rerio \\
\hline $\mathbf{K H}_{2} \mathbf{P O}_{4}-\mathbf{P O}_{4}$ & $260,75(105,14-$ & $2171,37(1811,21$ & $133,73(61,00-$ & $2056,98(1901,46$ \\
$\mathbf{C a}\left(\mathrm{H}_{2} \mathbf{P O}_{4}\right)_{2}+\mathrm{CaSO}_{4}$ & $646,65)$ & $-2603,15)$ & $293,16)$ & $-2225,22)$ \\
$-\mathbf{P O}_{4}$ & $>576,473$ & $>576,473$ & 515,26 & $>576,473$ \\
\hline
\end{tabular}




\section{DISCUSSÃO}

A escolha de usar um reagente e um fertilizante comercial no presente estudo deu-se a partir do momento em que se percebeu nos artigos consultados que, naqueles que informaram a procedência do fertilizante utilizado, existe uma tendência dos autores em utilizar a variedade química ao invés dos fertilizantes comerciais, tanto em testes envolvendo o fertilizante $\mathrm{KCl}$ (ROMANO; ZENG, 2007a; FREITAS; ROCHA, 2011; STRUEWING et al., 2014), quanto outros como fertilizantes nitrogenados, potássicos e fosfatados (RUBIN; ELMARAGHY, 1977; TCHOUNWOU; ENGLANDE JR; MALEK, 1991; HAMLIN, 2006; ROMANO; ZENG, 2007a; ROMANO; ZENG, 2007b). Esse fato possui algumas implicações dentro da análise dos resultados, pois a maior parte dos fertilizantes comercializados não possuem o grau de pureza que os químicos possuem, sendo que a pureza de potássio em um fertilizante comercial pode oscilar entre $18 \%$ a $60 \%$ dependendo do fertilizante e do fabricante (SOUSA; LOBATO, 2004b), tornando difícil a compreensão se a toxicidade está relacionada à substância testada ou às impurezas contidas na formulação do produto comercial.

Cada marca de fertilizante garante uma pureza diferente para seus produtos, pois a legislação brasileira para comércio de fertilizantes prevê apenas uma padronização mínima para as concentrações de nutrientes para os fertilizantes, sendo para o cloreto de potássio o mínimo de $58 \%$ de potássio, no nitrato de potássio $44 \%$ de potássio e $13 \%$ de nitrogênio, a ureia mínimo de 44\% de nitrogênio, e no superfosfato simples 16\% de fosfato solúvel em água (BRASIL, 2007b).

Nos Estados Unidos e no Canadá, suas respectivas legislações focam também nos metais pesados presentes nos fertilizantes (AAPFCO, 2012; CFIA, 2014), contudo nos Estados Unidos é mostrada a concentração média de nitrogênio, fósforo e potássio comercializada nos compostos em seu território, sendo que na ureia é encontrado em média 45,9\% de nitrogênio, no cloreto de potássio $60,1 \%$ de potássio, no nitrato de potássio é encontrado em média 13,6\% de nitrogênio e 43,3\% de potássio e no superfosfato simples 20,7\% de fosfato (USEPA, 1999).

Também é previsto pela legislação norte americana e canadense testes de concentração dos compostos comercializados nos fertilizantes, como forma de garantia ao consumidor da pureza do fertilizante que está adquirindo, sendo que para o nitrogênio a garantia pode ser dada em suas diversas formas (nitrogênio amoniacal, nitrato, nitrogênio insolúvel, entre outros). Para o 
fósforo, sua garantia pode ser dada na forma de fosfato e para o potássio, na forma de potássio solúvel $\left(\mathrm{K}_{2} \mathrm{O}\right)$ (AAPFCO, 2012; CFIA, 2014).

A presença dos íons potássio $\left(\mathrm{K}^{+}\right)$e Cloreto $\left(\mathrm{Cl}^{-}\right)$na água de diluição e na destinada para os organismos teste já era esperada, pois segundo a norma para criação de organismo aquáticos em laboratório, é previsto a presença de $\mathrm{KCl}$ na água de diluição, mas em concentrações recomendadas para o tipo de teste a ser executado (USEPA, 1975, 2002; ABNT, 2004). Logo, para o presente estudo, era previsto para a água de diluição uma concentração de $2 \mathrm{mg} / \mathrm{L} \mathrm{de} \mathrm{KCl}$, tendo sido encontrado valor próximo, visto as concentrações de $\mathrm{K}^{+}$e $\mathrm{Cl}^{-}$nas amostras da água de diluição.

Os resultados de toxicidade das substâncias apresentaram valores distintos em relação aos organismos teste utilizados em virtude de suas distintas biologia e hábito, uma vez que o D. rerio é uma espécie do nécton (KNIE; LOPES, 2004) e o B. glabrata do bentos.

\subsection{Toxicidade do cloreto de potássio $(\mathrm{KCl})$}

A mortalidade maior observada para os peixes expostos ao $\mathrm{KCl}$ em relação ao caramujo, evidencia que esta espécie é menos tolerante a salinização da água do que o B. glabrata, contudo quando comparada a toxicidade encontrada pelas espécies para o $\mathrm{KCl}$, percebeu-se que em relação ao reagente não há diferença encontrada na toxicidade do $\mathrm{KCl}$ para o cladócero Daphnia similis, onde Utz e Bohrer (2001) encontram $\mathrm{CE}_{50}$ igual a 986,66 mg/L em ensaio de 48 horas de exposição, Ignácio et al. (2014) encontraram CL 50 igual a 1370 mg/L em 48 horas de exposição para o pacu (Piaractus mesopotamicus), Struewing et al. (2014) encontraram CL $_{50}$ igual a 1956,7 mg/L para o inseto Centroptilum triangulifer e Mount et al. (1997) tiveram valores de CE's 50 iguais a 630,0 mg/L para o cladócero Ceriodaphnia dubia, 660,0 mg/L para Daphnia magna e $\mathrm{CL}_{50}$ igual 910,0 mg/L para o peixe Rosy red (Pimephales promelas). Todos os resultados mostraram-se dentro do intervalo de confiança para as espécies usadas no presente estudo, entretanto quando comparados esses mesmos resultados com os obtidos pelo fertilizante $\mathrm{KCl}$, a espécie B. glabrata destaca-se das demais como a segunda mais resistente, ficando atrás somente do inseto $C$. triangulifer (Figura 12). 
Figura 12: Comparação entre concentrações Letais $\left(\mathrm{CLs}_{50}\right)$ do $\mathrm{KCl}$ em diferentes espécies em 48 horas de exposição com intervalos de confiança, quando informados (unidades em $\mathrm{mg} / \mathrm{L}$ ). Dados obtidos no presente estudo(*) com a de outros estudos.

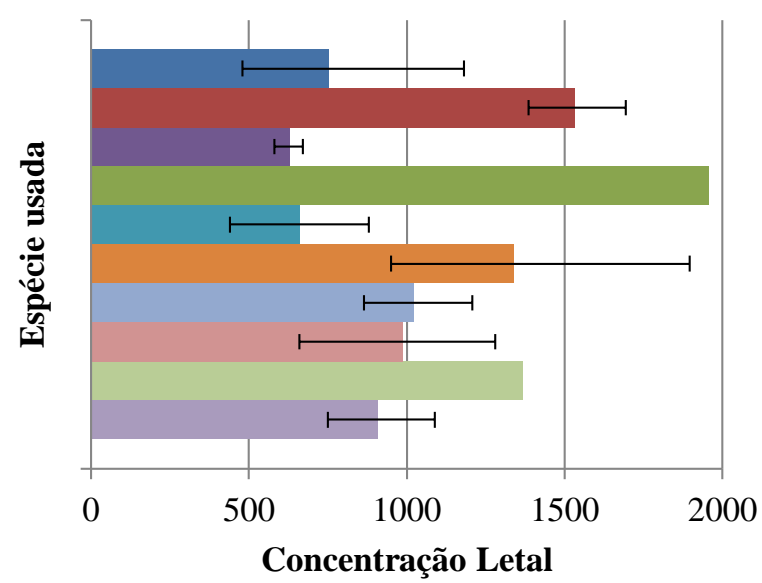

$$
\begin{aligned}
& \text { B. glabrata (reagente)* } \\
& \text { B. glabrata } \\
& \text { (comercial)* } \\
& \text { C. dubia } \\
& \text { C. triangulifer } \\
& \text { D. magna } \\
& \text { D. rerio (reagente)* } \\
& \text { D. rerio (comercial)* } \\
& \text { D. similis }
\end{aligned}
$$

Fonte: MOUNT et al., 1997; UTZ, BOHRER, 2001; IGNÁCIO et al., 2014; STRUEWING et al., 2014.

$\mathrm{Na}$ agricultura também se discute sobre o efeito salino que o $\mathrm{KCl}$ exerce sobre os solos dificultando principalmente a germinação de plantas em decorrência disso (VILELA; SOUSA; SILVA, 2004), contudo o maior foco é sobre o elemento potássio, pois quando dissolvido no solo, este é convertido para a sua forma iônica $\left(\mathrm{K}^{+}\right)$, o que favorece sua perda por lixiviação, uma vez que os solos de Cerrado possuem baixa capacidade de troca catiônica e este elemento possui baixa solubilidade em água (VIEIRA, RAMOS, 1999; VILELA, SOUSA, SILVA, 2004). Devido a isso é recomendado na agricultura poucas doses de potássio nos primeiros estágios de vida da cultura (até $100 \mathrm{~kg} / \mathrm{ha}$ de $\mathrm{KCl}$ ou $60 \mathrm{~kg} / \mathrm{ha}$ de $\mathrm{K}_{2} \mathrm{O}$ ) e depois maiores doses podendo variar de 20 a $450 \mathrm{~kg} / \mathrm{ha}$ de $\mathrm{K}_{2} \mathrm{O}$ por ano para as principais culturas cultivadas no Cerrado (ALVES et al., 1999a; ALVES et al., 1999b; CHAGAS et al., 1999; GUIMARÃES et al., 1999; NOVAIS, 1999; SOUSA, LOBATO, 2004b), aumento o risco por perda por lixiviação para o ambiente.

\subsection{Toxicidade do nitrato de potássio (KNO3)}

Os resultados encontrados de toxicidade para o $\mathrm{KNO}_{3}$ neste estudo mostraram menor resistência dos organismos utilizados do que outros presentes na literatura. Dowden e Bennet (1965), em estudo onde buscou definir a toxicidade de diversos químicos (entre eles o $\mathrm{KNO}_{3}$ ), obtiveram para o cladócero D. magna toxicidade igual $490 \mathrm{mg} / \mathrm{L}$ e para o peixe de água doce conhecido como perca do sol de guelras azuis (Lepomis macrochirus) toxicidade igual a 5.500 
mg/L em ensaios de 24 horas. Rubin e Elmaraghy (1977) obtiveram $\mathrm{CL}_{50}$ igual a $1.380 \mathrm{mg} / \mathrm{L}$ para o peixe de água doce barrigudinho (Poecilia reticulata) em ensaio com 96 horas de exposição. Para facilitar a compreensão e comparação entre os resultados de toxicidade encontrados neste estudo com os presentes na literatura, também calculou-se a $\mathrm{CL}_{50}$ do $\mathrm{KNO}_{3} \mathrm{em}$ 24 horas de exposição do peixe e do caramujo (Figura 13).

Todos os resultados obtidos se comparado tanto o com reagente, quanto com o $\mathrm{KNO}_{3}$ comercial mostram a espécie $B$. glabrata como a segunda mais sensível das quatro espécies comparadas (depois da espécie D. magna) com base em testes similares encontrados na literatura.

Figura 13: Comparação entre concentrações Letais $\left(\mathrm{CLs}_{50}\right)$ do $\mathrm{KNO}_{3}$ em diferentes espécies em 24 e 96 horas de exposição com intervalos de confiança, quando informados (unidades em $\mathrm{mg} / \mathrm{L}$ ). Dados obtidos no presente estudo $\left(^{*}\right)$ com a de outros estudos.

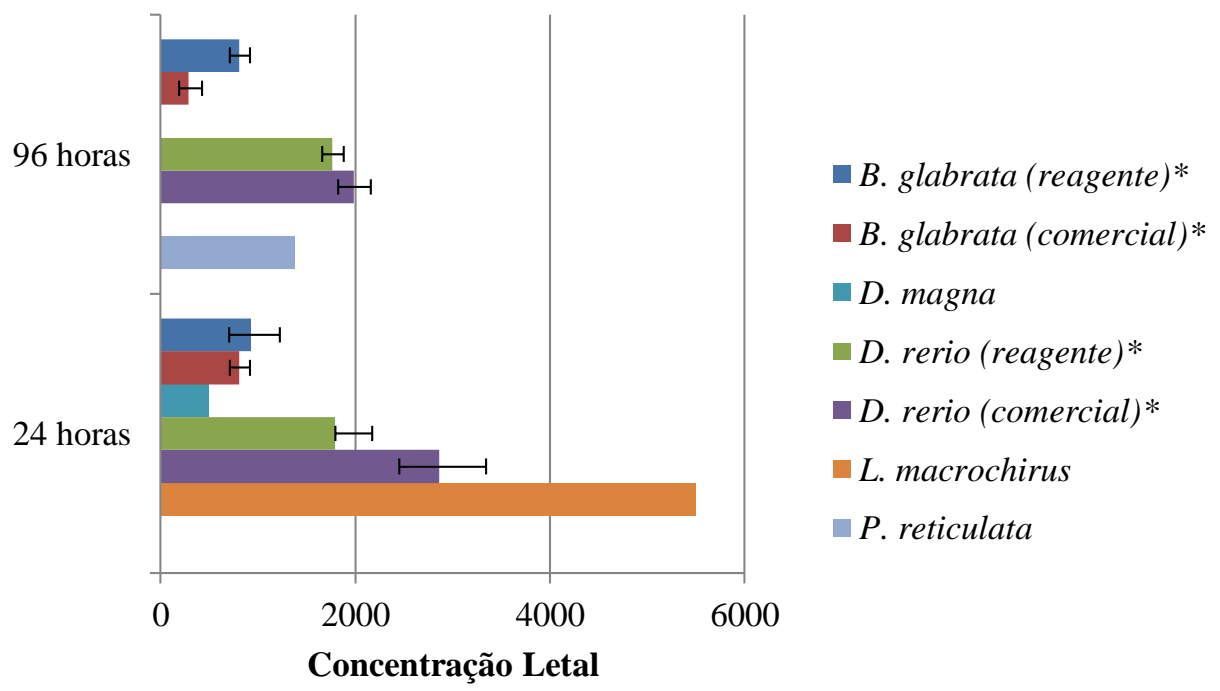

Fonte: DOWDEN, BENNET, 1965; RUBIN, ELMARAGHY, 1977.

$\mathrm{O}$ uso do $\mathrm{KNO}_{3}$ na agricultura vem como uma fonte de nitrogênio alternativa à ureia, uma vez que esta é mais propensa a perdas por volatilização e degradação, mesmo assim ainda existe o risco de perda no nitrato de potássio por escoamento, uma vez que sais extremamente solúveis (como o nitrato de sódio e o nitrato de potássio) possuem íons muito móveis em solo por terem pouca ou nenhuma interação com a fase sólida deste e, logo, são propensos a perda por lixiviação (LOPES, 1999). Mesmo assim, o uso do $\mathrm{KNO}_{3}$ na agricultura ainda constitui uma alternativa melhor do que a ureia e o $\mathrm{KCl}$, desde que usado na fertirrigação, onde este modelo reduz perdas 
de nitrogênio no processo e por exigir o uso de fertilizantes com alta solubilidade, tornando o $\mathrm{KNO}_{3}$ uma fonte tanto de nitrogênio, quanto de potássio para as culturas (SOUSA; LOBATO, 2004a, VIEIRA; RAMOS, 1999).

Ainda sobre a movimentação do nitrogênio quando diluído em água, Vieira e Ramos (1999) mostram que a sua forma diluída (amônio, nitrito ou nitrato) influencia na infiltração deste no solo e também pela planta. O N na forma de nitrato movimenta-se livremente pela água de irrigação e não são adsorvidos quando em contato com o solo, tendo a vantagem de fornecerem $\mathrm{N}$ para a planta de maneira imediata (VIEIRA; RAMOS, 1999; RESENDE, 2002). A ureia, por sua vez, quando diluída em água comporta-se como uma molécula neutra, não ionizando-se, mas quando em contato com solo, é hidrolisada em amônio devido a ação de bactérias presentes no solo (VIEIRA; RAMOS, 1999).

\subsection{Toxicidade da Ureia $\left(\mathrm{CO}\left(\mathrm{NH}_{2}\right)_{2}\right)$}

Os compostos (contaminantes ou não), em geral, quando são transportados até uma fonte aquosa, como lagos, córregos e açudes, sofrem alterações na sua quantidade, que podem ser de diluição, reconcentração ou transferência. Também sofrem alterações em sua qualidade, sendo alterados por processos de degradação ou em múltiplas reações que podem participar durante o processo de transporte formando compostos com distintas propriedades, podendo mesmo elevar ou diminuir a toxicidade desse composto (MOZETO; ZAGATTO, 2006).

A ausência de um dos subprodutos da degradação da ureia, como $\mathrm{NO}_{2}{ }^{-}$ou $\mathrm{NO}_{3}{ }^{-}$, não significa que a substância não estivesse presente no ensaio, mas sim que a metodologia de ensaio semi-estático, com renovação diária da solução, pode não ter dado tempo para a ureia ser convertida em $\mathrm{NH}_{4}{ }^{+}$ou em outra substância que pudesse ser detectado pelo processo de cromatografia iônica.

Os resultados deste estudo com outros semelhantes na literatura mostraram que a ureia é igualmente tóxica para as demais espécies somente em elevadas concentrações, como foi mostrado no teste de Tchounwou, Englande Jr. e Malek (1991), onde os autores também trabalharam com caramujos aquáticos da espécie Biomphalaria havanensis e Helisoma trivolvis em diferentes estágios de vida encontraram valores de toxicidade para a ureia reagente (em 48 horas de exposição) igual a 21412,08 mg/L e 13476,59 mg/L, respectivamente, para organismos na idade adulta (com 8 a $10 \mathrm{~mm}$ de diâmetro na concha). 
Em outros trabalhos, onde focou-se na ureia comercial, Eshra (2014) analisou a toxicidade deste fertilizante para os caramujos terrestres Eobania vermiculata e Theba pisana encontraram valores de $\mathrm{CL}_{50}$ iguais a $54860 \mathrm{mg} / \mathrm{L}$ e $48860 \mathrm{mg} / \mathrm{L}$, respectivamente. Para a carpa indiana catla (Catla catla) na fase de alevino, Sangeetha et al. (2011) encontraram toxicidade igual a 280 mg/L. Em outro estudo semelhante ao anterior, Harless et al. (2011) avaliando a toxicidade de várias substância (entre elas o fertilizante ureia) para a rã do bosque (Rana sylvatica) na fase de girino, encontraram valor de $\mathrm{CL}_{50}$ igual a $14370 \mathrm{mg} / \mathrm{L}$ (Figura 14). Todos os testes citados foram de 48 horas de exposição.

Todos os resultados apresentados por esses estudos comparados com os resultados de toxicidade dos organismos utilizados neste, apontam a espécie B. glabrata como a mais sensível à ureia na forma de reagente, contudo se visto somente do ponto de vista do fertilizante, a espécie C. catla aparece como a mais sensível, seguido da $R$. sylvatica, da B. glabrata e do D. rerio juntos (devido aos limites do intervalo de confiança) e depois T. pisana e o E. vermiculata como os mais resistentes.

Figura 14: Comparação entre concentrações Letais (CLs 50) da ureia em diferentes espécies em 48 horas de exposição com intervalos de confiança, quando informados (unidades em mg/L). Dados obtidos no presente estudo(*) com a de outros estudos.

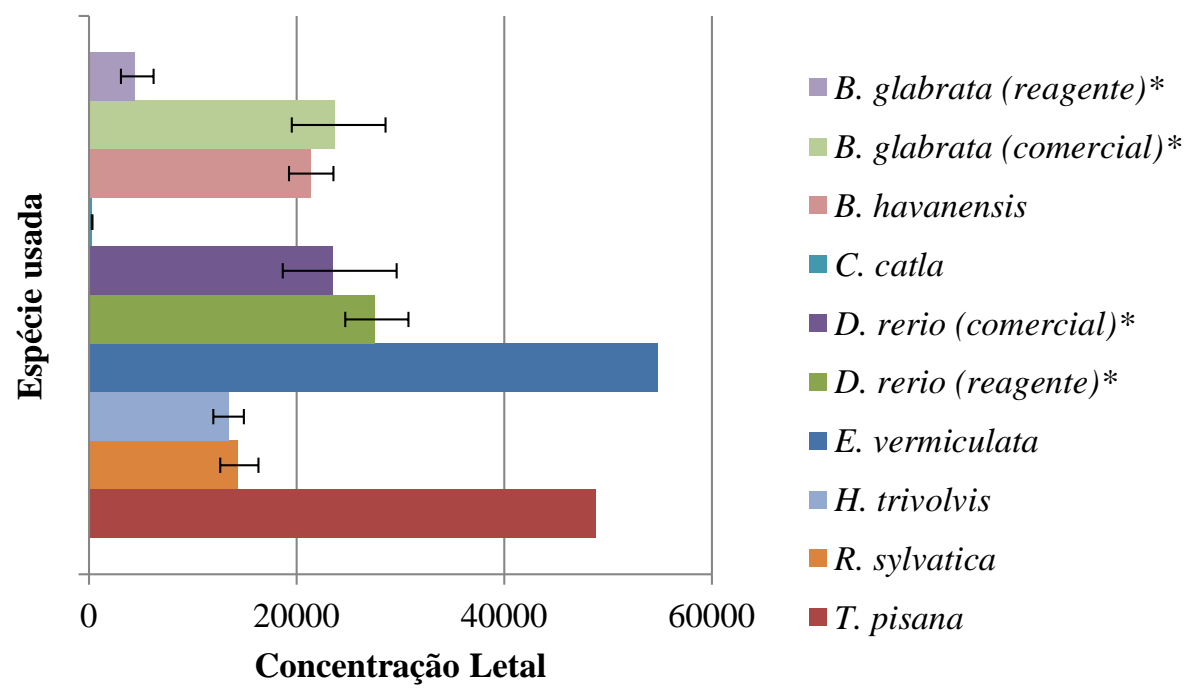

Fonte: TCHOUNWOU, ENGLANDE JR, MALEK (1991); HARLESS et al. (2011); SANGEETHA et al. (2011); ESHRA (2014). 
A maior sensibilidade do B. glabrata em função das demais espécies a ureia pode ser explicada uma vez que esta substância possui efeito moluscicida (PERRET; EGGER; DEGREMONT, 1972), contudo mesmo a ureia tendo esse efeito sobre caramujos, a espécie $B$. glabrata ainda foi mais sensível do que os caramujos de água doce utilizados por Tchounwou, Englande Jr. e Malek (1991). Esse fato pode estar relacionado ao tipo de bioensaio que foi empregado, onde no presente estudo houve a renovação diária das soluções teste e no trabalho dos referidos autores não foi explicado se a metodologia de exposição foi estática, semi-estática ou de fluxo contínuo. Este esclarecimento metodológico algo importante na compreensão do ensaio, uma vez que a ureia se perde rapidamente ou por volatilização, ou por conversão em amônia na presença de urease (LOPES, 1999).

A razão de a ureia despertar mortalidade em todos os organismos somente em concentrações elevadas pode estar relacionado ao fato de estes não produzirem a enzima urease em sua fisiologia, não gerando a rápida conversão deste composto em amônia que é mais tóxica para as células dos organismos (MORAES; POLEZ; IWAMA, 2004). Nos ambientes naturais, onde bactérias que produzem urease estão presentes, a toxicidade da ureia pode ser maior do que os valores encontrados em ensaios laboratoriais (PALANIVELU et al., 2005).

Um dos maiores problemas em se empregar a ureia no campo, além de sua rápida perda por volatilização, é o fato desta substância também se solubilizar facilmente em água, além disso, uma vez degradada em $\mathrm{NH}_{4}{ }^{+}$, este possui pouca ou nenhuma interação com o solo e tende a ser mais carregado pela água e, por isso sendo necessária a aplicação de mais fertilizantes nitrogenados para complementar a adubação (LOPES, 1999). Por isso, cerca de metade dos fertilizantes nitrogenados aplicados ao solo são perdidos pela água da chuva (VARGAS et al., 2004).

Devido a essa grande perda que os fertilizantes nitrogenados possuem, em geral, é recomendado também o uso deste em grandes quantidades na agricultura, uma vez que a perda para o solo ou por escoamento superficial é grande, sendo recomendado o uso de 10 a $450 \mathrm{~kg} / \mathrm{ha}$ de $\mathrm{N}$ por ano para as principais culturas cultivadas no Cerrado (ALVES et al., 1999a; ALVES et al., 1999b; CHAGAS et al., 1999; GUIMARÃES et al., 1999; NOVAIS, 1999; SOUSA, LOBATO, 2004b). 


\subsection{Toxicidade do fosfato}

Os resultados encontrados na literatura para $\mathrm{o} \mathrm{KH}_{2} \mathrm{PO}_{4}$ mostram maior resistência da espécie D. rerio em relação às demais. Num estudo envolvendo os moluscos mexilhão zebra (Dreissena polymorpha) e amêijoa-asiática (Corbicula fluminea), Fisher et al. (1991) encontraram valores de toxicidade muito distintos para esses organismos próximos, sendo a $\mathrm{CL}_{50}$ encontrada para o D. polymorpha igual a $92 \mathrm{mg} / \mathrm{L}$ e para o $C$. fluminea não foi possível encontrar mortalidade para concentrações até $2000 \mathrm{mg} / \mathrm{L}$ de $\mathrm{KH}_{2} \mathrm{PO}_{4}$ em 24 horas de exposição. Para facilitar a compreensão e comparação entre os resultados de toxicidade encontrados neste estudo com os presentes na literatura, também calculou-se a $\mathrm{CL}_{50}$ do $\mathrm{KH}_{2} \mathrm{PO}_{4}$ em 24 horas de exposição do peixe e do caramujo (Figura 15).

Figura 15: Comparação entre concentrações Letais (CLs ${ }_{50}$ ) do fosfato em diferentes espécies em 24 horas de exposição com intervalos de confiança, quando informados (unidades em $\mathrm{mg} / \mathrm{L}$ ). Dados obtidos no presente estudo(*) com a de outros estudos.

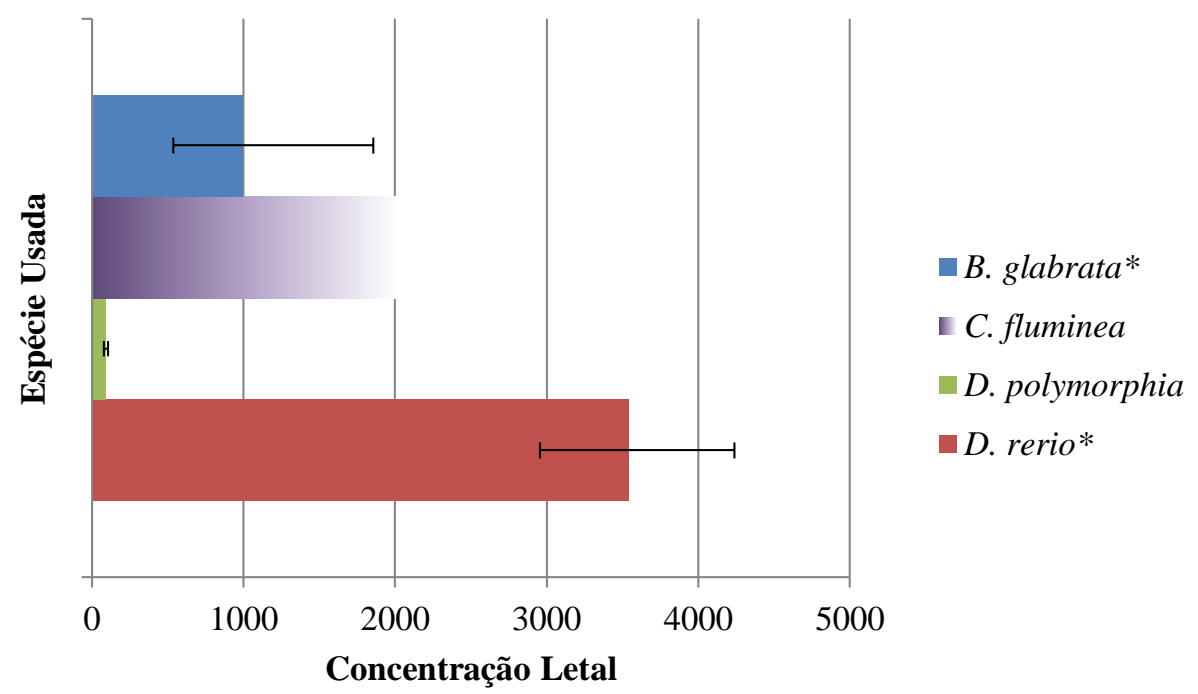

Fonte: FISHER et al., 1991.

Em outros trabalhos onde o objetivo não era analisar a sobrevivência, mas sim o crescimento e a alimentação de trutas arco-íris (Oncorhynchus mykiss), Satoh et al. (1993) perceberam que entre os compostos fosfatados testados, envolvendo o fosfato de cálcio, o fosfato de sódio e o fosfato de potássio, os que apresentaram maior mortalidade de organismos foram as variações do fosfato de sódio $\left(\mathrm{NaH}_{2} \mathrm{PO}_{4}\right.$ e $\left.\mathrm{Na}_{2} \mathrm{HPO}_{4}\right)$ seguido das variações do fosfato de potássio 
$\left(\mathrm{KH}_{2} \mathrm{PO}_{4}\right.$ e $\left.\mathrm{K}_{2} \mathrm{HPO}_{4}\right)$, além da taxa de crescimento dos organismos terem sido menores quando expostos ao fosfato de potássio.

Além desses autores, Reish (1970) trabalhando com tolerância de poliquetas das espécies Nereis grubei, Neanthes arenaceodentata, Dorvillea articulata e Capitella capitata ao fosfato, usou a substância $\mathrm{KH}_{2} \mathrm{PO}_{4}$ como fonte de fosfato para o experimento e obteve valores médios de tolerância iguais a $0,920 \mathrm{mg} / \mathrm{L}, 1,900 \mathrm{mg} / \mathrm{L}, 2,100 \mathrm{mg} / \mathrm{L}$ e 2,400 mg/L, respectivamente para as espécies, tendo sido observado mortalidade para as 3 primeiras espécies nas concentrações de 0,9 $\mathrm{mg} / \mathrm{L}$ e para a última na de 1,2 mg/L. Esses dados mostram que a toxicidade da substância tente aumentar em função do tempo de exposição.

A notável falta de trabalhos envolvendo a toxicidade aguda das formas do fosfato de potássio para as espécies aquáticas foi o que levou a utilizar dados também de toxicidade crônica para esta seção. A provável carência de dados com relação a essa substância pode estar associado ao fato desta não ser considerada tóxica pelos órgãos de proteção e controle ambiental, sendo até recomendado como solução tampão para cultivo de organismos aquáticos (USEPA, 1975).

A toxicidade do $\mathrm{KH}_{2} \mathrm{PO}_{4}$ pode estar intimamente relacionada ao potássio quando vê-se nos resultados nas Tabelas 12 e 13 que a $\mathrm{CL}_{50}$ encontrada para este elemento destaca das encontradas para o $\mathrm{PO}_{4}{ }^{3-}$ e do próprio $\mathrm{KH}_{2} \mathrm{PO}_{4}$. No experimento de Fisher et al. (1991), os autores chegaram à mesma conclusão quando expuseram o D. polymorpha também ao ácido fosfórico $\left(\mathrm{H}_{3} \mathrm{PO}_{4}\right)$ como critério para analisar a toxicidade do fosfato isoladamente e não obtiveram nenhuma mortalidade até concentrações de $640 \mathrm{mg} / \mathrm{L}$. Satoh et al. (1993) também não encontraram nenhuma alteração no desenvolvimento da truta arco-íris quando expostas ao $\mathrm{H}_{3} \mathrm{PO}_{4}$, tendo sido até obtido sobrevivência de 91,5\% dos organismos ao final do teste.

Para o fertilizante comercial, a toxicidade observada somente nos caramujos na concentração de $3000 \mathrm{mg} / \mathrm{L}$ do superfosfato simples pode ser vista a partir do momento em que Vieira e Ramos (1999) dizem que quando a concentração de cálcio na água está acima de 120 mg/L, fertilizantes fosfatados tendem a precipitar. Como pôde ser observado na Tabela 17, já na diluição de $500 \mathrm{mg} / \mathrm{L}$ as concentrações de cálcio superavam $158 \mathrm{mg} / \mathrm{L}$, promovendo assim a precipitação do fosfato presente na água. Como a espécie B. glabrata possui hábito bentônico, a sua mortalidade pode ter sido explicada em virtude da decantação da substância. Além disso, mesmo a presença de cálcio na água sendo benéfica para a formação da concha do caramujo, a 
espécie B. glabrata somente consegue suportar concentrações de até $129 \mathrm{mg} / \mathrm{L}$ de cálcio (BRASIL, 2007b).

Em um estudo onde também buscou-se observar a toxicidade do fosfato para organismos aquáticos de 3 níveis tróficos diferentes (peixe, alga e cladócero), envolvendo os compostos fosfato tricálcico $\left(\mathrm{Ca}_{3}\left(\mathrm{PO}_{4}\right)_{2}\right)$ e o hidrogenofosfato de cálcio $\left(\mathrm{CaHPO}_{4}\right)$, Kim et al. (2013) não conseguiram estipular precisamente a toxicidade do fosfato para os organismos testados devido a baixa solubilidade do fosfato impedir a realização de ensaios em concentração acima de 100 mg/L. Problemas parecidos tiveram também Fisher et al. (1991) quando tentaram determinar a toxicidade do $\mathrm{KH}_{2} \mathrm{PO}_{4}$ em águas naturais, onde houve precipitação do composto na presença de cálcio em $\mathrm{Ca}_{2} \mathrm{PO}_{4}$.

Tanto no presente estudo, quanto no trabalho dos autores citados acima é possível notar que existe uma dificuldade em se determinar a toxicidade do fosfato para os organismos aquáticos devido à baixa solubilidade desse composto e sua tendência em precipitar na presença de cálcio. Como nos ensaios realizados com o $\mathrm{KH}_{2} \mathrm{PO}_{4}$ a disponibilidade de cálcio na água era pequena, advinda somente da água de diluição, não houve precipitação do fosfato e, com isso sua toxicidade foi melhor definida do que no superfosfato.

Em outro estudo realizado por Omoregie et al. (2009), onde buscou-se definir a toxicidade do superfosfato para a tilápia do Nilo (Oreochromis niloticus), os autores conseguiram definir a $\mathrm{CL}_{50}$ para a espécie igual a $3760 \mathrm{mg} / \mathrm{L}$ em 96 horas de exposição. Os autores ainda reportaram que as primeiras mortalidades ocorreram a partir da concentração de $3500 \mathrm{mg} / \mathrm{L}$. Frente a esses resultados encontrados por Omoregie et al. (2009), é possível deduzir que para o D. rerio também somente seria encontrada mortalidade em concentrações acima de $3000 \mathrm{mg} / \mathrm{L}$ de superfosfato simples (Figura 16).

Devido aos poucos dados encontrados na literatura disponível relativos a toxicidade do superfosfato simples para organismos aquáticos, foi pesquisado nas bases de dados Pesticide info (http://www.pesticideinfo.org/) e Ecotox database (http://cfpub.epa.gov/ecotox/) valores de CL $_{50}$ para superfosfatos, em geral, limitando os resultados para ilustrarem somente organismos aquáticos e ensaios de 96 horas de exposição. Os resultados desta nova busca mostraram que o superfosfato tende a ser mais tóxico em altas concentrações, sendo encontrado $\mathrm{CL}_{50}$ igual a 1520 $\mathrm{mg} / \mathrm{L}$ para a larva e inseto aquático Chironomus yoshimatsui e $2280 \mathrm{mg} / \mathrm{L}$ e $3000 \mathrm{mg} / \mathrm{L}$ para os 
caramujos de água doce Viviparus bengalensis e Radix luteola, respectivamente (KEGLEY et al., 2014; USEPA, 2015).

Figura 16: Comparação entre concentrações Letais (CLs ${ }_{50}$ ) do superfosfato simples em diferentes espécies em 96 horas de exposição com intervalos de confiança, quando informados (unidades em mg/L). Dados obtidos no presente estudo(*) com a de outros estudos.

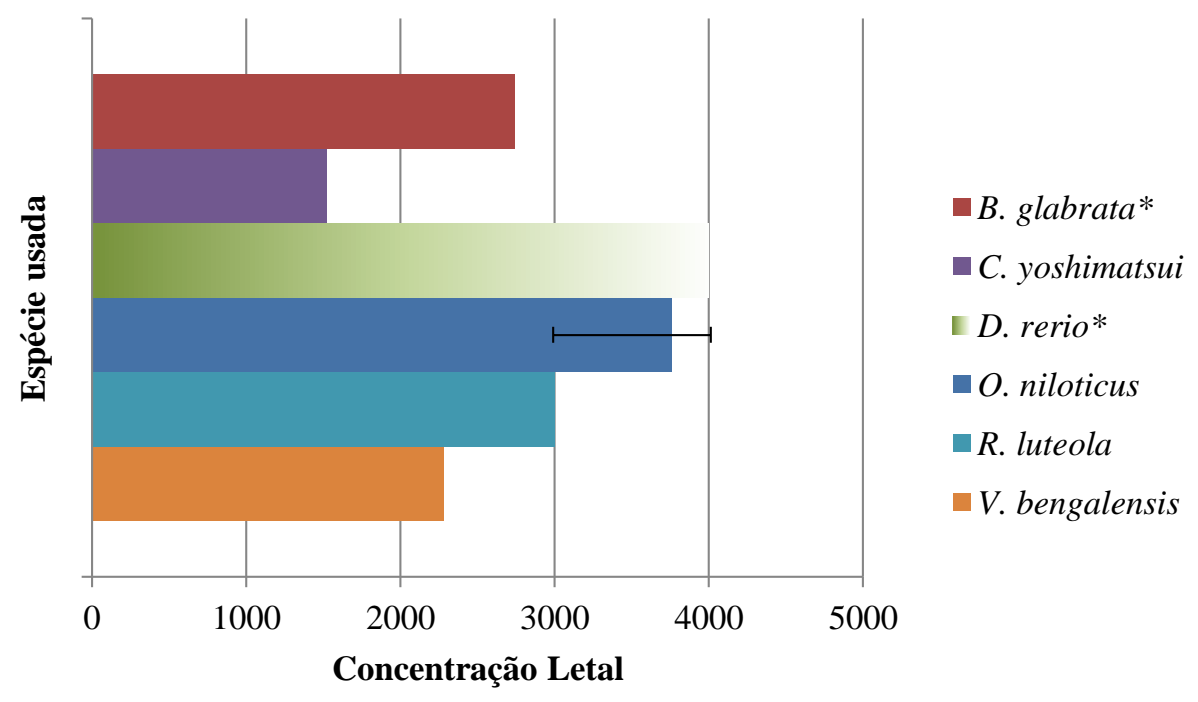

Fonte: OMOREGIE et al., 2009; KEGLEY et al, 2014; USEPA, 2015.

$\mathrm{Na}$ agricultura, o fósforo é conhecido por ser pouco solúvel no solo (LOPES; GUILHERME, 1994; LOPES, 1999; VIEIRA, RAMOS, 1999), contudo dados de 1994 da Associação Nacional para Difusão de Adubos (ANDA) mostraram que o solo de Cerrado é pobre neste nutriente, contendo menos de $2 \mu \mathrm{g}$ de P/mL de solo (LOPES; GUILHERME, 1994). Logo, a recomendação é o uso de altas quantidades deste fertilizante até mesmo acima da recomendada, que são de até $160 \mathrm{~kg}$ de $\mathrm{P}_{2} \mathrm{O}_{5} / \mathrm{ha}$ ao ano para as principais culturas no Cerrado, para ter maior disponibilidade deste no solo (ALVES et al, 1999a; ALVES et al, 1999b; CHAGAS et al, 1999; GUIMARÃES et al, 1999; NOVAIS, 1999; SOUSA, LOBATO, 2004b; SOUSA, LOBATO, REIN, 2004), aumento o risco de perda deste por escoamento.

\subsection{Toxicidade dos Elementos}

Os dados da toxicidade dos elementos individualmente nos testes com os reagentes mostraram que o $B$. glabrata tende a ser mais resistente ao potássio isoladamente, uma vez que a 
publicação do Ministério da Saúde para controle de moluscos (BRASIL, 2007b) mostra que a espécie é resistente a concentrações entre 0,1 a $54,5 \mathrm{mg} / \mathrm{L}$ de potássio, sendo que neste estudo todas as CL50's calculadas para o B. glabrata, bem como seus limites de intervalo de confiança, ficaram acima deste valor.

Quando comparada a toxicidade obtida nos testes deste estudo com outros na literatura, os caramujos testados apresentaram maior $\mathrm{CL}_{50}$ ao potássio no teste de $48 \mathrm{~h}$ do que no teste realizado por Freitas e Rocha (2011) com o cladócero Pseudosida ramosa e valores dentro do intervalo de confiança ao obtido por Romano e Zeng (2007a) para o caranguejo de água salgada Portunus pelagicus nos testes realizados com $\mathrm{KCl}$ e $\mathrm{KNO}_{3}$ em 96 horas de exposição. Todavia todos estes ficaram abaixo do $D$. rerio para o $\mathrm{KCl}, \mathrm{KNO}_{3}$ e $\mathrm{KH}_{2} \mathrm{PO}_{4}$ e dos resultados obtidos por Vijayavel e Balasubramanian (2007) para a tilápia de Moçambique (Oreochromis mossambicus) no teste de 96 horas. Mostrando que numa escala de tolerância ao potássio, o P. ramosa como o mais sensível, seguido do B. glabrata e o P. pelagicus e, como mais resistente, os peixes $D$. rerio e $O$. mossambicus (Figura 17).

Figura 17: Comparação entre concentrações Letais (CLs ${ }_{50}$ ) do potássio em diferentes espécies em 48 e 96 horas de exposição com intervalos de confiança, quando informados (unidades em mg/L). Dados obtidos no presente estudo(*) com a de outros estudos.

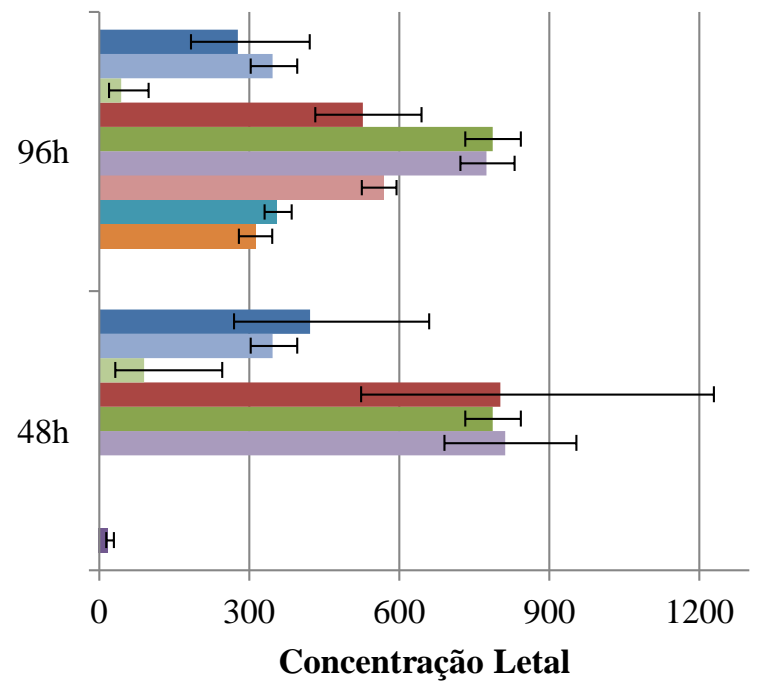

$$
\begin{aligned}
& \text { B. glabrata }(\mathrm{KCl}-\mathrm{K})^{*} \\
& \text { B. glabrata }(\mathrm{KNO} 3-\mathrm{K})^{*} \\
& \text { B. glabrata }(\mathrm{KH} 2 \mathrm{PO} 4-\mathrm{K})^{*} \\
& \square . \text { rerio }(\mathrm{KCl}-\mathrm{K})^{*} \\
& \square . \text { rerio }(\mathrm{KNO} 3-\mathrm{K})^{*} \\
& \square . \text { rerio }(\mathrm{KH} 2 \mathrm{PO} 4-\mathrm{K})^{*} \\
& \square . \text { mossambicus }(\mathrm{HKO}-\mathrm{K}) \\
& \square . \text { pelagicus }(\mathrm{KCl}-\mathrm{K}) \\
& \square . \text { pelagicus }(\mathrm{KNO} 3-\mathrm{K}) \\
& \square . \text { ramosa }(\mathrm{KCl}-\mathrm{K})
\end{aligned}
$$

Fonte: ROMANO, ZENG , 2007a; VIJAYAVEL, BALASUBRAMANIAN, 2007; FREITAS, ROCHA, 2011.

Para o nitrogênio, diferentes formas deste possuíram diferentes valores de toxicidade para as espécies, sendo que o nitrogênio na forma de amônia $\left(\mathrm{NH}_{3}\right)$ ou amônio $\left(\mathrm{NH}_{4}{ }^{+}\right)$geralmente é 
mais tóxico do que o nitrogênio na forma de nitrato $\left(\mathrm{NO}_{3}{ }^{-}\right)$(ALONSO, CAMARGO, 2003; CAMARGO, ALONSO, SALAMANCA, 2005; HAMLIN, 2006).

As espécies B. glabrata e D. rerio demonstraram ser mais sensíveis do que outras espécies ao $\mathrm{NO}_{3}{ }^{-}$quando somente comparados testes realizados com o nitrato de sódio $\left(\mathrm{NaNO}_{3}\right)$ nos outros organismos. Como exemplo pode-se citar o teste realizado por Alonso e Camargo (2003) com o caramujo de água doce Potamopyrgus antipodarum que teve $\mathrm{CL}_{50}$ igual a 1042 mg/L, o teste conduzido por Hamlin (2006) com o esturjão-siberiano (Acipenser baeri) que teve toxicidade igual a $1028 \mathrm{mg} / \mathrm{L}$, o caranguejo de água salgada $P$. pelagicus com $\mathrm{CL}_{50}$ igual a 3452 mg/L para o $\mathrm{NaNO}_{3}$ como fonte de nitrato (ROMANO; ZENG, 2007a) e também para outra espécie de caranguejo de água salgada, Scylla serrata, onde a toxicidade encontrada foi igual a 3601 mg/L (ROMANO; ZENG, 2007b), todos esses testes com 96 horas de exposição. Com os resultados de 48 horas de exposição, houve somente diferença quando comparado com os valores de $\mathrm{CL}_{50}$ obtidos para o A. baeri novamente (CL50 igual a $\left.1443 \mathrm{mg} / \mathrm{L}\right)$ (HAMLIN, 2006) e o peixe de água doce $P$. promelas ( $\mathrm{CL}_{50}$ igual a $\left.1341 \mathrm{mg} / \mathrm{L}\right)$, mas sem diferença para os cladóceros $C$. dubia e D. magna (CL50 igual a $374 \mathrm{mg} / \mathrm{L}$ e $462 \mathrm{mg} / \mathrm{L}$, respectivamente) encontrados por Scott e Crunkilton (2000) devido aos limites do intervalo de confiança.

Quando comparado os resultados com o $\mathrm{KNO}_{3}$ como fonte doadora de $\mathrm{NO}_{3}{ }^{-}$para os testes, o B. glabrata e o D. rerio mostraram-se mais resistentes quando comparado com o trabalho de Romano e Zeng (2007a), mas agora com o $\mathrm{KNO}_{3}$ como fonte doadora de nitrato para o ensaio, onde a toxicidade obtida pelos autores foi igual a $112 \mathrm{mg} / \mathrm{L}$ para o $P$. pelagicus e para o peixe barrigudinho (P. reticulata) nos ensaios de Rubin e Elmaraghy (1977), onde a toxicidade foi igual a $191 \mathrm{mg} / \mathrm{L}$ no teste com 96 horas de exposição. Todos esses valores abaixo do limite do intervalo de confiança encontrado para o B. glabrata e para o D. rerio (Figura 18).

Esses valores tanto no presente estudo, quanto nos trabalhos analisados na literatura mostram como o $\mathrm{K}^{+}$pode interferir na toxicidade do $\mathrm{NO}_{3}{ }^{-}$, sendo o nitrato melhor tolerado pelos organismos aquáticos quando expostos junto com o sódio (como no caso do $\mathrm{NaNO}_{3}$ ) do que com o potássio (como no caso do $\mathrm{KNO}_{3}$ ), tendo sido inclusive mostrado por Romano e Zeng (2007b) que a toxicidade do nitrato é maximizada na presença de $\mathrm{K}^{+}$comparando a sensibilidade do $S$. serrata e do $P$. pelagicus ao $\mathrm{NaNO}_{3}$ sozinho e em uma mistura desta substância com o $\mathrm{KCl}$, onde os valores de $\mathrm{CL}_{50}$ foram menores na mistura do que na substância de nitrato de sódio somente com água de diluição. 
Figura 18: Comparação entre concentrações Letais ( $\left.\mathrm{CLs}_{50}\right)$ do nitrogênio em diferentes espécies em 48 e 96 horas de exposição com intervalos de confiança, quando informados (unidades em $\mathrm{mg} / \mathrm{L}$ ). Dados obtidos no presente estudo(*) com a de outros estudos.

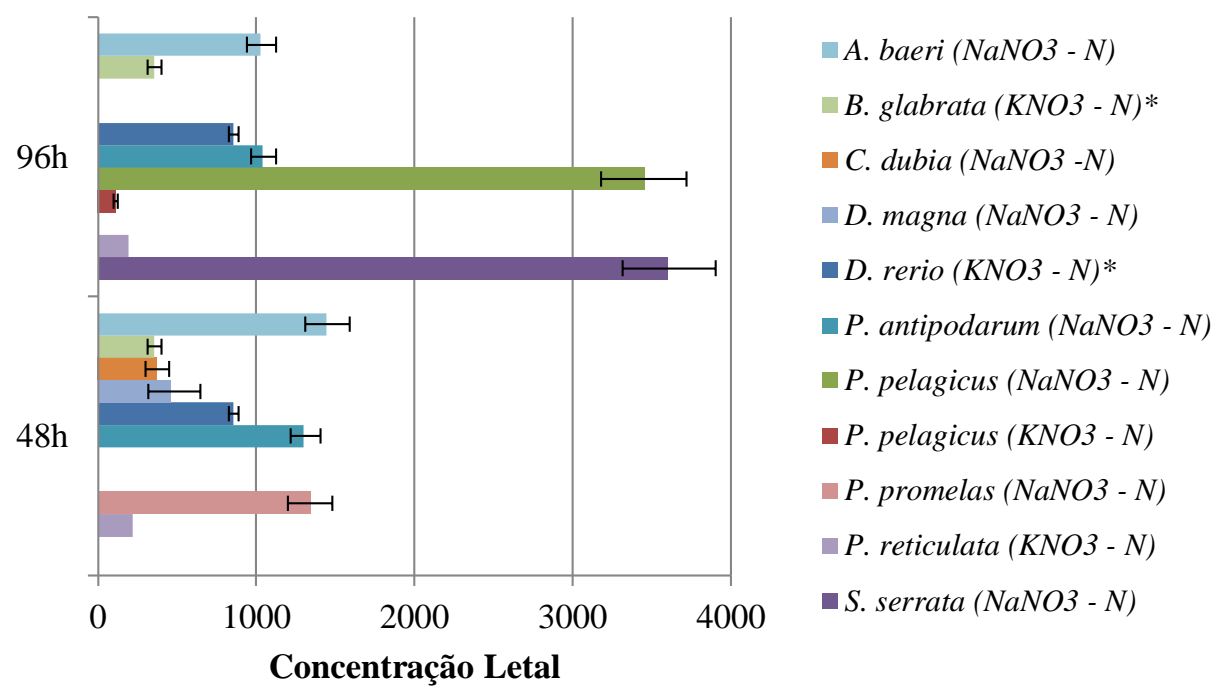

Fonte: RUBIN, ELMARAGHY, 1977; SCOTT, CRUNKILTON, 2000; ALONSO, CAMARGO, 2003; HAMLIN, 2006; ROMANO, ZENG , 2007a, 2007b.

Os dados de toxicidade para o $\mathrm{NH}_{4}{ }^{+}$mostraram maior sensibilidade da espécie $B$. glabrata em relação às demais, tendo o caramujo P. antipodarum no teste de Alonso e Camargo (2003) sido a segunda mais vulnerável, com $\mathrm{CL}_{50}$ igual a $2,23 \mathrm{mg} / \mathrm{L}$, seguido dos peixes pacu $(P$. mesopotamicus), com $\mathrm{CL}_{50}$ igual a $3,98 \mathrm{mg} / \mathrm{L}$ (BARBIERI; BONDIOLI, 2015), D. rerio e o barrigudinho ( $P$. reticulata), com valor de toxicidade igual a 93,9 mg/L (RUBIN; ELMARAGY, 1977), sendo esta última a espécie mais resistente ao $\mathrm{NH}_{4}{ }^{+}$se analisados somente os resultados de 48 horas (Figura 19).

Aos dados de 96 horas, devido ao grande intervalo de confiança que se teve para o $B$. glabrata, não foi possível ver diferença desse organismo para os demais, sendo somente o $P$. reticulata ainda sendo o mais resistente. 
Figura 19: Comparação entre concentrações Letais $\left(\mathrm{CLs}_{50}\right)$ do amônio em diferentes espécies em 48 e 96 horas de exposição com intervalos de confiança, quando informados (unidades em $\mathrm{mg} / \mathrm{L}$ ). Dados obtidos no presente estudo $(*)$ com a de outros estudos.

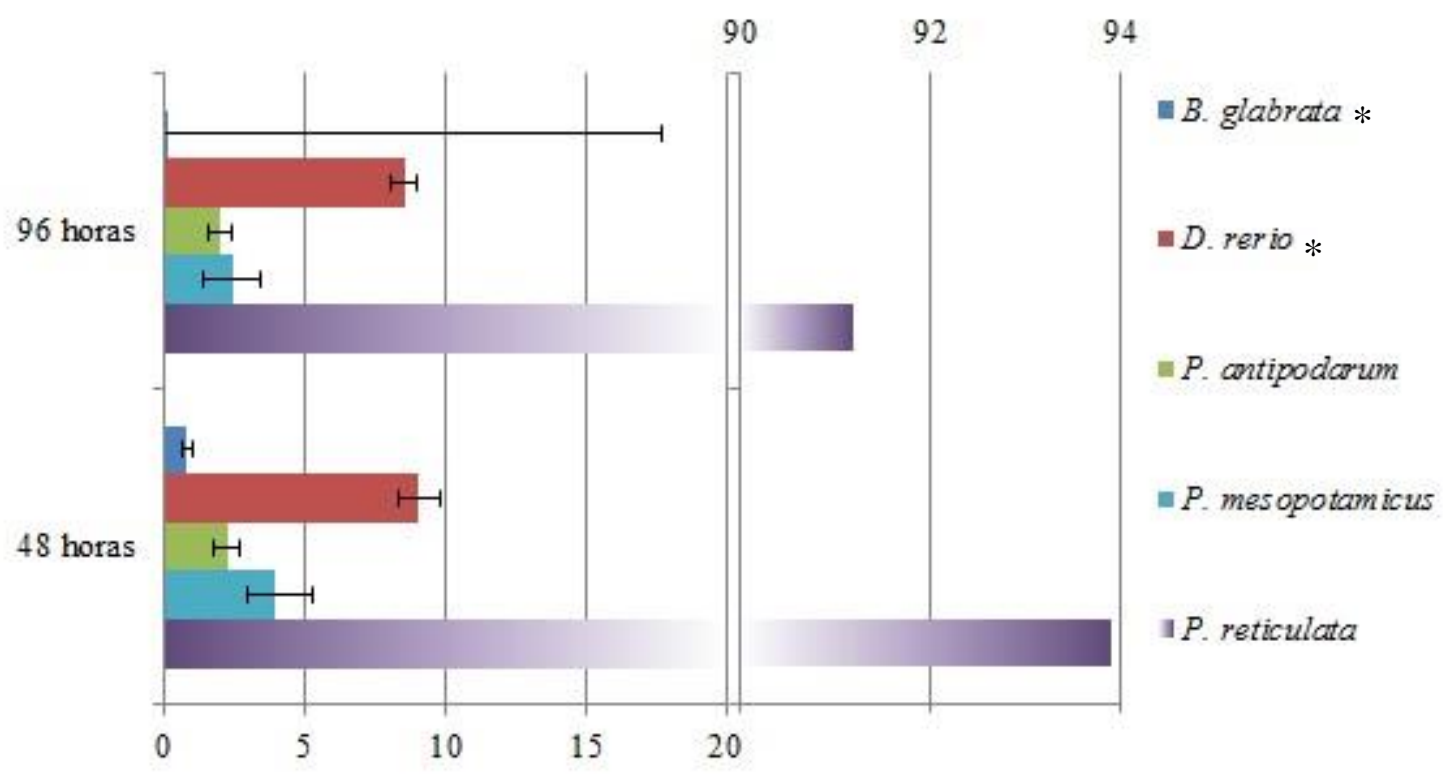

Fonte: RUBIN, ELMARAGHY, 1977; ALONSO, CAMARGO, 2003; BARBIERI; BONDIOLI, 2015.

A maior sobrevivência dos peixes ao amônio em relação às outras espécies pode ser decorrente do fato de estes organismos serem mais suscetíveis à forma da amônia não ionizada $\left(\mathrm{NH}_{3}\right)$ do que sua fora ionizada, ou amônio $\left(\mathrm{NH}_{4}{ }^{+}\right)$, uma vez que as membranas dos peixes são mais permeáveis ao $\mathrm{NH}_{3}$ do que ao $\mathrm{NH}_{4}{ }^{+}$(CAMARGO; ALONSO, 2006, MARTINEZ; AZEVEDO; WINKALER, 2006). Esse fato se torna claro quando são analisados trabalhos que tiveram como objetivo comparar a toxicidade do $\mathrm{NH}_{3}$ com o $\mathrm{NH}_{4}^{+}$em peixes, sendo as concentrações letais calculadas para $\mathrm{o}_{3}$ já nas primeiras 24 horas de exposição variando de 0,023 a 0,85 mg/L em função da espécie de peixe exposta (MARTINEZ, AZEVEDO, WINKALER, 2006; BARBIERI, BONDIOLI, 2015).

A extrema vulnerabilidade do B. glabrata ao amônio presente na ureia não foi esperada, uma vez que é sabido que esta espécie pode sobreviver em concentrações de 0,1 a 2,6 mg/L de $\mathrm{NH}_{3}$ (BRASIL, 2007b) e que outras espécies de caramujos quando foram expostas a fontes de amônio tanto oriundas de reagentes (como o sulfato de amônio), quanto de fertilizantes (como a ureia) não obtiveram a mesma mortalidade que a espécie obteve neste estudo, sendo reportados valores de toxicidade de 490,79 a 700,73 mg/L para o sulfato de amônio (TCHOUNWOU; ENGLANDE JR; MALEK, 1991) e de 48,86 a 54,86 mg/L para a ureia (ESHRA, 2014). 
Devida a falta de trabalhos na bibliografia disponível abordando sobre a toxicidade do fosfato, novamente foi necessário o uso das bases de dados Pesticide info e Ecotox database para encontrara valores de $\mathrm{CL}_{50}$ para ter-se um critério de comparação deste estudo com outros. Os critérios de busca foram pelas substâncias $\mathrm{H}_{3} \mathrm{PO}_{4}, \mathrm{Na}_{2} \mathrm{HPO}_{4}, \mathrm{NaH}_{2} \mathrm{PO}_{4}, \mathrm{CaHPO}_{4}, \mathrm{Ca}\left(\mathrm{H}_{2} \mathrm{PO}_{4}\right)_{2}$ e $\mathrm{Ca}_{3}\left(\mathrm{PO}_{4}\right)_{2}$ por serem fontes de fosfato quando diluídas e buscou-se somente testes que englobassem o período de 48 e 96 horas de exposição.

Os dados de toxicidade para o $\mathrm{PO}_{4}{ }^{3-}$ mostraram que existe certa dificuldade em definir a toxicidade deste íon para os organismos aquáticos e que, provavelmente, sua interação com outros compostos pode interferir na sua toxicidade, como foi destacado por Fisher et al. (1991). Kim et al. (2013) não conseguiram definir a toxicidade do $\mathrm{PO}_{4}{ }^{3-}$ para o peixe anfídromo Oryzias latipes e para o cladócero D. magna usando o $\mathrm{CaHPO}_{4}$ e $\mathrm{Ca}_{3}\left(\mathrm{PO}_{4}\right)_{2}$ como fonte de fosfato, contudo quando interage com o sódio, o fosfato aparenta ser menos tóxico do que as demais variações, uma vez que foram encontrados valores de toxicidade iguais a $3580 \mathrm{mg} / \mathrm{L}$ para $D$. magna e $720 \mathrm{mg} / \mathrm{L}$ para o alevino do peixe-mosquito (Gambusia affinis) em ensaios de 48 horas (Figura 20). A forma mais tóxica do fosfato aparenta estar no ácido fosfórico $\left(\mathrm{H}_{3} \mathrm{PO}_{4}\right)$, tendo sido encontrado valores de toxicidade iguais a $60 \mathrm{mg} / \mathrm{L}$ e $87 \mathrm{mg} / \mathrm{L}$ para a perca do sol $(L$. macrochirus) e a truta arco-íris (Oncorhynchus mykiss), respectivamente, em ensaios de 96 horas e 138 mg/L para o G. affinis com 48 horas de exposição (KEGLEY et al., 2014; USEPA, 2015).

Para os dados do $\mathrm{KH}_{2} \mathrm{PO}_{4}$ encontrados no presente estudo, a espécie B. glabrata apresentou dados de toxicidade dentro dos limites de confiança que as demais espécies apresentaram para o $\mathrm{H}_{3} \mathrm{PO}_{4}$, contudo o D. rerio demonstrou maior tolerância ao $\mathrm{KH}_{2} \mathrm{PO}_{4}$.

Frente aos resultados do presente estudo e aos encontrados na literatura, é possível notar que o fosfato presente no $\mathrm{Na}_{2} \mathrm{HPO}_{4}, \mathrm{NaH}_{2} \mathrm{PO}_{4}, \mathrm{CaHPO}_{4}, \mathrm{Ca}\left(\mathrm{H}_{2} \mathrm{PO}_{4}\right)_{2}$ e $\mathrm{Ca}_{3}\left(\mathrm{PO}_{4}\right)_{2}$ são menos tóxicos do que o presente no $\mathrm{KH}_{2} \mathrm{PO}_{4}$ e no $\mathrm{H}_{3} \mathrm{PO}_{4}$ quando são analisados somente dados de toxicidade aguda. Entretanto, vale destacar que os dados de toxicidade crônica para O. mykiss mostrados por Satoh et al. (1993) mostraram o contrário dos vistos para a toxicidade aguda, onde a longo prazo a mortalidade foi maior nas variedades de fosfato de sódio e de potássio testadas, tendo a sobrevivência sido maior nas variedades de ácido fosfórico e fosfato de cálcio, mas com crescimento reduzido na última. 
Figura 20: Comparação entre concentrações Letais $\left(\mathrm{CLs}_{50}\right)$ do fosfato de diversas substâncias em diferentes espécies em 48 e 96 horas de exposição com intervalos de confiança, quando informados (unidades em mg/L). Dados obtidos no presente estudo com a de outros estudos.

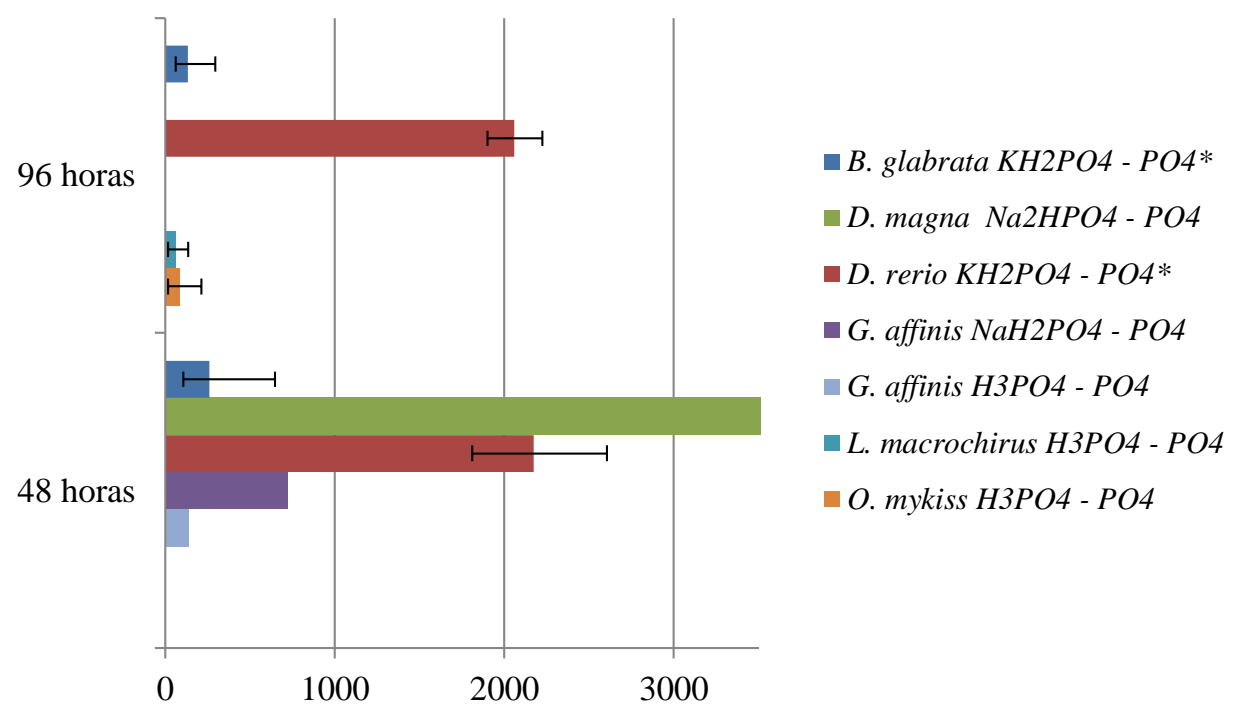

Fonte: KEGLEY et al, 2014; USEPA, 2015.

Salienta-se que para todos os testes ecotoxicológicos comparados nesta seção, as diferenças de toxicidades observadas podem não estar somente ligadas a substância ou ao composto em si, mas também à fase de vida do organismo utilizado para o ensaio, onde é conhecido que organismos mais jovens tendem a ser mais suscetíveis do que organismos adultos (SCOTT, CRUNKILTON, 2000; USEPA, 2002; CAMARGO, ALONSO, SALAMANCA, 2005).

Trabalhos que abordem a ação dessas substâncias isoladamente são importantes dentro da literatura, pois a interação dos elementos no ambiente pode induzir a toxicidade de outros (OLIVEIRA-FILHO, 2013), como o potássio, onde já foi observado que quando na forma iônica, eleva a toxicidade de outros elementos, como o nitrato (ROMANO; ZENG, 2007a) e que as diferentes formas do nitrogênio solúvel podem definir seu impacto no ambiente (CAMARGO; ALONSO, 2006; MARTINEZ, AZEVEDO, WINKALER, 2006; BARBIERI, BONDIOLI, 2015). Outro estudo mostrou que o cádmio, quando em solução aquosa, tem o seu efeito tóxico maximizado dependendo da concentração de cálcio na água (PENTTINEN et al., 2011), além de ter sido visto neste estudo e em outros que o cálcio diluído pode reduzir a toxicidade do fosfato ao promover a precipitação deste (FISHER et al., 1991; KIM et al., 2013). 


\section{CONCLUSÕES}

Diante do apresentado, pode-se concluir que os fertilizantes $\mathrm{KCl}, \mathrm{KNO}_{3}$ e ureia possuem efeitos tóxicos para o B. glabrata e o D. rerio, sendo este mais suscetível ao $\mathrm{KCl}$ presente no fertilizante e aquele aos demais compostos. Quanto ao superfosfato simples, não foi encontrado valores de toxicidade significativos a este frente ao que normalmente é utilizado na agricultura.

Além disso, os bioensaios demonstraram servir de complemento às análises químicas na definição de parâmetros ambientais sobre os efeitos adversos do elemento presente nos compostos testados para o ambiente e os organismos, sendo que a espécie B. glabrata foi a que demonstrou ser mais sensível aos compostos com nitrogênio presente na composição em suas diferentes formas tanto como $\mathrm{NO}_{3}{ }^{-}$, quanto $\mathrm{NH}_{4}{ }^{+}$, além de ser mais suscetível ao $\mathrm{PO}_{4}{ }^{3-}$ presente no $\mathrm{KH}_{2} \mathrm{PO}_{4}$ e também no superfosfato simples, mas somente em altas concentrações neste último por causa da decantação do $\mathrm{PO}_{4}{ }^{3-}$.

Por sua vez o $D$. rerio mostrou ser mais sensível ao potássio presente no fertilizante comercial não somente em virtude deste composto, mas também por causa das impurezas contidas neste e baseado na sensibilidade que a espécie possui ao processo de salinização.

Não foi possível estabelecer uma diferença na toxicidade do fertilizante comercial para o seu reagente químico devido a alguns casos não existir diferenças entre ambos, como aconteceu com a ureia para a espécie $D$. rerio, ou em outros casos uma espécie ser mais suscetível ao fertilizante e outra ao reagente, como foi para o $\mathrm{KCl}$, onde o peixe foi mais suscetível ao fertilizante e o caramujo ao reagente, e para o $\mathrm{KNO}_{3}$, onde aconteceu o inverso ao descrito.

Como qualquer análise de risco feita neste estudo, sempre existirá um nível de incerteza associado às avaliações feitas. Esta incerteza certamente é um erro que mais superestima do que subestima o potencial risco dos fertilizantes, mas ainda devem ser levadas em consideração e analisadas criticamente à luz das ações a serem traçadas.

Os riscos dos fertilizantes para os ecossistemas e também para a saúde humana ocorrem em função da quantidade e da frequência em que esses compostos são usados no solo, sendo isso dependente de vários fatores, como a composição do fertilizante, a concentração de cada elemento neste (não somente dos nutrientes, mas também de metais pesados) e a quantidade de fertilizante aplicado no solo. 
Para trabalhos futuros recomenda-se a realização de ensaios de toxicidade crônica como forma de complementar os resultados de toxicidade aguda, pois muitos dos elementos analisados, mesmo que não causem mortalidade imediata, podem afetar no desenvolvimento e reprodução dos organismos, caso este que foi visto na discussão das diversas formas do $\mathrm{PO}_{4}{ }^{3-}$, onde a toxicidade deste parece diferir em função tempo de exposição e mesmo que outras formas não tivessem valores de toxicidade aguda expressivo, terminaram influenciando em outros fatores como alimentação e crescimento. 


\section{REFERÊNCIAS}

AAPFCO (Association of American Plant Food Control Officials), Product Label Guide. 24p. 2012. Disponível em: <http://www.aapfco.org/pdf/label_guide_2012.pdf>. Acesso em: 05 mai. 2015.

ABBASI, T.; ABBASI, S. A. Water quality indices. Oxford: Elsevier, 2012.

ABNT (Associação Brasileira de Normas Técnicas). Ecotoxicologia aquática - Toxicidade aguda - Método de ensaio com peixes. NBR 15088. Rio de Janeiro: ABNT, 2004.

ALONSO, A.; CAMARGO, J. A. Short-term toxicity of ammonia, nitrite, and nitrate to the aquatic snail Potamopyrgus antipodarum (Hydrobiidae, Mollusca). Bulletin of Environmental Contamination and Toxicology, v. 70, n. 5, p. 1006-1012, 2003.

ALVES, V. M. C.; VASCONCELlOS, C. A.; FREIRE, F. M.; PITTA, G. V. E.; FRANÇA, G. E. Sorgo. In: RIBEIRO, A.C.; GUIMARÃES, P. T. G.; AlVAREZ, V. V. H. (Eds.) Recomendações para o uso de corretivos e fertilizantes em Minas Gerais. $5^{\text {a }}$ aproximação. Viçosa: Comissão de Fertilidade do Solo do Estado de Minas Gerais, 1999a.

ALVES, V. M. C.; VASCONCELlOS, C. A.; FREIRE, F. M.; PITTA, G. V. E.; FRANÇA, G. E.; RODRIGUES-FILHO, A.; ARAÚJO, J. M.; VIEIRA, J. R.; LOUREIRO, J. E. Milho. In: RIBEIRO, A.C.; GUIMARÃES, P. T. G.; ALVAREZ, V. V. H. (Eds.) Recomendações para o uso de corretivos e fertilizantes em Minas Gerais. $5^{\text {a }}$ aproximação. Viçosa: Comissão de Fertilidade do Solo do Estado de Minas Gerais, 1999b.

APHA (American Public Health Association). Standard methods for the examination of water and wastewater. 20 ed. Washington, DC, 1998.

BARBIERI, E.; BONDIOLI, A. C. V. Acute toxicity of ammonia in pacu fish (Piaractus mesopotamicus, Holberg, 1887) at different temperature levels. Aquaculture Research, v. 46, n. 3, p. 565-571, 2015.

BARBOSA, F. T.; BERTOL, I.; LUCIANO, R. V.; GONZALEZ, A. P.; VAZQUEZ, E. V. Teor de nitrogênio solúvel na água de erosão hídrica em cultura de aveia e ervilhaca em três formas de semeadura. Revista Brasileira de Ciência do Solo, v. 33, n. 2, p. 439-436, 2009.

BEDIN, I.; FURTINI NETO, A. E.; RESENDE, A. V.; FAQUIN, V.; TOKURA, A. M.; SANTOS, J. Z. L. Fertilizantes fosfatados e produção da soja em solos com diferentes capacidades tampão fosfato. Revista Brasileira de Ciência do Solo, v. 27, n. 4, p. 639-646, 2003. 
BELLAVERE, C.; GORBI, J. Comparative analysis of acute toxicity of chromium, copper and cadmium to Daphnia magna, Biomphalaria glabrata and Brachydanio rerio. Environmental Technology Letters, v. 2, n. 3, p. 119-128, 1981

BERTOL, O. J.; RIZZI, N. E.; FAVARETTO, N.; LANA, M. D. Phosphorus loss by surface runoff in no-till system under mineral and organic fertilization. Scientia Agricola, v. 67, n. 1, p. 71-77, 2010.

BERTOLETTI, E. Estatística aplicada em ensaios toxicológicos e ecotoxicológicos. In: SISINNO, C. L. S.; OLIVEIRA-FILHO, E. C. (Orgs.) Princípios de Toxicologia Ambiental. Rio de Janeiro: Interciência, 2013.

BRASIL, Ministério da Agricultura, Pecuária e Abastecimento. Instrução Normativa $n^{\circ}$ 5, de 23 de fevereiro de 2007. Diário Oficial da República Federativa do Brasil. Seção 1. Brasília, DF, 01 de março de 2007. p. 5-21. 2007a.

BRASIL, Ministério da Saúde. Secretaria de vigilância em saúde. Vigilância e controle de moluscos de importância epidemiológica, 2 ed., Brasília: Editora do Ministério da Saúde, 2007b.

BRASIL, Casa Civil. Lei $\mathrm{n}^{\circ} 11.794$, de 8 de outubro de 2008. Diário Oficial da República Federativa do Brasil. Seção 1. Brasília, DF, 09 de outubro de 2008. p. 1-2. 2008.

BRASIL, Ministério de Minas e Energia. Departamento Nacional da Produção Mineral. Potássio - Sumário mineral 2014. 2014.

Disponível em: <http://www.dnpm.gov.br/dnpm/sumarios/potassio-sumario-mineral-2014/view>. Acesso em: 05 mai. 2015

BURATINI, S. V.; BERTOLETTI, E. Análise Estatística. In: ZAGATTO, P. A.; BERTOLETTI, E. (Eds.) Ecotoxicologia aquática: Princípios e aplicações. São Carlos: Rima, 2006, p. 221249.

CAMARGO, J. A., AlONSO, A., SAlAmANCA, A. Nitrate toxicity to aquatic animals: a review with new data for freshwater invertebrates. Chemosphere, v. 58, n. 9, p. 1255-1267, 2005.

CAMARGO, J. A., ALONSO, A. Ecological and toxicological effects of inorganic nitrogen pollution in aquatic ecosystems: A global assessment. Environment International, v. 32, n. 6, p. 831-849, 2006.

CEREDA, M. P. Tecnologia para agricultura familiar. In: VILPOUX, O. (Org.) Sustentabilidade e Agricultura Familiar. Curitiba: CRD, 2011, p. 95-122. 
CETESB. Governo do Estado de São Paulo. Relatório de Estabelecimento de Valores Orientadores para Solos e Águas Subterrâneas no Estado de São Paulo - CETESB, 2001. Disponível em: <www.cetesb.sp.gov.br>. Acesso em 01 de Junho de 2013.

CFIA (Canadian Food Inspection Agency). Regulation of composts under the Fertilizer Act and regulations. 2014. Disponível em: <http://www.inspection.gc.ca/plants/fertilizers/tradememoranda/t-4-120/eng/1307910204607/1307910352783>. Acesso em: 05 mai. 2015

CHAGAS, J. M.; BRAGA, J. M.; VIEIRA, C.; SAlGADO, L. T.; NETO, A. J.; ARAÚJO, G. A. A.; ANDRADE, M. J. B.; LANA, R. M. Q.; RIBEIRO, A. C. Feijão. In: RIBEIRO, A.C.; GUIMARÃES, P. T. G.; ALVAREZ, V. V. H. (Eds.) Recomendações para o uso de corretivos e fertilizantes em Minas Gerais. $5^{\text {a }}$ aproximação. Viçosa: Comissão de Fertilidade do Solo do Estado de Minas Gerais, 1999.

COFIEL, L. P. V.; MATTIOLI, R. L-histidine enhances learning in stressed zebrafish. Brazilian Journal of Medical and Biological Research, v. 42, n. 1, p. 128-134, 2009.

CONLEY, D. J.; PAERL, H. W.; HOWARTH, R. W.; BOESCH, D. F.; SEITZINGER, S. P.; HAVENS, K. E.; LANCELOT, C.; LIKENS, G. E. Controlling eutrophication: nitrogen and phosphorus. Science, v. 323, p. 1014-1015, 2009.

DIEKOW, J.; MIELNICZUK, J.; KNICKER, H.; BAYER, C.; DICK, D. P.; KÖGELKNABNER, I. Soil C and N stocks as affected by cropping systems and nitrogen fertilization in a southern Brazil Acrisol managed under no-tillage for 17 years. Soil and Tillage Research, v. 81, n. 1, p. 87-95, 2005.

DOWDEN, B. F.; BENNET, H. J. Toxicity of selected chemicals to certain animals. Journal of Water Pollution Control Federation, v. 37, n. 9, p. 1308-1316, 1965.

DRISCOLL, C. T.; WHITALL, D.; ABER, J.; BOYER, E.; CASTRO, M.; CRONAN, C.; GOODALE, C. L.; GROFFMAN, P.; HOPKINSON, C.; LAMBERT, K.; LAWRENCE, G.; OLLINGER, S. Nitrogen Pollution in the northeastern United States: sources, effects and management options. American Institute of Biological Sciences. v.53 n. 4, 2003.

ESHRA, E. H. Toxicity of methomyl, copper hydroxide and urea fertilizer on some land snails. Annals of Agricultural Science, v. 59, n. 2, p. 281-284, 2014.

ESTEVES, F. A. Fundamentos de Limnologia. 2. Ed. Rio de Janeiro: Interciência, 1998.

FARIAS, T. R. L.; ARAÚJO, J. C. Modelagem hidrossedimentológica como ferramenta para manejo de pequenas bacias. In: LIMA, J. E. F. W.; LOPES, W. T. A. Engenharia de sedimentos: Na busca de soluções para problemas de erosão e assoreamento. Brasília: ABRH, 2011. p. 419-441. 
FISHER, S. W.; STROMBERG, P.; BRUNER, K. A.; BOULET, L. D. Molluscicidal activity of potassium to the zebra mussel, Dreissena polymorphia: toxicity and mode of action. Aquatic Toxicology, v. 20, n. 4, p. 219-234, 1991.

FRANKENBERGER JR, W. F.; MEHRA, H. C.; GJERD, D. T. Environmental applications of ion chromatography. Journal of Chromatography, v. 504, p. 211-245, 1990.

FREITAS, E. C.; ROCHA, O. Acute and chronic effects of sodium and potassium on the tropical freshwater cladoceran Pseudosida ramosa. Ecotoxicology, v. 20, n. 1, p.88-96, 2011.

GOMES, E. R. S.; SAMPAIO, S. C.; CORREA, M. M.; BOAS, M. A. V.; ALVES, L. F. A.; SOBRINHO, T. A. Movimento de nitrato proveniente de água residuária em colunas de solos. Engenharia Agrícola, v. 24, n. 3, p. 557-568, 2004.

GOMES, M. A. F.; BARIZON, R. R. M. Panorama da contaminação ambiental por agrotóxicos e nitrato de origem agrícola no Brasil: cenário 1992/2011. Embrapa Meio Ambiente, Jaguariúna, 2014.

Disponível em: <http://www.infoteca.cnptia.embrapa.br/bitstream/doc/987245/1/Doc98.pdf>. Acesso em: 05 mai. 2015.

GONÇALVES, C. S.; RHEINHEIMER, D. S.; PELLEGRINI, J. B. R.; KIST, S. L. Qualidade da água numa microbacia hidrográfica de cabeceira situada em região produtora de fumo. Revista Brasileira de Engenharia Agrícola e Ambiental, v. 9, n. 3, p. 391-399, 2005.

GUIMARÃES, P.T.G.; GARCIA, A. W. R.; ALVAREZ, V. H. V.; PREZOTTI, L.C.; VIANA, A. S.; MIGUEL, A. E.; MALAVOLTA, E.; CORREAA, J. B.; LOPES, A. S.; NOGUEIRA, F. D.; MONTEIRO, A. V. C. Cafeeiro. In: RIBEIRO, A.C.; GUIMARÃES, P. T. G.; ALVAREZ, V. V. H. (Eds.) Recomendações para o uso de corretivos e fertilizantes em Minas Gerais. $5^{\text {a }}$ aproximação. Viçosa: Comissão de Fertilidade do Solo do Estado de Minas Gerais, 1999.

HAMLIN, H. J. Nitrate toxicity in Siberian sturgeon (Acipenser baeri). Aquaculture, v. 253, n. 1, p. 688-693, 2006.

HAMILTON, M. A.; RUSSO, R. C.; THURSTON, R. V. Trimmed Spearman-Karber method for estimating median lethal concentrations in toxicity bioassays. Environmental Science and Technology, v. 11, p. 714-719, 1977.

HARLESS, M. L.; HUCKINS, C. J.; GRANT, J. B.; PYPKER, T. G. Effects of six chemical deicers on larval wood frogs (Rana sylvatica). Environmental Toxicology and Chemistry, v. 30, n. 7, p. 1637-1641, 2011.

IFA (International Fertilizer Industry Association). Assessment of fertilizer use by crop at the global level, Paris, IFA, 2013. Disponível em: 〈http://www.fertilizer.org>. Acesso em: 14 abr. 2014. 
IGNÁCIO, N. F.; AMÉRICO, J. H. P.; SILVA, M. A.; CARRASCHI, S. P.; IKEFUTI, C. V.; CRUZ, C.; MACHADO-NETO, J. G. Classificação ecotoxicológica do inseticida Fipronil para o peixe de espécie pacu. In: Anais do Congresso Nacional de Meio Ambiente de Poços de Caldas, v. 6, n. 1, 2014. Disponível em:

<http://meioambientepocos.com.br/portal/anais/2014/index.php>. Acesso em: 05 mai. 2015.

KEGLEY, S. E.; HILL, B. R.; CHOI, A. H. PAN Pesticide Database. Pesticide Action Network, Oakland, United States, 2014. Disponível em: < http://www.pesticideinfo.org/>. Acesso em: 05 mai. 2015.

KIM, E.; YOO, S.; RO, H. Y.; HAN, H. J.; BAEK, Y. W.; EOM, I. C.; KIM, H. M.; KIM, P.; CHOI, K. Aquatic toxicity assessment of phosphate compounds. Environmental Health and Toxicity, n. 28, p. 1-7, 2013.

KNIE, J. L. W.; LOPES, E. W. B. Testes Ecotoxicológicos: Métodos, técnicas e aplicações. Florianópolis: FATMA/GTZ, 2004.

KRULL, M.; BARROS, F. Key issues in aquatic ecotoxicology in Brazil: A critical review. Journal of the Brazilian Society of Ecotoxicology, v. 7, n. 2, p. 57-66, 2012.

LOPES, A. S.; COX, F. R. A survey of the fertility status of surface soils under "Cerrado" vegetation in Brazil. Soil Science Society of America Journal, v. 41, n. 4, p. 742-747, 1977.

LOPES, A. S.; GUILHERME, L. A. G. Solos sob Cerrado: Manejo da fertilidade para a produção agropecuária. 2. Ed. São Paulo: ANDA, 1994. Disponível em: <http://www.anda.org.br/multimidia/boletim_05.pdf>. Acesso em: 05 mai. 2015.

LOPES, A. S. Extratos de definições, conceitos e legislação sobre fertilizantes. In: RIBEIRO, A.C.; GUIMARÃES, P. T. G.; ALVAREZ, V. V. H. (Eds.) Recomendações para o uso de corretivos e fertilizantes em Minas Gerais. $5^{\text {a }}$ aproximação. Viçosa: Comissão de Fertilidade do Solo do Estado de Minas Gerais, 1999.

MARCATTO, C. Agricultura sustentável: alguns conceitos e princípios, 2006. Disponível em: <https://permacoletivo.files.wordpress.com/2008/05/cartilha-agricultura-sustentavel.doc>, acesso em 05 mai. 2015.

MARTINEZ, C. B. R.; AZEVEDO, F.; WINKALER, E. U. Toxicidade e efeitos da amônia em peixes neotropicais. In: CYRINO, J. E. P.; URBINATI, E. C. (Orgs). Tópicos Especiais em Biologia Aquática e Aqüicultura. Jaboticabal: Sociedade Brasileira Aqüicultura e Biologia aquática, p. 81-95, 2006.

MARTÍNEZ-BASTIDA, J. J.; ARAUZO, M.; VALLADOLID, M. Diagnóstico de la calidad ambiental del río Oja (La Rioja, España) mediante el análisis de la comunidad de macroinvertebrados bentónicos. Limnetica, v. 25, n.3, p. 733-744, 2006. 
MOUNT, D. R.; GUlleY, D. D.; HOCKETT, J. R.; GARRISON, T. D.; EVANS, J. M. Statistical models to predict the toxicity of major ions to Ceriodaphnia dubia, Daphnia magna and Pimephales promelas (fathead minnows). Environmental Toxicology and Chemistry, v. 16, n. 10, p. 2009-2019, 1997.

MORAES, G.; POLEZ, V. L. P.; IWAMA, G. K. Biochemical responses of two erythrinidae fish to environmental ammonia. Brazilian Journal of Biology, v. 64, n. 1, p. 95-102, 2004.

MOZETO, A. A.; ZAGATTO, P. A. Introdução de agentes químicos no ambiente. In: ZAGATTO, P. A.; BERTOLETTI, E. (Eds.) Ecotoxicologia aquática: Princípios e aplicações. São Carlos: Rima, 2006. p. 14-38.

MÜNZINGER, A. Biomphalaria glabrata (Say), a suitable organism for a biotest. Environmental Technology Letters, v. 8, n. 1-12, p. 141-148, 1987.

NOVAIS, R. F. Soja. In: RIBEIRO, A.C.; GUIMARÃES, P. T. G.; ALVAREZ, V. V. H. (Eds.) Recomendações para o uso de corretivos e fertilizantes em Minas Gerais. $5^{\text {a }}$ aproximação. Viçosa: Comissão de Fertilidade do Solo do Estado de Minas Gerais, 1999.

NUNES, R. S.; LOPES, A. A. C.; SOUSA, D. M. G.; MENDES, I. C. Sistemas de manejo e os estoques de carbono e nitrogênio em latossolo de cerrado com a sucessão soja-milho. Revista Brasileira de Ciência do Solo, v. 35, n. 4, p. 1407-1419, 2011.

OLIVEIRA, L. F. C.; MARTINEZ, M. A.; PRUSKI, F. F.; RUIZ, H. A; LIMA, L. A. Transporte de solutos no solo e no escoamento superficial: I - desenvolvimento do modelo e simulação do movimento de água e escoamento superficial. Revista Brasileira de Engenharia Agrícola e Ambiental, v. 4, n. 1, p. 63-69, 2000.

OLIVEIRA-FILHO, E. C.; LOPES, R. M.; PAUMGARTTEN, F. J. R. Comparative study on the susceptibility of freshwater species to copper-based pesticides. Chemosphere, v. 56, n. 4, p. 369374, 2004.

OLIVEIRA-FILHO, E. C.; GERALDINO, B. R.; GRISOLIA, C. K.; PAUMGARTTEN, F. J. R. Acute Toxicity of Endosulfan, Nonylphenol Ethoxylate and Ethanol to Different Life Stages of the Freshwater Snail Biomphalaria tenagophila (Orbigny, 1835). Bulletin of Environmental Contamination and Toxicology, v. 75, n.6, p. 1185-1190, 2005.

OLIVEIRA-FILHO, E. C.; GERALDINO, B. R.; GRISOLIA, C. K.; PAUMGARTTEN,F. J. R. Método Multigeração para avaliação dos efeitos de poluentes sobre a reprodução de caramujos de água doce. Journal of the Brazilian Society of Ecotoxicology, v. 1, n. 2, p. 115-118, 2006.

OLIVEIRA-FILHO, E. C.; PARRON, L. M. Avaliação de qualidade das águas no Brasil: o Rio Preto examinado. Espaço \& Geografia, v. 10, n. 2, p. 1-16, 2007. 
OLIVEIRA-FILHO, E. C. Avaliação da toxicidade. In: SISINNO, C. L. S.; OLIVEIRA-FILHO, E. C. (Orgs.) Princípios de Toxicologia Ambiental. Rio de Janeiro: Interciência, 2013.

OLIVEIRA-FILHO, E. C.; CAIXETA, N. R.; SIMPLICIO, N. C. S.; SOUSA, S. R.; ARAGÃO, T. P.; MUNIZ, D. H. F. Implications of water hardness in ecotoxicological assessments for water quality regulatory purposes: a case study with the snail Biomphalaria glabrata (Say, 1818). Brazilian Journal of Biology, v. 74, n. 1, p. 175-180, 2014.

OMOREGIE, E.; AJIMA, M. N. O.; KEKE, R. I.; WIESKI, K. Effect of single superphosphate fertilizer on survival and respiratory dynamics of Nile tilapia, Oreochromis niloticus (Actinopterygii: Perciformes: Cichlidae). Acta Ichthyologica et Piscatoria, v. 39, n. 2, p. 103110, 2009.

PALANIVELU, V.; VIJAYAVEL, K.; EZHILARASIBALASUBRAMANIAN, S.; BALASUBRAMANIAN, M. P. Impact of fertilizer (urea) on oxygen consumption and feeding energetics in the fresh water fish Oreochromis mossambicus. Environmental Toxicology and Pharmacology, v. 19, n. 2, p. 351-355, 2005.

PENTTINEN, S.; MALK, V.; VÄISÄNEN, A.; PENTTINEN, O. P. Using the critical body residue approach to determine the acute toxicity of cadmium at varying levels of water hardness and dissolved organic carbon concentrations. Ecotoxicology and Environmental Safety, v. 74, n. 5, p. 1151-1155, 2011.

PERRET, P.; EGGER, M.; DEGRÉMONT, A. A. Essai de lutte anti-mollusque par augmentation de la biomasse planctonique et traitement molluscicide: Association Urée-N-tritylmorpholine. Acta Tropica, v. 29, n. 2, p. 175-181, 1972.

R CORE TEAM. R: A language and environment for statistical computing. R Foundation for Statistical Computing, Vienna, Austria. ISBN 3-900051-07-0. Disponível em: <http://www.rproject.org/>. Acesso em: 05 mai. 2015.

RAVERA, O. Effects of heavy metals (cadmium, copper, chromium and lead) on a freshwater snail: Biomphalaria glabrata Say (Gastropoda, Prosobranchia). Malacologia, v. 16, n. 1, p. 231236, 1977.

REISH, D. L. The effects of varying concentrations of nutrient, chlorinity, and dissolved oxygen on polychaetous annelids. Water Research, v. 4, n. 11, p. 721-735, 1970.

RESENDE, A. V. Agricultura e qualidade da água: Contaminação da água por nitrato. Planaltina: Embrapa Cerrados, 2002. Disponível em:

<http://www.infoteca.cnptia.embrapa.br/bitstream/doc/546464/1/doc57.pdf>. Acesso em: 05 mai. 2015. 
RESENDE, A. V.; MARTINS, E. S.; OLIVEIRA, C. G.; SENA, M. C.; MACHADO, C. T. T.; KINPARA, D. I.; OLIVEIRA-FILHO, E. C. Suprimentos de potássio e pesquisa de uso de rochas "in natura" na agricultura brasileira. Espaço \& Geografia, v. 9, n. 1, p. 19-42, 2006.

ROMANO, N.; ZENG, C. Acute toxicity of sodium nitrate, potassium nitrate, and potassium chloride and their effects on the hemolymph composition and gill structure of early juvenile blues swimmer crabs (Portunus pelagicus Linnaeus, 1758) (Decapoda, Brachyura, Portunidae). Environmental Toxicology and Chemistry, v. 26, n. 9, p. 1955-1962, 2007a.

ROMANO, N.; ZENG, C. Effects of potassium on nitrate mediated alterations of osmoregulation in marine crabs. Aquatic Toxicology, v. 85, n. 3, p. 202-208, $2007 \mathrm{~b}$.

ROSOLEM, C. A.; VICENTINI, J. P. T. M. M.; STEINER, F. Suprimento de potássio em função da adubação potássica residual em um Latossolo Vermelho do Cerrado. Revista Brasileira de Ciência do Solo, v. 36, n. 5, p. 1507-1515, 2012.

RUBIN, A. J.; ELMARAGHY, G. A. Studies on the toxicity of ammonia, nitrate and their mixtures to guppy fry. Water Research, v. 11, n. 10, p. 927-935, 1977.

RUBINSTEIN, A. L. Zebrafish: From disease modeling to drug discovery. Current Opinion in Drug Discovery \& Development, v. 6, n. 2, p. 218-223, 2003.

SAAB, A. A.; PAULA, R. A. O mercado de fertilizantes no Brasil: Diagnósticos e propostas de políticas. Revista de Política Agrícola, Brasília, ano 17, n. 2, p. 5-24, 2008.

SANGEETHA, S.; SUJATHA, K.; SENTHILKUMAAR, P.; KALYANARAMAN, V.; ESWARI, S. Acute toxicity of some agriculture fertilizers to fingerlings of Catla catla. Indian Journal of Science and Technology, v. 4, n. 7, p.770-772, 2011.

SATOH, S.; PORN-NGAM, N.; TAKEUCHI, T.; WATANABE, T. Effect of various types of phosphate on zinc availability to rainbow trout. Nippon Suisan Gakkaishi, v. 59, n. 8, p. 13951400, 1993.

SAUER, S.; BALESTRO, M. W. Agroecologia e os desafios da transição ecológica. São Paulo, Expressão Popular, 2009. p. 7-15.

SCOTT, G.; CRUNKILTON, R. L. Acute and chronic toxicity of nitrate to fathead minnows (Pimephales promelas), Ceriodaphnia dubia, and Daphnia magna. Environmental Toxicology and Chemistry, v. 19, n. 12, p. 2918-2922, 2000.

SHIGAKI, F.; SHARPLEY, A.; PROCHNOW, L. I. Animal-based agriculture, phosphorus management and water quality in Brazil: Options for the future. Scientia Agricola, Piracicaba, v.63, n.2, p. 194-209, 2006. 
SIMMONS, J. A. Toxicity of major cations and anions $\left(\mathrm{Na}^{+}, \mathrm{K}^{+}, \mathrm{Ca}^{2+}, \mathrm{Cl}^{-}\right.$, and $\left.\mathrm{SO}_{4}{ }^{2-}\right)$ to a macrophyte and an alga. Environmental Toxicology and Chemistry, v. 31, n. 6, p. 1370-1374, 2012.

SISTI, C. P. J.; SANTOS, H. P.; KOHHANN, R.; ALVES, B. J. R.; URQUIAGA, S.; BODDEY, R. M. Change in carbon and nitrogen stocks in soil under 13 years of conventional zero tillage in southern Brazil. Soil and Tillage Research, v. 76, n. 1, p. 39-58, 2004.

SOUSA, D. M. G.; VOLKWEISS, S. J.; CASTRO, L. H. R. Efeito residual do superfosfato triplo em função da granulação e dose e do sistema de preparo do solo. Planaltina: EMBRAPA-CPAC, 1987. 5 p. (Pesquisa em Andamento, 21)

SOUSA, D. M. G.; LOBATO, E. Adubação com nitrogênio. In: SOUSA, D. M. G.; LOBATO, E. (Eds.) Cerrado: Correção do solo e adubação. Brasília: Embrapa Informação Tecnológica, 2004a.

SOUSA, D. M. G.; LOBATO, E. Calagem e adubação para culturas anuais e semiperenes. In: SOUSA, D. M. G.; LOBATO, E. (Eds.) Cerrado: Correção do solo e adubação. Brasília: Embrapa Informação Tecnológica, 2004b.

SOUSA, D. M. G.; LOBATO, E.; REIN, T. A. Adubação com fósforo. In: SOUSA, D. M. G.; LOBATO, E. (Eds.) Cerrado: Correção do solo e adubação. Brasília: Embrapa Informação Tecnológica, 2004.

STRUEWING, K. A.; LAZORCHAK, J. M.; WEAVER, P. C.; JOHNSON, B. R.; FUNK, D. H.; BUCHWALTER, D. B. Part 2: Sensitivity comparisons of the mayfly Centroptilum triangulifer to Ceriodaphnia dubia and Daphnia magna using standard reference toxicants; $\mathrm{NaCl}, \mathrm{KCl}$ and $\mathrm{CuSO}_{4}$. Chemosphere, 2014 (no prelo).

TALLARICO, L. F.; BORRELY, S. I.; HAMADA, N.; GRAZEFFE, V. S.; OHLWEILER, F. P.; OKAZAKI, K.; GRANATElli, A. T.; PEREIRA, I. W.; PEREIRA, C. A. B.; NAKANO, E. Developmental toxicity, acute toxicity and mutagenicity testing in freshwater snails Biomphalaria glabrata (Mollusca: Gastropoda) exposed to chromium and water samples. Ecotoxicology and Environmental Safety, v. 110, p. 208-215, 2014.

TCHOUNWOU, P. B.; ENGLANDE JR., A. J.; MALEK, E. A. Toxicity evaluation of ammonium sulphate and urea to three developmental stages of freshwater snails. Archives of Environmental Contamination and Toxicology, v. 21, n. 3, p. 359-364, 1991.

TUCCI, C. E. M. Hidrologia: Ciência e aplicação. Porto Alegre: UFRGS/ABRH, 2009.

USEPA. Methods for acute toxicity tests with fish, macroinvertebrates, and amphibians. EPA-660-3-75-009, 62p. 1975. 
USEPA. Background report on fertilizer use, contaminants and regulations. 395p. 1999.

USEPA. Methods for measuring the acute toxicity of effluents and receiving waters to freshwaters and marine organisms. EPA-821-R-02-012, 275p. 2002.

USEPA. ECOTOX User Guide: ECOTOXicology Database system. Version 4.0. 2015. Disponível em: 〈http:/www.epa.gov/ecotox/>. Acesso em: 05 mai. 2015.

UTZ, L. R. P.; BÖHRER, M. B. C. Acute and chronic toxicity of potassium chloride (KCl) and potassium acetate $\left(\mathrm{KC}_{2} \mathrm{H}_{3} \mathrm{O}_{2}\right)$ to Daphnia similis and Ceriodaphnia dubia (Crustacea; Cladocera). Bulletin of Environmental Contamination and Toxicology, v. 66, n. 3, p.379-385, 2001.

VARGAS, M. A. T.; MENDES, I. C.; CARVALHO, A. M.; LOBO-BURLE, M.; HUNGRIA, M. Inoculação de leguminosas e manejo de adubos verdes. In: SOUSA, D. M. G.; LOBATO, E. (Eds.) Cerrado: Correção do solo e adubação. Brasília: Embrapa Informação Tecnológica, 2004.

VIEIRA, R.F.; RAMOS, M. M. Fertirrigação. In: RIBEIRO, A.C.; GUIMARÃES, P. T. G.; ALVAREZ, V. V. H. (Eds.) Recomendações para o uso de corretivos e fertilizantes em Minas Gerais. $5^{\text {a }}$ aproximação. Viçosa: Comissão de Fertilidade do Solo do Estado de Minas Gerais, 1999.

VIJAYAVEL, K.; BALASUBRAMANIAN, M. P. Interaction of potash and decis in the ecophysiology of a freshwater fish Oreochromis mossambicus. Ecotoxicology and Environmental Safety, v. 66, n. 2, p. 154-158, 2007.

VILELA, L.; SOUSA, D. M. G.; SILVA, J. E. Adubação potássica. In: SOUSA, D. M. G.; LOBATO, E. (Eds.) Cerrado: Correção do solo e adubação. Brasília: Embrapa Informação Tecnológica, 2004.

ZAGATTO, P. A. Ecotoxicologia. In: ZAGATTO, P. A.; BERTOLETTI, E. (Eds.) Ecotoxicologia aquática: Princípios e aplicações. São Carlos: Rima, 2006. p. 1-13. 